\title{
ESTIMAÇÃO DE ESTADO EM SISTEMAS ELÉTRICOS DE POTÊNCIA: PROGRAMA PARA ANÁLISE E ATUALIZAÇÃO DAS CARACTERÍSTICAS QUALITATIVAS DE CONJUNTO DE MEDIDAS
}

EDUARDO MARMO MOREIRA

Dissertação de Mestrado apresentada à Escola de Engenharia de São Carlos, da Universidade de São Paulo, como parte dos requisitos para obtenção do Título de Mestre em Engenharia Elétrica.

Orientador: Prof. Dr. João Bosco A. London Junior

São Carlos

2006 
"Dedico a todos aqueles que não tiveram a oportunidade de chegar a uma escola, deixando a certeza de continuar a lutar para exterminar as nossas diferenças sociais, e assim contribuir para a mudança do mundo."

(Autor desconhecido) 
"Fé inabalável é aquela que pode encarar a razão face à face, em todas as épocas da humanidade." (Allan Kardec) 


\section{Agradecimentos}

Em primeiro lugar a DEUS, sem o qual nada seria possível realizar.

Aos meus pais, que com muito amor acreditaram em mim.

Ao meu irmão o professor Edmilson Marmo Moreira, que me apoiou e me ensinou muito neste trabalho.

Ao meu irmão Leonardo Marmo Moreira, por estar junto comigo durante todos estes anos.

Ao senhor Walter Moreira e a senhora Lourdes Moreira, pois sem eles a realização deste trabalho não seria possível.

Ao professor Dr. João Bosco Augusto London Jr., pela paciência e excelente orientação fornecida durante a elaboração deste trabalho.

Ao professor Dr. Newton Geraldo Bretas, pela sua amizade e por ter acreditado em mim.

A Msc. Lizandra Castilho Fabio, pela amizade e apoio durante as disciplinas.

Ao mestrando Raphael Augusto de S. Benedito, pela amizade e auxílio nos trabalhos que juntos realizamos.

Aos colegas e professores do LACO, por toda afeição, coleguismo e horas de trabalho.

A Coordenação de Aperfeiçoamento de Pessoal de Nível Superior - CAPES, pela concessão da bolsa de estudo.

E a todos os amigos que fiz neste campus e nesta cidade. 


\section{Agradecimentos}

Em primeiro lugar a DEUS, sem o qual nada seria possível realizar.

Aos meus pais, que com muito amor acreditaram em mim.

Ao meu irmão o professor Edmilson Marmo Moreira, que me apoiou e me ensinou muito neste trabalho.

Ao meu irmão Leonardo Marmo Moreira, por estar junto comigo durante todos estes anos.

Ao senhor Walter Moreira e a senhora Lourdes Moreira, pois sem eles a realização deste trabalho não seria possível.

Ao professor Dr. João Bosco Augusto London Jr., pela paciência e excelente orientação fornecida durante a elaboração deste trabalho.

Ao professor Dr. Newton Geraldo Bretas, pela sua amizade e por ter acreditado em mim.

A Msc. Lizandra Castilho Fabio, pela amizade e apoio durante as disciplinas.

Ao mestrando Raphael Augusto de S. Benedito, pela amizade e auxílio nos trabalhos que juntos realizamos.

Aos colegas e professores do LACO, por toda afeição, coleguismo e horas de trabalho.

A Coordenação de Aperfeiçoamento de Pessoal de Nível Superior - CAPES, pela concessão da bolsa de estudo.

E a todos os amigos que fiz neste campus e nesta cidade. 


\section{Resumo}

Moreira, E. M. (2006). Estimação de Estado em Sistemas Elétricos de Potência: Programa para Análise e Atualização das Características Qualitativas de Conjuntos de Medidas. Dissertação (Mestrado) - Escola de Engenharia de São Carlos, Universidade de São Paulo, São Carlos, 2006.

Para obter-se uma operação segura dos Sistemas Elétricos de Potência (SEP), é imprescindível uma estimação de estado (EE) confiável, pois, as ações de controle e operação, em tempo real, dos SEP se baseiam no banco de dados obtido pelo processo de EE. O primeiro passo, para o sucesso do processo de EE, é a obtenção de um plano de medição confiável, ou seja, um plano de medição que garanta a observabilidade do sistema e a não presença de medidas críticas e dos conjuntos críticos de medidas. Entretanto, tendo em vista a possibilidade de ocorrer, durante a operação de um SEP, de problemas causando a perda de medidas, a obtenção de um plano de medição confiável é uma condição necessária, mas não suficiente, para o sucesso do processo de EE. Face ao exposto, desenvolveu-se neste trabalho um programa computacional que possibilita uma EE confiável mesmo em situação de perda de medidas. O programa proposto permite, de uma forma rápida em termos de velocidade de execução, análise e restauração da observabilidade, identificação de medidas críticas e de conjuntos críticos de medidas, bem como a atualização dessas características qualitativas de conjunto de medidas após a perda de medidas. Como embasamento teórico para o desenvolvimento do programa proposto, foram utilizados dois algoritmos destinados à análise das características qualitativas de conjuntos de medidas, que se baseiam na fatoração triangular da matriz Jacobiana, bem como técnicas de esparsidade e de desenvolvimento de programas computacionais. Para comprovar a eficiência do programa proposto, vários testes foram realizados, utilizando o sistema de 6, 14 e 30 barras do IEEE e 121 barras da ELETROSUL.

Palavras-Chaves: Sistemas Elétricos de Potência, Estimação de Estado, Observabilidade, Medidas Críticas, Conjuntos Críticos de Medidas, Técnicas de Esparsidade. 


\section{Abstract}

Moreira, E. M. (2006). Power System State Estimation: Computer program for analysis and updating of measurement set qualitative characteristics. Dissertation (Master study) - Escola de Engenharia de São Carlos, Universidade de São Paulo, São Carlos, 2006.

To obtain a safe Power System (PS) operation, becomes necessary a reliable State Estimation (SE), since the real time control actions of a PS are based on the data obtained through the SE process. The first requirement for a successful SE process is the existence of a reliable measurement placement plan, that is, a measurement placement plan that guarantees system observability and the absence of both critical measurements and critical sets. However, considering that during the operation of a PS measurements can be lost decreasing the measurement-redundancy, one can say that although a reliable measurement placement plan is a necessary condition to guarantee a reliable state estimation, it is not sufficient. This dissertation presents a computer program that allows for a reliable SE, even in situations of problems causing loss of measurements. The proposed software allows, in a very fast way in terms of execution time, observability analysis and restoration, identification of critical measurements and critical sets, as well as the updating of these measurement set qualitative characteristics after loss of measurements. As a theoretical background for the development of the software, two algorithms were utilized allowing for the analysis of measurement set qualitative characteristics based on the triangular factorization of the Jacobian matrix, as well as sparsity techniques and techniques for the development of programs. To prove the efficiency of the proposed software, several tests were performed using the system of 6,14 and 30 buses from IEEE and 121 buses from ELETROSUL.

Key-words: Electrical Power Systems, State Estimation, Observability, Critical Measurements, Critical Sets, Sparsity Techniques. 


\section{Lista de Figuras}

Figura 3.1 - Sistema teste de 6 barras IEEE $\quad 34$

Figura 4.1 - Exemplo do armazenamento de Zollenkopf 48

Figura 4.2 - Etapa "Forward" na matriz A $\quad 49$

Figura 4.3 - Etapa Diagonalização na matriz A 50

Figura 4.4 - Etapa "Backward" na matriz A 50

Figura 4.5 - Etapas aplicadas no vetor $\underline{\mathrm{b}} \quad 51$

Figura 4.6 - "Fill-ins" durante a fatoração $\quad \mathbf{5 2}$

Figura 4.7 - Exemplo de caminhos de fatoração para "Forward" $\quad 54$

Figura 4.8 - Exemplo de caminhos de fatoração para "Backward" $\quad \mathbf{5 4}$

Figura 5.1 - Listas estáticas $\quad 62$

Figura 5.2 - Listas Dinâmicas $\quad 63$

Figura 6.1 - Classe MatrizEsparsa $\quad \mathbf{6 8}$

Figura 6.2 - Diagramas de Atividades - Objeto Matriz Esparsa 70

Figura 6.3 - Estrutura de dados proposta para o armazenamento de matriz Esparsa $\quad \mathbf{7 1}$

Figura 6.4 - Representação Gráfica do Nó $\quad \mathbf{7 1}$

Figura 6.5 - Buscando elemento na matriz A $\quad 72$

Figura 6.6 - Atribuindo elementos na matriz A 73

Figura 6.7 - Diagrama Caso de Uso $\quad 75$

Figura 6.8 - Diagrama de Atividade $1 \quad 76$

Figura 6.9 - Identificação de Medidas Críticas e de Conjuntos Críticos a $\begin{array}{ll}\text { partir da submatriz } \mathrm{R} & \mathbf{7 8}\end{array}$

$\begin{array}{ll}\text { Figura } 6.10 \text { - Identificação de Pares Críticos a partir da submatriz R } & 79\end{array}$ 


\section{Lista de Abreviaturas e Siglas}

SEP Sistemas Elétricos de Potência

UTR Unidade Terminal Remota

LACO Laboratório de Análise Computacional em Sistemas Elétricos de Potência

WLS Estimador de Mínimos Quadrados Ponderados

NR Nível de Redundância

GE Grau de esparsidade

OO Programação orientada a objetos

UML Linguagem de Modelagem Unificada

OMG Object Management Group

RAD Rapid Application Development

VCL Visual Components Library

SGBDs Sistema de Gerenciador de Banco de Dados 
Figura 6.11 - Identificação de Conjuntos Críticos a partir de Pares Críticos $\quad 79$

Figura 6.12 - Troca de Colunas - Submatriz P 83

Figura 6.13 - Troca de Colunas - Submatriz R $\quad \mathbf{8 4}$

Figura 6.14 - Sistema teste de 6 barras $\quad \mathbf{8 5}$

Figura 6.15 - Identificação dos Conjuntos Críticos a partir dos Pares Críticos do Exemplo $\quad \mathbf{8 6}$

Figura 6.16 - Exemplo: Perda de Conjunto P-Crítico [F(4-6), 16] 89

Figura 6.17 - Tela $1 \quad 91$

Figura 6.18 - Criando arquivo de Leitura (banco de dados) 92

Figura 6.19 - Abrindo arquivo de Leitura (banco de dados) 92

Figura 6.20 - Tela $2 \quad 93$

Figura 6.21 - Tela $3 \quad 94$

Figura 7.1 - Sistema de 14 barras do IEEE $\quad 96$

Figura 7.2 - Sistema de 30 barras do IEEE $\quad 97$ 


\section{Sumário}

\section{CAPÍTULO 1}

1. INTRODUÇÃO

1.1 Objetivos $\quad 5$

1.2 Discriminação dos próximos capítulos $\quad 6$

\section{CAPÍTULO 2}

2. ESTIMAÇÃO DE ESTADOS EM SISTEMAS ELÉTRICOS DE POTÊNCIA

2.1 Revisão Bibliográfica $\quad 7$

2.2 Estimação Estática de Estado $\quad 10$

2.2.1 Estimação de Estados baseado no Método de Mínimos Quadrados $\quad 11$

2.3 Processamento de Medidas com Erros Grosseiros 13

2.4 Medidas Críticas 16

2.5 Conjuntos Críticos de Medidas $\quad 17$

2.6 Metodologias Desenvolvidas para Identificação de Medidas $\begin{array}{ll}\text { Críticas e de Conjuntos Críticos de Medidas } & \mathbf{1 8}\end{array}$

\section{CAPÍTULO 3}

3. TRATAMENTO DAS CARACTERÍSTICAS QUALITATIVAS DE CONJUNTO DE MEDIDAS 23

3.1 Introdução $\quad 23$

3.2 A Matriz Jacobiana $\quad 25$ 
3.3 Metodologia

3.4 Algoritmo para identificação de medidas críticas e conjuntos críticos de medidas

3.4.1 Exemplo

3.5 Algoritmo para atualização das características qualitativas de conjunto de medidas, para efeito de estimação de estados em SEP

3.5.1 Algoritmo proposto em London Jr. et al (2004)

3.5.2 Exemplo

\section{CAPÍTULO 4}

4. TÉCNICAS DE ESPARSIDADE

4.1 Introdução $\quad 45$

4.2 Estrutura para o armazenamento de matrizes esparsas 47

$\begin{array}{ll}4.3 \text { Solução via fatores triangulares } & 48\end{array}$

4.4 Esquemas de Ordenação 52

4.5 Método dos vetores esparsos $\quad 53$

\section{CAPÍTULO 5}

5. TÉCNICAS PARA O DESENVOLVIMENTO DE PROGRAMAS COMPUTACIONAIS 55

5.1 Programação Orientada a Objetos 55

5.2 Modelando sistemas com a Linguagem de Modelagem Unificada $\quad 57$

5.3 Linguagem de Programação $\quad 59$

5.4 Tipos e Estrutura de Dados $\quad 61$

$\begin{array}{ll}5.5 \text { Interface gráfica } & 64\end{array}$

\section{CAPÍTULO 6}

6. PROGRAMA PROPOSTO 66

6.1 Introdução $\quad 66$

6.2 Modelando o objeto para o armazenamento da matriz $H_{\Delta}{ }^{t} \quad \mathbf{6 8}$

6.3 Técnicas de esparsidade utilizadas no desenvolvimento do programa proposto $\quad \mathbf{7 0}$

$\begin{array}{ll}6.3 .1 \text { Estrutura de dados } & \mathbf{7 0}\end{array}$ 
6.3.2 Fatoração através do processo de Eliminação de Gauss

6.4 Modelando o programa

6.4.1 Identificação de medidas críticas e de conjuntos críticos de medidas (Etapas 3 e 4)

6.4.2 Atualização das características qualitativas de conjuntos de medidas (Etapa 5)

6.5 Exemplo

6.6 Análise comparativa entre os algoritmos desenvolvidos em London Jr. et al (2004) e os algoritmos propostos

6.7 Interface gráfica

\section{CAPÍTULO 7}

7. TESTES E ANÁLISE DOS RESULTADOS 95

7.1 Testes com o Sistema de 14 barras do IEEE 95

7.2 Testes com o Sistema de 30 barras do IEEE $\quad 97$

7.3 Testes com o Sistema de 121 barras da ELETROSUL 98

$\begin{array}{ll}7.4 \text { Análise dos resultados } & 99\end{array}$

\section{CAPÍTULO 8}

8. CONCLUSÕES 100

$\begin{array}{ll}\text { 8.1 Principais Contribuições do trabalho } & 102\end{array}$

$\begin{array}{ll}\text { 8.2 Perspectivas Futuras } & 103\end{array}$

BIBLIOGRAFIA 


\section{Capítulo 6}

\section{Programa Proposto}

Neste capítulo será apresentado o programa computacional proposto neste trabalho. Vale destacar que, como instrumento teórico para o seu desenvolvimento, utilizaram-se os algoritmos para 0 tratamento das características qualitativas de conjuntos de medidas, apresentado no capítulo 3, bem como técnicas de esparsidade e técnicas para o desenvolvimento de programas computacionais apresentadas, respectivamente, nos capítulos 4 e 5.

\subsection{Introdução}

$\mathrm{Na}$ tentativa de obter um programa com execução mais rápida, os algoritmos desenvolvidos neste trabalho são bem diferentes daqueles propostos em London Jr. et al (2004). A primeira diferença está no armazenamento da matriz $H^{t}$. 
Para o armazenamento da matriz Jacobiana transposta $\left(H^{t}\right)$, que será fatorada, o algoritmo proposto já inclui as colunas correspondentes às pseudomedidas. Assim, obtém-se a seguinte matriz $H_{\Delta}{ }^{t}$ :

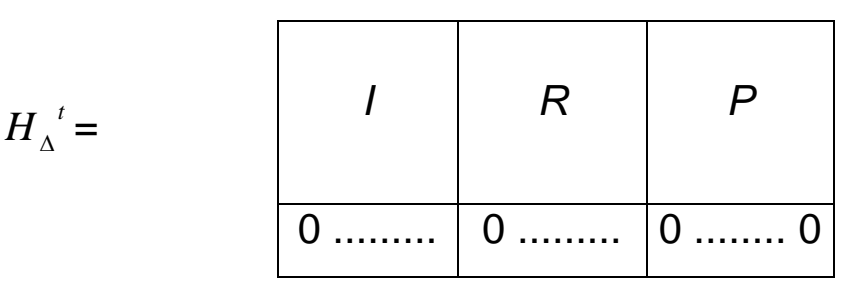

Onde:

$>1$ : submatriz identidade, de dimensão (n-1)x(n-1);

$>R$ : submatriz de dimensão $(n-1) x[m-(n-1)]$;

$>P$ : submatriz de pseudo-medidas de dimensão (n-1)x(mp);

$>n$ : número de barras do sistema;

$>m$ : número de medidas disponíveis no Caso Base;

mp: número de pseudo-medidas disponíveis.

Observação 6.1: A última linha de $H_{\Delta}{ }^{t}$ corresponde à barra escolhida como referência angular.

A vantagem obtida, com o armazenamento das pseudo-medidas na matriz $H^{t}$, é a minimização da quantidade de cálculos necessários para restauração da observabilidade. Pois, no algoritmo proposto em London Jr. et al (2004), em razão de as pseudo-medidas não serem armazenadas na matriz $H^{t}$, associada ao caso base, no instante em que se exige a restauração da observabilidade torna-se necessário aplicar os fatores triangulares, responsáveis pela obtenção da $H_{\Delta}{ }^{t}$, em uma por uma das pseudo-medidas disponíveis, até se encontrar aquela que permite a restauração da observabilidade.

Armazenando as pseudo-medidas na matriz $H^{t}$, associada ao caso base, no instante em que se exige a restauração da observabilidade, não se faz necessário cálculo algum para a determinação da pseudo-medida necessária, basta uma busca por elementos não nulos nas colunas da matriz $H_{\Delta}{ }^{t}$ correspondentes às pseudo-medidas. Isto porque essas colunas já foram 
consideradas no processo de fatoração triangular da matriz $H^{t}$, que resulta na obtenção da matriz $H_{\Delta}{ }^{t}$.

\subsection{Modelando o objeto para o armazenamento da Matriz $H_{\Delta}{ }^{t}$}

Para apresentar a estrutura desenvolvida para o armazenamento da matriz $H^{t}$, será utilizado um diagrama de classe.

Diagrama de Classe:

Trata-se de uma estrutura lógica estática em uma superfície de duas dimensões, mostrando uma coleção de elementos declarativos de modelo, como classes, tipos e seus respectivos conteúdos e relações.

A seguir visualiza-se a classe MatrizEsparsa, utilizada no programa, que possui três atributos e três operações.

\begin{tabular}{|l|}
\hline \multicolumn{1}{|c|}{$\begin{array}{c}\text { \&utility» } \\
\text { MatrizEsparsa }\end{array}$} \\
\hline -Lines : int = nBarras \\
-Columns : int = nMedidas \\
-Vector : *ListaPtr \\
\hline +MatrizEsparsa(lin : int = nBarras, col : int = nMedidas) \\
+Atrib(lin : int, col : int, value : float) : void \\
+Consul(lin : int, col : int) : float \\
\hline
\end{tabular}

Figura 6.1 - Classe MatrizEsparsa

Lines: atributo declarado como inteiro que limita o número de linhas da matriz esparsa que será armazenada;

$>$ Columns: atributo declarado como inteiro que limita o número de colunas da matriz esparsa que será armazenada;

$>$ Vector: atributo declarado como ponteiro de uma lista, utilizado para acessar o próximo elemento de uma determinada linha da matriz armazenada (essa estrutura será exemplificada na seção 6.3.1);

> MatrizEsparsa(int lin, int col): operação para alocação da dimensão da matriz esparsa, com parâmetros para linha e coluna, respectivamente; 
void Atrib (int lin, int col, float value): operação para atribuição de valores na matriz, com parâmetros do tipo inteiro, para linha e coluna, e do tipo float para o valor real de um determinado elemento da matriz;

$>$ float Consul(int lin, int col): operação para consulta de valores na matriz, com parâmetros do tipo inteiro, para linha e coluna, que retorna o valor real do elemento da matriz estipulado pelos parâmetros anteriores.

Para exemplificar a maneira como foi implementado o objeto para o armazenamento da Matriz $H^{t}$, serão utilizados diagramas de atividade.

$>$ Diagrama de Atividade:

Trata-se de um caso especial de diagrama de estado, no qual todos os estados, ou, a maioria dos estados são estados de ação, e a maioria das transições são ativadas por conclusões de ações nos estados precedentes.

O diagrama de atividade pode ser utilizado para diferentes propósitos, sendo que, dentro desses propósitos, esse diagrama é útil para visualizar o funcionamento interno de um objeto e constatar as ações que serão desempenhadas quando uma operação é executada.

A figura 6.2 apresenta 3 diagramas de atividades que exemplificam todo o processo de implementação do objeto. 


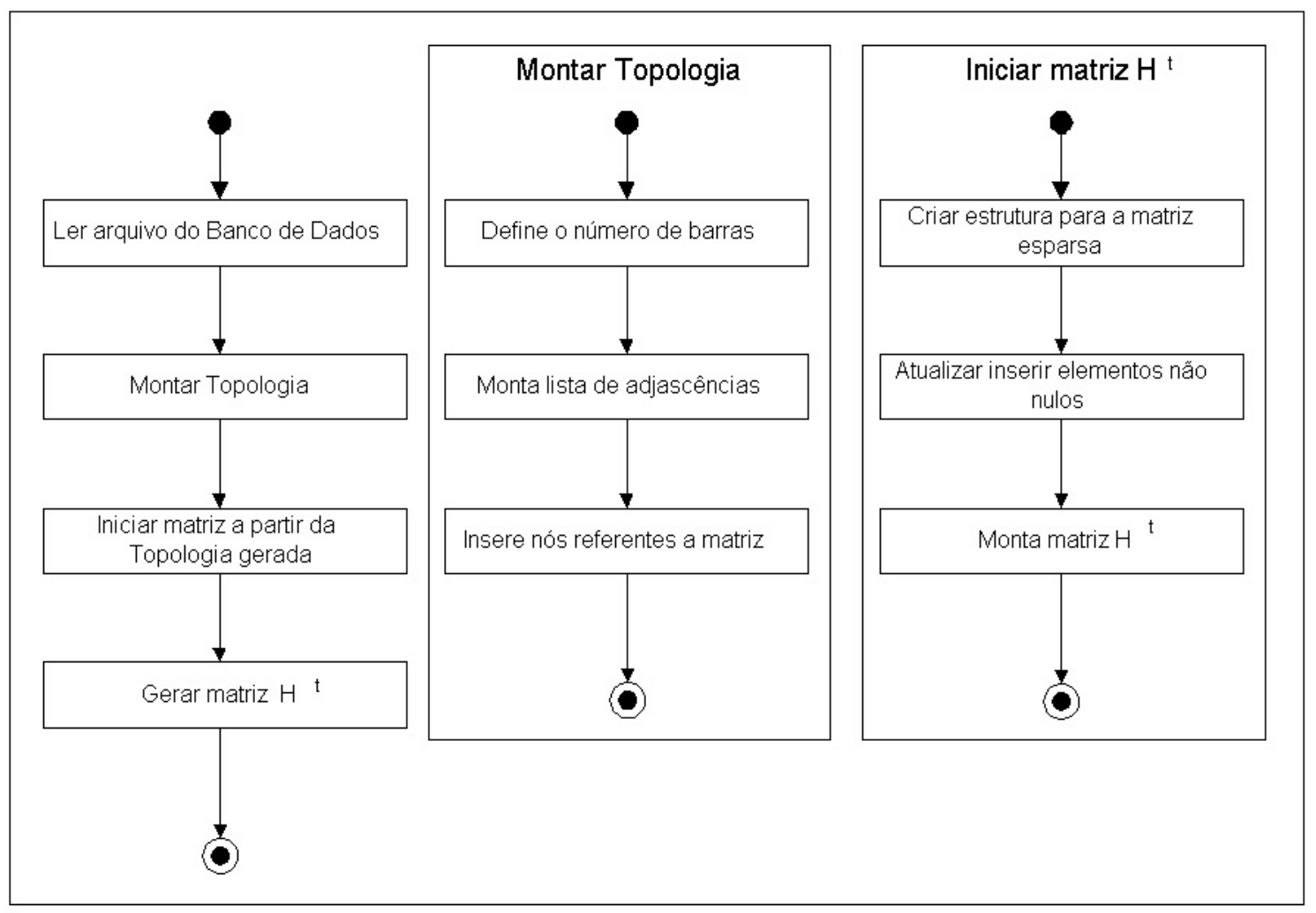

Figura 6.2 - Diagramas de Atividades - Objeto Matriz Esparsa

Observação 6.2: No APÊNDICE A encontra-se o código fonte referente à implementação da Classe MatrizEsparsa.

\subsection{Técnicas de esparsidade utilizadas no desenvolvimento do programa proposto}

Apresenta-se, nesta seção, a estrutura de dados desenvolvida para o armazenamento da matriz $H^{t}$, bem como o processo de fatoração triangular aplicado à matriz $H^{t}$, para obtenção da matriz $H_{\Delta}{ }^{t}$.

\subsubsection{Estrutura de dados}

A estrutura para armazenamento de matriz esparsa, proposta neste trabalho, foi obtida tomando por base as estruturas desenvolvidas por Zollenkopf (1971), apresentadas no capítulo 4. 
A figura 6.3 mostra como se realiza o armazenamento de uma matriz na estrutura proposta.

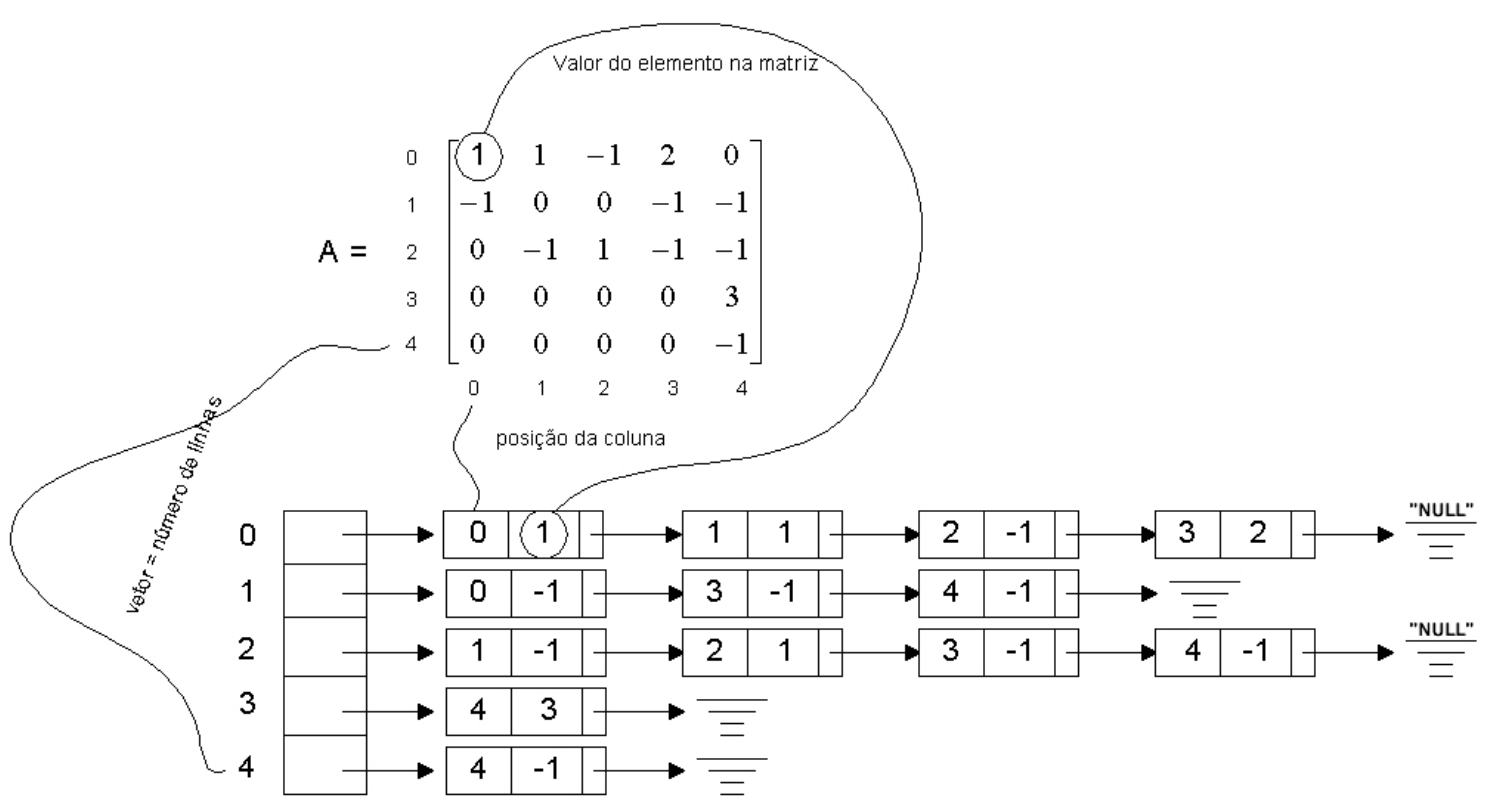

Figura 6.3 - Estrutura de dados proposta para o armazenamento de matriz Esparsa

Nesta estrutura, as $n$ linhas da matriz A são armazenados através de $n$ listas encadeadas, existindo então uma lista para cada linha da matriz. As linhas são referenciadas por um vetor de ponteiros. Os nós, como pode ser visualizado de uma maneira mais detalhada na figura 6.4, trazem as seguintes informações: (i) a linha (na matriz) do elemento que está sendo armazenado; (ii) o valor real do elemento; (iii) um ponteiro "apontando" para um nó que contém informações do próximo elemento não nulo da linha. Caso não haja mais elemento não nulo na linha que está sendo armazenada, o ponteiro apontará para "NULL".

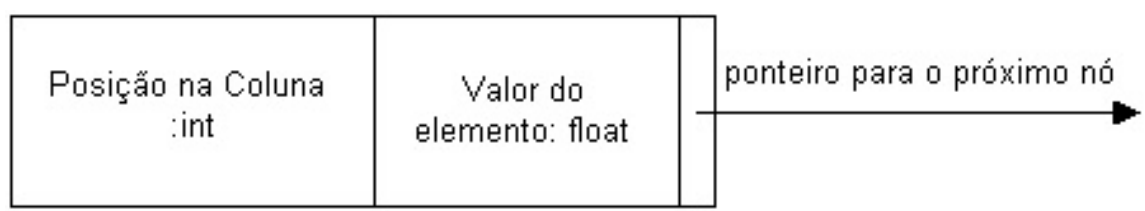

Figura 6.4 - Representação Gráfica do Nó

Para trabalhar com a estrutura proposta, foi desenvolvido dois operadores:

> Matriz->Consulta(i,j): operador que realiza a busca pelo elemento $(\mathrm{i}, \mathrm{j}) \mathrm{da}$ matriz, retornando o valor daquele elemento ou zero quando não existe 
elemento não nulo naquela posição. Para realizar essa tarefa, o operador dá início à busca na posição do vetor referente à linha "i”, e, caminhando pelos ponteiros com origem naquela posição, busca o nó correspondente ao parâmetro “j”. A busca retorna o valor armazenado no próprio nó (a figura 6.5 indica o procedimento de busca realizado por este operador);

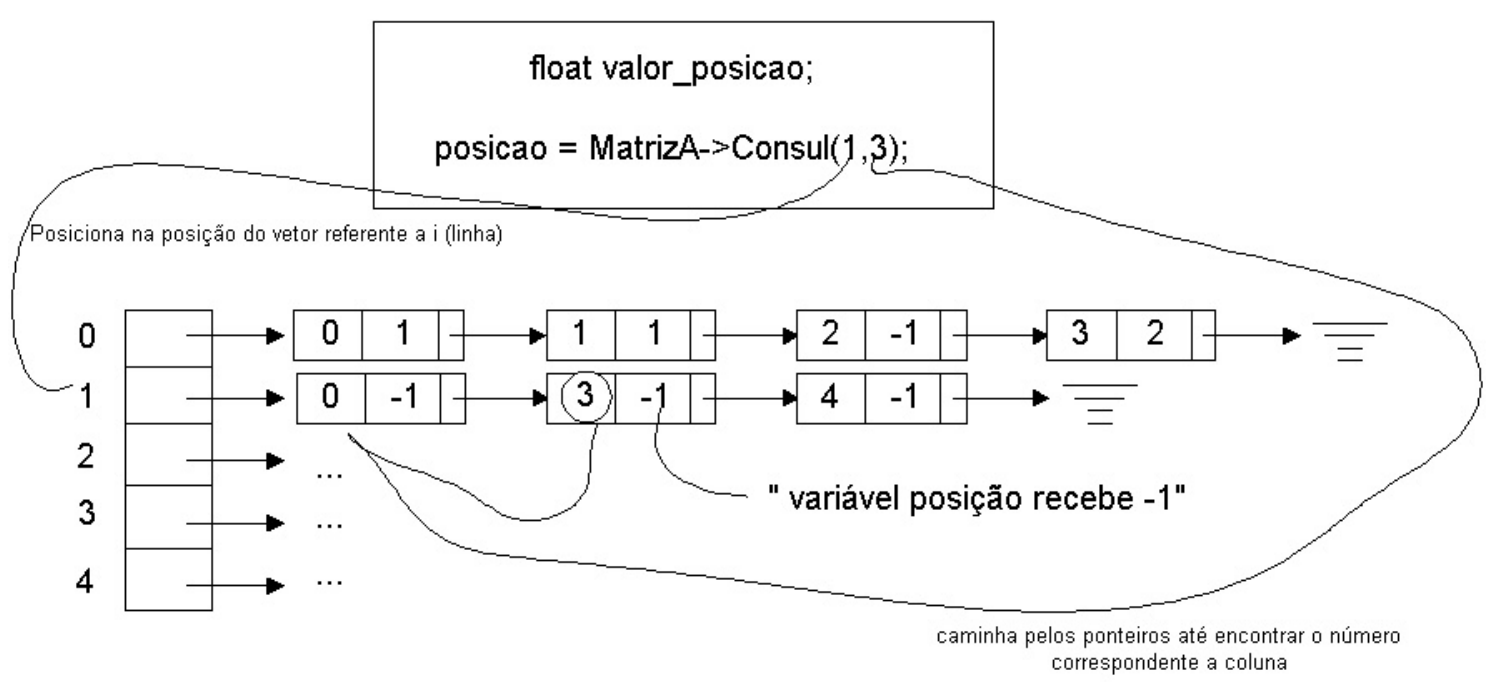

Figura 6.5 - Buscando elemento na matriz A

matriz->atrib(i, j, elemento): O operador faz uma busca através dos parâmetros i e j, caso não seja encontrado o nó, cria-se um novo nó, redirecionando os ponteiros. Encontrando a posição, o elemento na variável do valor é alterado, e se na atribuição, o valor do elemento for "0", o nó é removido da lista, atualizando o ponteiro que chega nele para o nó que ele aponta. A figura 6.6 ilustra o processamento deste operador. 

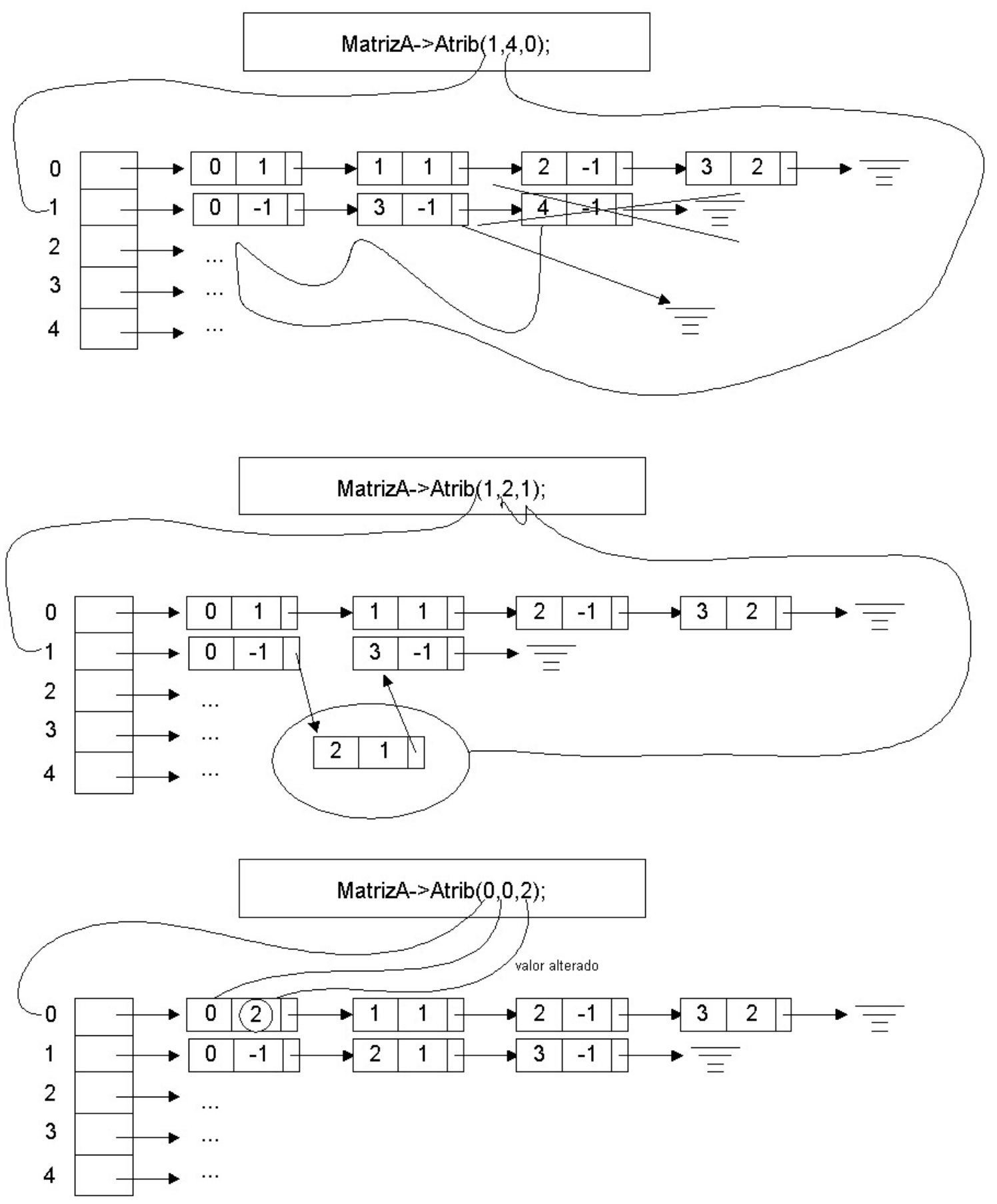

Figura 6.6 - Atribuindo elementos na matriz A

\subsubsection{Fatoração através do processo de Eliminação de Gauss}

O processo de eliminação de Gauss aqui implementado possui algumas particularidades, mesmo aplicado à matriz $H^{t}$. Antes de apreciá-las, serão recordadas, sucintamente, as etapas do processo de eliminação de Gauss, que foram apresentados detalhadamente no capítulo 4 : 
$1^{0}$ Etapa: Forward $\Rightarrow$ são zerados os elementos do triângulo inferior da matriz em análise, através de combinações lineares efetuadas com as linhas dessa matriz;

$2^{0}$ Etapa: "Diagonalização" $\Rightarrow$ igualamos a 1 todos os elementos da diagonal principal, dividindo-se cada linha da matriz resultante, do passo anterior, pelo elemento correspondente da diagonal principal dessa matriz;

$3^{\circ}$ Etapa: Backward $\Rightarrow$ são zerados os elementos do triângulo superior, pertencentes à matriz resultante da operação Diagonal, através de combinações lineares efetuadas com as linhas dessa matriz.

A definição de observabilidade algébrica, aplicada à matriz $H$, também se aplica à matriz $H^{t}$. Assim, como a condição necessária, para que o sistema seja algebricamente observável, é que o posto da matriz $H^{t}$ seja igual a (n-1), o processo de Forward será realizado até a diagonal (n-1). Para realizar o passo Forward, o algoritmo adota o esquema de eliminação por colunas. Após a realização desse passo, a última linha da matriz constituir-se-á apenas de zeros, pois essa linha corresponderá à barra escolhida como referência angular.

O passo "Diagonalização" será então realizado, considerando as (n-1) linhas da matriz $H^{t}$; em seguida realiza-se o passo Backward, através do qual se eliminarão os elementos não nulos da parte superior da submatriz $H^{t}$, resultante do passo anterior, de dimensão (n-1) $x$ (n-1). É necessário, entretanto, que o passo Backward se realize através de combinações lineares a efetuar com as linhas daquela matriz, já que desta forma todas as colunas da matriz $H^{t}$ serão consideradas.

Ao final do passo Backward, a matriz $H^{t}$ terá a forma mostrada na equação (6.1).

\subsection{Modelando o programa}

O diagrama de caso de uso, utilizado na figura 6.7, demonstra 0 comportamento geral do programa. 
Diagramas de caso de uso descrevem a visão externa de um sistema e suas interações com o usuário ou outros meios externos, representando uma visão de alto nível de funcionalidade intencional, mediante o recebimento de um tipo de requisição do usuário.

De uma forma geral, as principais interações entre o programa e 0 usuário podem ser descritas da seguinte forma (veja o diagrama de caso de uso apresentado na figura 6.7):

Através de um arquivo de dados, o usuário informa ao programa o sistema elétrico e o correspondente plano de medição a ser analisado. Mediante essas informações, o programa executa as seguintes operações:

o Construção da matriz $H^{t}$ e obtenção da matriz $H_{\Delta}{ }^{t}$;

o Identificação das medidas críticas e dos conjuntos críticos de medidas, através da análise da estrutura da matriz $H_{\Delta}{ }^{t}$.

Através do mouse o usuário informa as medidas perdidas e o programa, então, executa as seguintes operações:

- Atualização das características qualitativas do conjunto de medidas, isto é: - análise de observabilidade e, se necessário, restauração da observabilidade, através da seleção de pseudomedidas; - análise da "criticalidade" das medidas ainda disponíveis, isto é, verifica a existência de medidas críticas e de conjuntos críticos de medidas no conjunto de medidas atual.

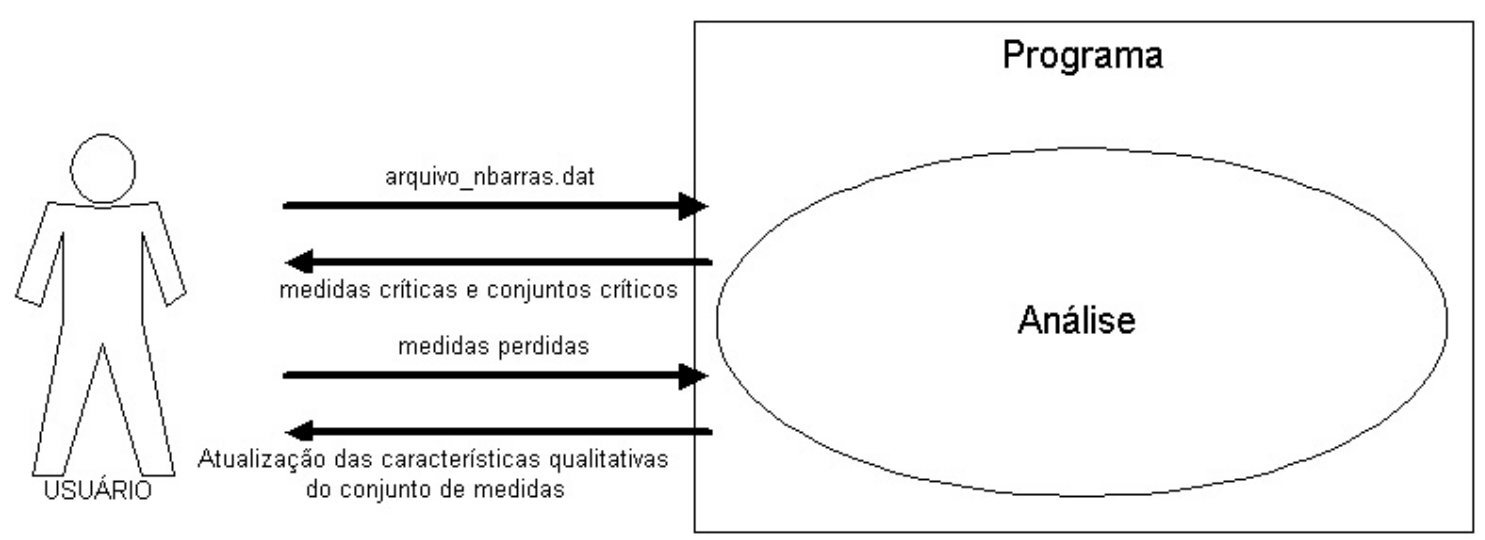

Figura 6.7 - Diagrama Caso de Uso 
Para verificar o comportamento do programa diante das informações enviadas pelo usuário, apresenta-se, na figura 6.8, o Diagrama de Atividade 1.

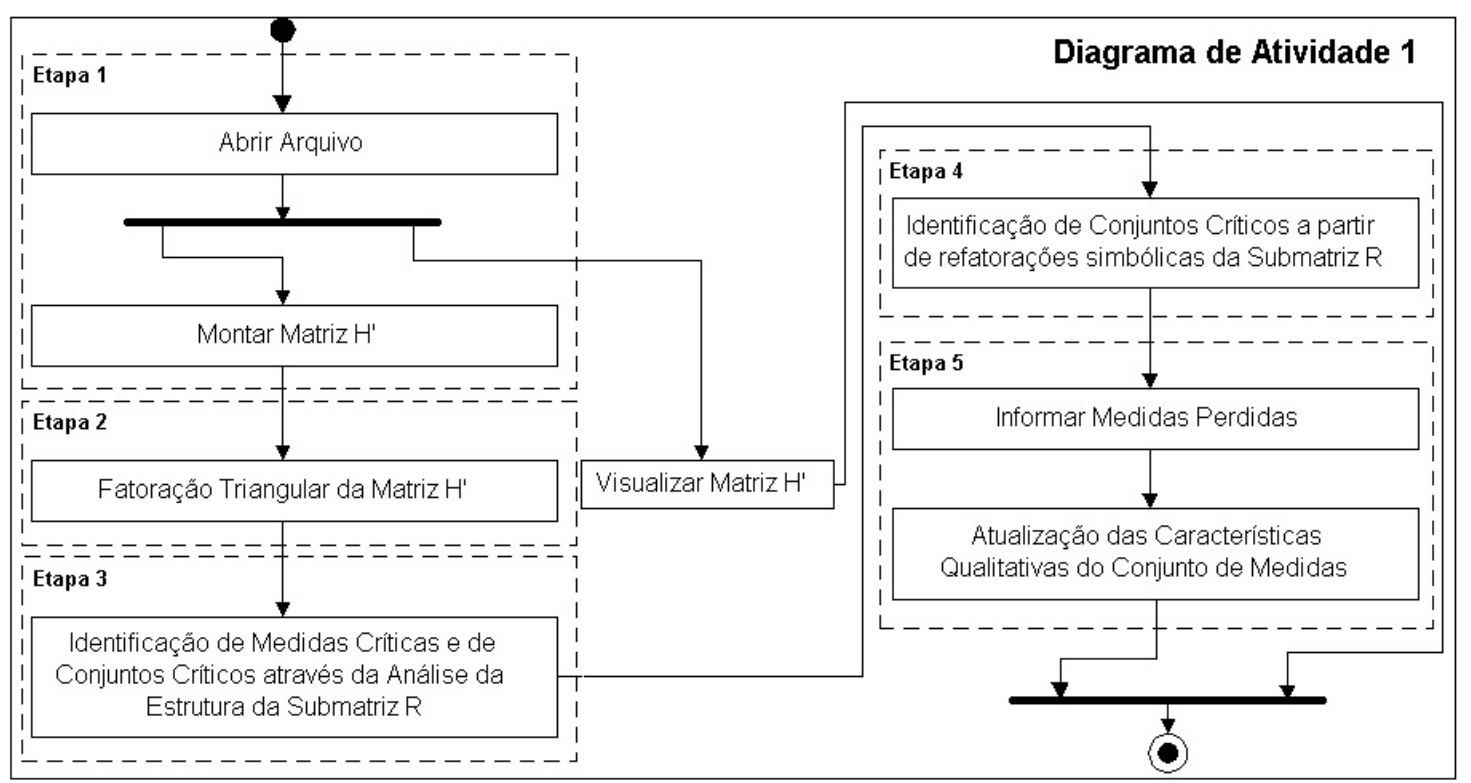

Figura 6.8 - Diagrama de Atividade 1

As etapas indicadas no Diagrama de Atividade 1, ilustradas na figura 6.8, são as seguintes:

Etapa 1: Processo de leitura do arquivo texto que contém as informações da topologia do sistema e da localização dos medidores. Analisando este arquivo texto, o programa monta e armazena a Matriz $H^{t}$, através da estrutura apresentada na seção 6.3.1.

Etapa 2: Obtenção da matriz $H_{\Delta}{ }^{t}$, através da fatoração triangular da matriz $H^{t}$.

Etapa 3: Analisando a submatriz $\mathrm{R}$, da matriz $H_{\Delta}{ }^{t}$, o programa possibilita a identificação de medidas críticas e de conjuntos críticos de medidas, informando-os.

Etapa 4: Se existir alguma Medida Básica não crítica, não pertencente aos conjuntos críticos já identificados, existe a possibilidade das mesmas constituírem conjuntos críticos de medidas, que não são identificáveis através 
da análise da matriz $\mathrm{R}^{1}$. Para possibilitar a identificação de tais conjuntos, 0 algoritmo proposto realiza re-fatorações simbólicas da submatriz R.

Etapa 5: Informando ao programa as medidas perdidas, o mesmo permite, através da análise da matriz $H_{\Delta}{ }^{t}$ obtida no passo 2, a atualização das características qualitativas do conjunto de medidas disponível.

As Etapas 3, 4 e 5, serão apresentadas detalhadamente nas próximas seções.

\subsubsection{Identificação de medidas críticas e de conjuntos críticos de medidas (Etapas 3 e 4)}

\section{Etapa 3:}

Para identificar as medidas críticas e os conjuntos críticos de medidas, a partir da submatriz R, é necessário um vetor "Contador" (VC), que vai armazenar, em cada uma das suas linhas, o número de elementos não nulos que aparecem nas respectivas linhas da submatriz R (veja figura 6.8). Importa destacar ainda que, em razão de a submatriz I, da matriz $H_{\Delta}{ }^{t}$, ser uma matriz identidade de dimensão [(n-1)x(n-1)], pode-se dizer que a coluna "j", da submatriz I, tem elemento não nulo apenas na linha "j". Lembrando que as Medidas Básicas correspondem às colunas da submatriz I, pode-se afirmar que: a Medida Básica correspondente à coluna “j” da matriz $H_{\Delta}{ }^{t}$, para $\mathrm{j}=1, \ldots$, (n-1), dá informação apenas do estado equivalente correspondente à linha “j”.

Ante o exposto, o procedimento de identificação de medidas críticas, através da submatriz R, torna-se bem simples. Por exemplo, se a linha "i" do VC for igual a zero, a Medida Básica correspondente à coluna "i”, da matriz $H_{\Delta}{ }^{t}$, é uma medida crítica. Na figura 6.9. a Medida Básica "MB1" é crítica.

\footnotetext{
${ }^{1}$ Isto em razão de não ser possível, através da análise da estrutura da matriz $H_{\Delta}{ }^{t}$, identificar os pares críticos formados por mais de uma Medida Básica (conforme mencionado no capítulo 3).
} 


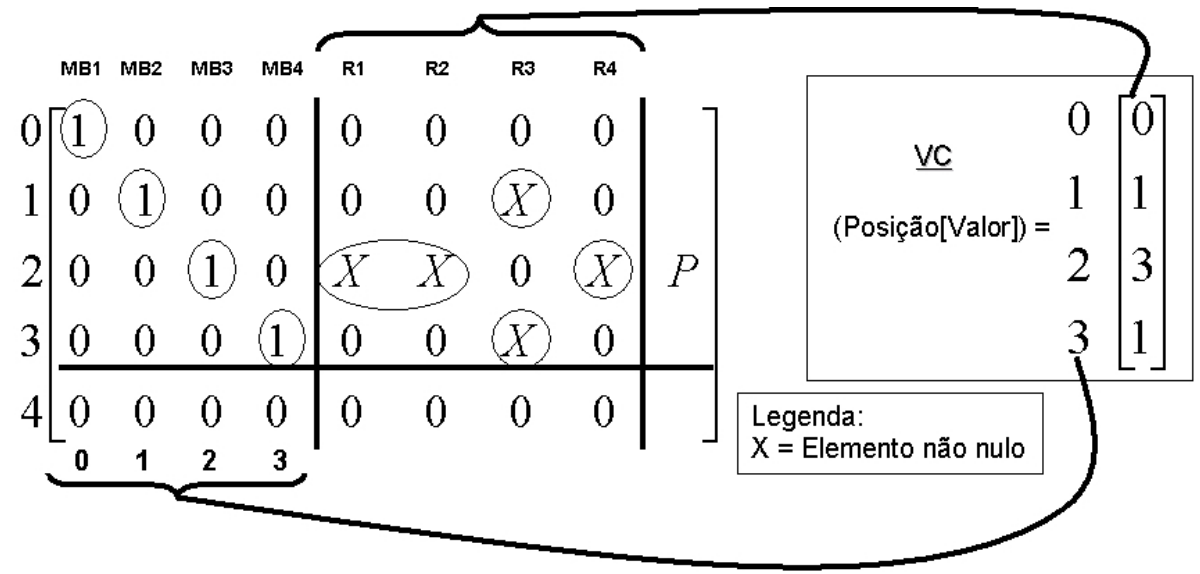

Figura 6.9 - Identificação de Medidas Críticas e de Conjuntos Críticos a partir da submatriz R

Para identificar os conjuntos críticos o primeiro passo é a identificação dos pares críticos.

A identificação dos pares críticos ocorre durante a obtenção do VC. Lembrando que cada linha desse vetor indica o número de elementos não nulos da correspondente linha da submatriz $R$, para obtê-lo é necessário percorrer as (n-1) linhas da submatriz R, procurando por elementos não nulos. Quando uma das linhas dessa matriz está sendo percorrida e verifica-se a existência de um elemento não nulo, além de ser incrementado o valor armazenado na correspondente linha do VC, um vetor do tipo String armazenará o nome da Medida Suplementar correspondente à coluna daquele elemento não nulo, bem como o nome da Medida Básica correspondente à linha percorrida. Se no final da análise de uma linha de $R$, o valor da correspondente linha do VC for igual a 1, identifica-se um par crítico, formado pelas medidas cujos nomes estão armazenados na variável supracitada (veja figura 6.10). 


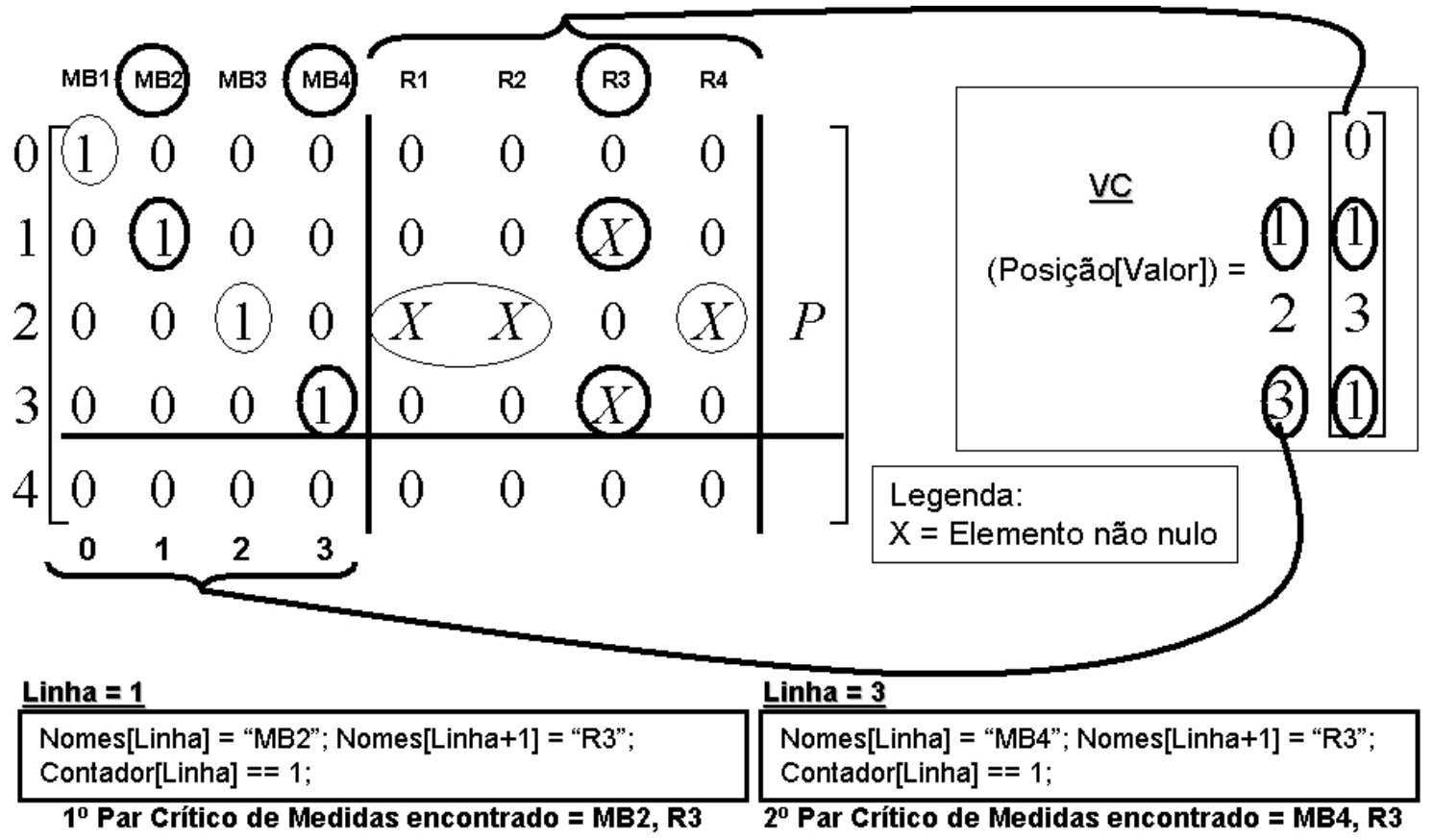

Figura 6.10 - Identificação de Pares Críticos a partir da submatriz R

Após a identificação dos pares críticos, da forma apresentada anteriormente, a identificação dos conjuntos críticos de medidas realiza-se através de dois passos:

Passo 1: Dentre os pares críticos identificados, selecione aqueles que não possuem Medida Suplementar em comum. As duas medidas, de cada um desses pares críticos, constituem um conjunto crítico formado por apenas duas medidas;

Passo 2: Dentre os pares críticos identificados, selecione grupos que possuem pelo menos uma Medida Suplementar em comum. As medidas pertencentes, a cada um desses grupos, constituem um único conjunto crítico de medidas, formado por mais de duas medidas. Para implementar tal procedimento, utilizou-se uma estrutura de dados do tipo lista ${ }^{2}$ (esse procedimento é ilustrado na figura 6.11).

Pares Críticos

\begin{tabular}{|l|l|}
\hline MB2 & R3 \\
\hline MB4 & R3 \\
\hline
\end{tabular}

Conjuntos Críticos

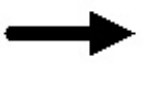

Figura 6.11 - Identificação de Conjuntos Críticos a partir de Pares Críticos

\footnotetext{
${ }^{2}$ No capítulo 5 definiu-se o que é uma estrutura de dados do tipo lista.
} 


\section{Etapa 4:}

Como mencionado anteriormente, esta etapa será executada apenas quando existir alguma Medida Básica, não crítica, não pertencente aos conjuntos críticos já identificados.

Conforme pode ser visto no capítulo 3, página 24, o algoritmo desenvolvido em London Jr. et al (2004) permite a realização desta análise, através de um processo iterativo que consiste em eliminação daquelas Medidas Básicas e re-fatorações parciais da matriz $H_{\Delta}{ }^{t}$.

Por outro lado, para aumentar a eficiência do algoritmo aqui proposto, em termos de tempo de execução, o mesmo possibilita tal análise "simulando" re-fatorações parciais apenas na submatriz $R$, isto é, não se altera efetivamente o valor de nenhum elemento da submatriz R.

O algoritmo aqui proposto identifica as Medidas Básicas a serem analisadas neste passo, ou seja, as não críticas e não pertencentes aos conjuntos críticos já identificados, através de um vetor de "Status", com dimensão (n-1), sendo (n-1) o número de Medidas Básicas existentes. Este vetor recebe o caractere " $x$ ", nas linhas correspondentes às colunas daquelas Medidas Básicas.

Para otimizar o algoritmo, é necessária a criação de um vetor contador auxiliar (VCA), com as mesmas dimensões de VC, que será atualizado a cada iteração do algoritmo.

Considerando o vetor VC, já definido e utilizado na Etapa 3, o algoritmo aqui proposto compreende os seguintes passos:

Passo 1: Faça i = 0 e "inicializar" os vetores VF e VCA da seguinte forma: para cada uma das "k" linhas de VF faça: VF[k] = 0; para cada uma das "k" linhas do vetor VCA faça: VCA[k] = VC [k]. Vá para o próximo passo.

Passo 2: Se Status[i] = "x", vá para o próximo passo. Caso contrário, percorra as colunas da submatriz $\mathrm{R}$, até encontrar uma coluna com elemento não nulo na linha "i”3. Armazene na variável "CP" o número dessa coluna. Em seguida, obtenha os fatores triangulares necessários para transformar, essa coluna, em uma coluna formada apenas por zeros, com exceção do elemento da linha "i", que deve ser feito igual a 1 (um). Armazene esses fatores nas correspondentes

\footnotetext{
${ }^{3}$ Em razão da coluna "i" corresponder a uma Medida Básica não crítica, certamente será encontrado um elemento não nulo, na linha "i", em pelo menos uma das colunas da submatriz R.
} 
linhas do vetor VF, e atualize VCA, decrementando os valores armazenados nas suas linhas correspondentes às linhas do VF onde foram armazenados os fatores da Forward e Backward. Vá para o Passo 4.

Passo 3: Se $\mathrm{i} \leq(n b-1)$, incremente o valor de $\mathrm{i}$, isto é, $\mathrm{i}=\mathrm{i}+1$, e volte ao Passo 2. Caso contrário, fim de processamento.

Passo 4: $\mathrm{j}=(n-1)+1$.

Passo 5: Se $R(i, j)=0$ e $j \neq C P$, vá para o próximo passo. Caso contrário, vá para o Passo 7.

Passo 6: Se $\mathrm{j} \leq(\mathrm{m})$, incremente o valor de j, isto é, $\mathrm{j}=\mathrm{j}+1$, e volte ao Passo 5. Caso contrário, vá para o Passo 9.

Passo 7: Se não existirem fatores da Forward, vá para o passo 8. Caso contrário, pra cada uma das linhas "f" de VF, onde foram armazenados os fatores da Forward, faça:

Se $R(f, j)=0$, o elemento armazenado na linha "f" de VCA é incrementado, isto é: $\mathrm{VCA}[\mathrm{f}]=\mathrm{VC}[\mathrm{f}]+1$.

Se $R(f, j) \neq 0$ e valor $=\{[\operatorname{VF}[f] * R(i, j)]+R(f, j)\}=0$, o elemento armazenado na linha "f" de VCA é decrementado, isto é: $\mathrm{VCA}[\mathrm{f}]=\mathrm{VCA}[\mathrm{f}]-1$

Vá para o Passo 8.

Passo 8: Se não existirem fatores da Backward, vá para o passo 6. Caso contrário, pra cada uma das linhas "b" de VF, onde foram armazenados os fatores da Backward, faça:

Se $R(b, j)=0$, o elemento armazenado na linha "b" de VCA é incrementado, isto é: $\mathrm{VCA}[\mathrm{b}]=\mathrm{VCA}[\mathrm{b}]+1$.

Se $R(b, j) \neq 0$ e valor $=\left\{\operatorname{VF}[b]^{*}[R(i, j) * V F[i]]+R(b, j)\right\}=0,0$ elemento armazenado na linha "b" de VCA é decrementado, isto é: $V C A[f]=V C A[f]-1$.

Vá para o passo 6.

Passo 9: As Medidas Básicas correspondentes às linhas de VCA cujo valor tenha se tornado zero, processamento dos passos 2, 7 e 8 , constituem um conjunto crítico com a Medida Básica correspondente a linha "i" da matriz $H_{\Delta}{ }^{t}$. Vá para o Passo 10. 
Passo 10: Inicialize os vetores VF e VCA, da seguinte forma: -para cada uma das "k" linhas de VF faça: VF[k] = 0; -para cada uma das "k" linhas de VCA faça: VCA $[k]=$ VC[k]. Volte ao Passo 3.

\subsubsection{Atualização das características qualitativas de conjuntos de medidas (Etapa 5)}

Através da matriz $H_{\Delta}{ }^{t}$ e do vetor VC obtidos na Etapa 2, bem como das medidas perdidas, o algoritmo aqui desenvolvido, para atualização das características qualitativas de conjunto de medidas, consiste de três passos:

Passo 1: Se foram perdidas apenas Medidas Suplementares, o sistema continua observável. Em seguida, elimina-se, de $H_{\Delta}{ }^{t}$, as colunas correspondentes às medidas perdidas, e, através da nova matriz $H_{\Delta}{ }^{t}$, verificase a "criticalidade" das medidas ainda disponíveis" ; Fim da análise.

Passo 2: Se dentre as medidas perdidas, existe apenas uma Medida Básica, o sistema pode ter perdido a observabilidade. Assim, antes de verificar a criticalidade das medidas, realiza-se análise e, se necessário, restauração da observabilidade.

Para isso o algoritmo processa os seguintes passos:

Passo 2.1: Elimine da matriz $H_{\Delta}{ }^{t}$, as colunas correspondentes às Medidas Suplementares que foram perdidas, decrementando adequadamente os valores armazenados em cada uma das linhas do Vetor Contador (VC) ${ }^{5}$. Vá para o passo 2.2.

Passo 2.2: Armazene na variável "LP", o número da linha do elemento não nulo, pertencente à coluna de $H_{\Delta}{ }^{t}$, correspondente à Medida Básica que foi perdida. Elimine a coluna de $H_{\Delta}{ }^{t}$ correspondente à essa medida, decrementando o valor armazenado na linha "LP" do VC. Se VC [LP] = 0, é porque não existe nenhuma medida ainda disponível dando informação do estado equivalente correspondente à linha "LP", isto é, o sistema perdeu a observabilidade. Vá para o passo 2.3. Caso contrário, vá para o passo 2.5.

\footnotetext{
${ }^{4}$ Da forma apresentada na seção anterior.

5 Vale lembrar que em cada linha desse vetor armazena-se o número de elementos não nulos da correspondente linha da submatriz R.
} 
Passo 2.3: Percorrendo as colunas da submatriz $P$, determine a primeira coluna com elemento não nulo na linha "LP". A pseudo-medida corresponde à essa coluna fornece informação do estado equivalente associado à linha "LP". Assim, tal medida é selecionada para restaurar a observabilidade do sistema. Vá para o passo 2.4 .

Passo 2.4: Troque a posição das colunas da matriz $H_{\Delta}{ }^{t}$, de tal forma que a pseudo-medida selecionada no passo anterior seja armazenada na coluna "LP" da matriz $H_{\Delta}{ }^{t}$ (veja figura 6.12). Em seguida, através de fatoração triangular, obtenha a nova matriz $H_{\Delta}{ }^{t}$. Verifica-se, agora, a criticalidade das medidas ainda disponíveis; Fim da análise.

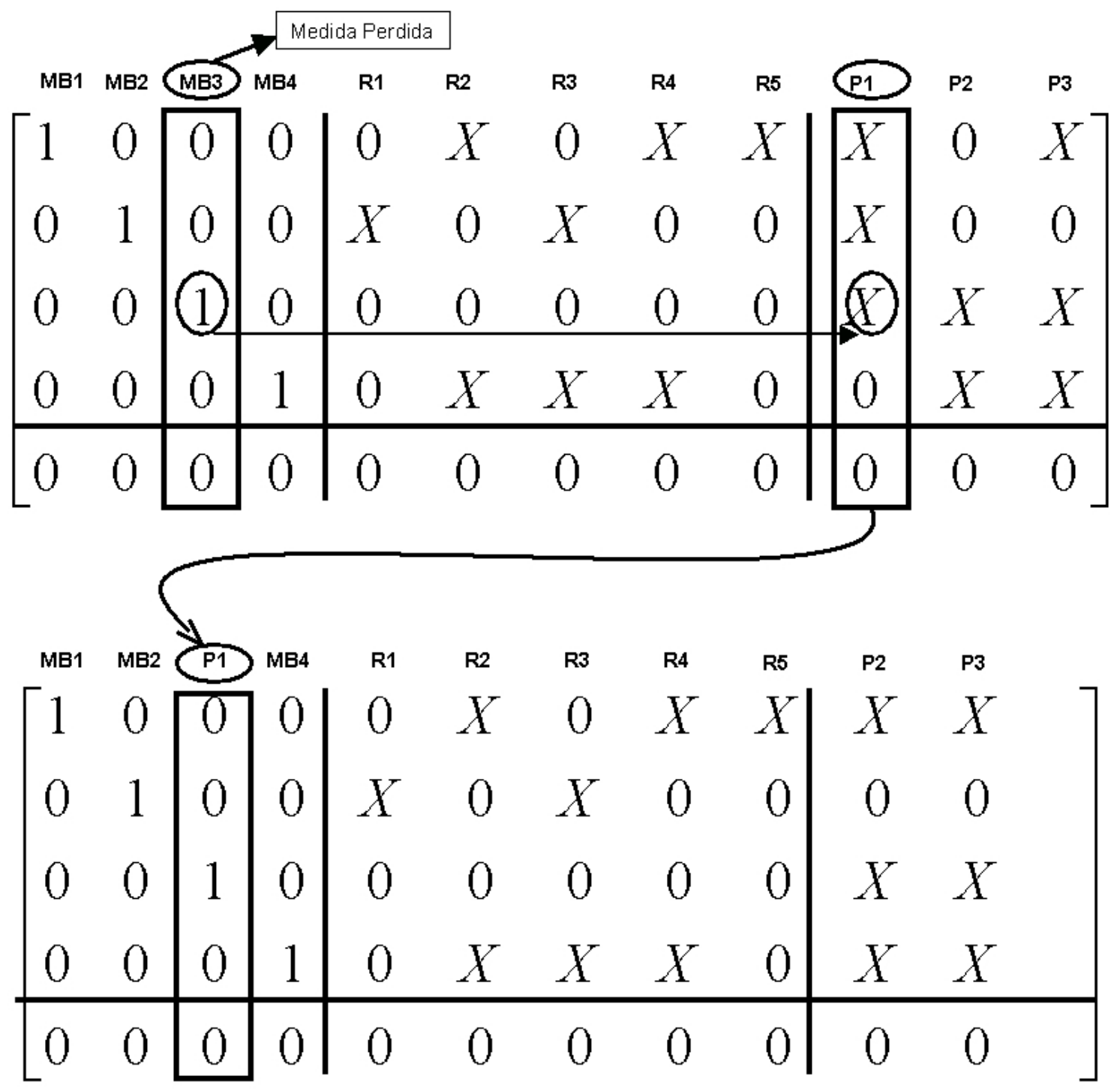

Figura 6.12 - Troca de Colunas - Submatriz P 
Passo 2.5: Percorrendo as colunas da submatriz $R$, determine a primeira coluna com elemento não nulo na linha "LP". Vá para o passo 2.6.

Passo 2.6: Troque a posição das colunas da matriz $H_{\Delta}{ }^{t}$, de tal forma que a Medida Suplementar correspondente à coluna identificada no Passo 2.5, seja armazenada na coluna "LP" da matriz $H_{\Delta}{ }^{t}$ (veja figura 6.13). Através de fatoração triangular, obtenha a nova matriz $H_{\Delta}{ }^{t}$. Em seguida, verifica-se a criticalidade das medidas ainda disponíveis; Fim da análise.

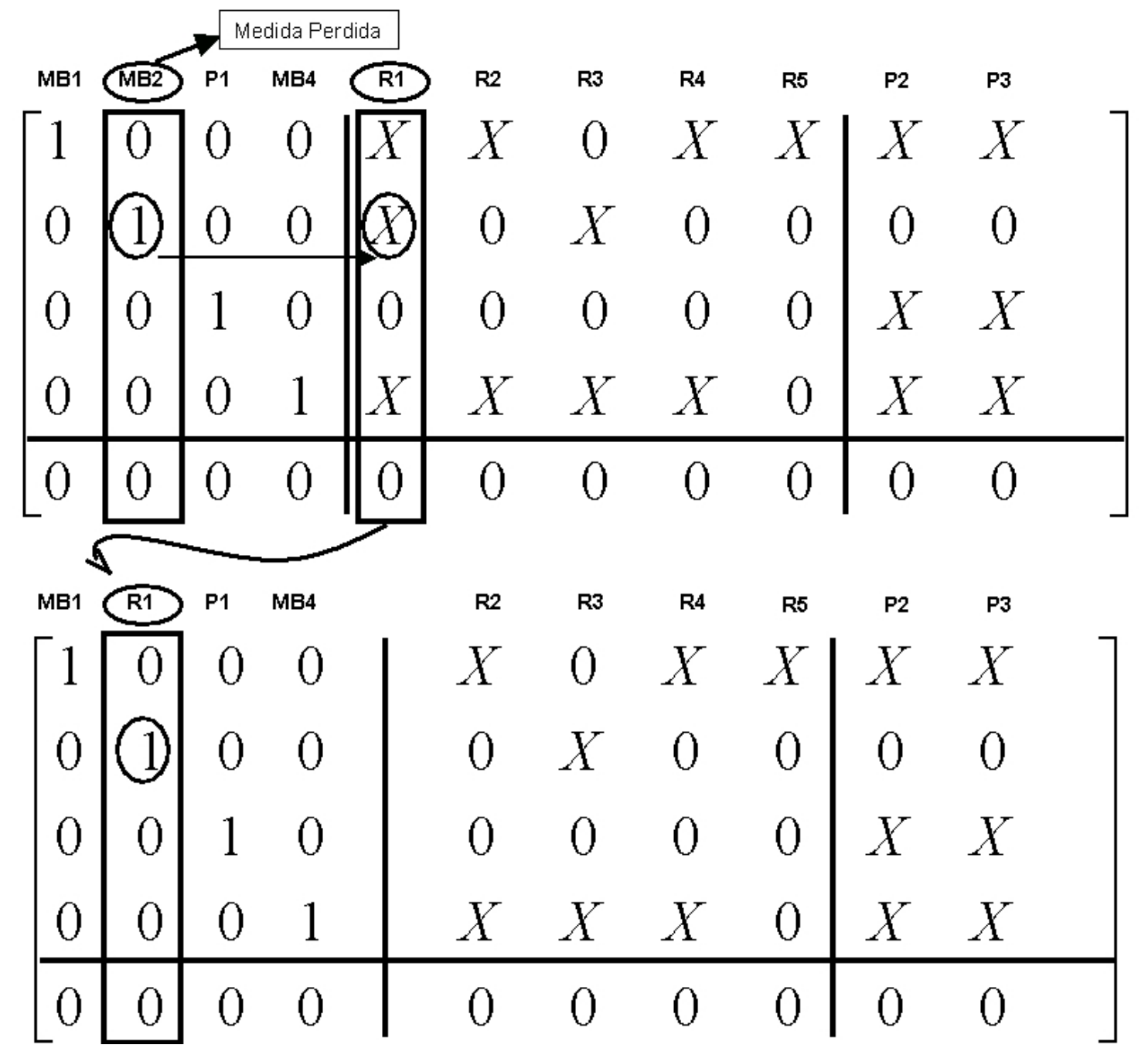

Figura 6.13 - Troca de Colunas - Submatriz R

Observação 6.3: É importante destacar que, em virtude das estruturas das matrizes $H_{\Delta}{ }^{t}$, que serão re-fatoradas nos Passos 2.4 e 2.6, são mínimos os cálculos necessários para tal re-fatoração (veja as figuras 6.12 e 6.13). 
Passo 3: Se dentre as medidas perdidas, existem mais de uma Medida Básica, os Passos 2.1, 2.2, 2.3, 2.4, 2.5 e 2.6, supracitados, serão processados iterativamente, para cada uma das Medidas Básicas perdidas.

\subsection{Exemplo}

Neste exemplo, o algoritmo proposto é aplicado ao Sistema de 6 barras, associado ao plano de medição ilustrado na figura 6.14.

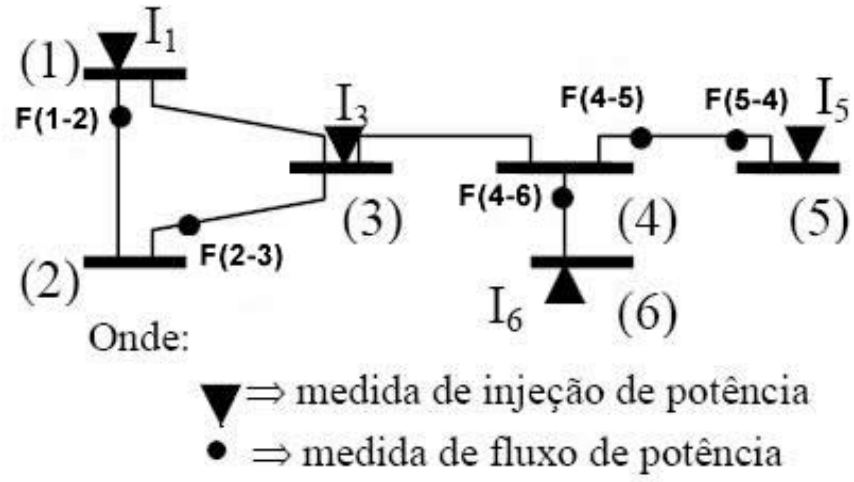

Figura 6.14 - Sistema teste de 6 barras

Além das medidas apresentadas na figura 6.14, considera-se ainda a existência das seguintes pseudo-medidas: $\mathrm{P}(1-3)^{6}, \mathrm{P}(2-1), \mathrm{P}(3-1), \mathrm{P}(3-2), \mathrm{P}(3-$ 4), $\mathrm{P}(4-3), \mathrm{P}(6-4), \mathrm{P} 1$ e $\mathrm{P} 4 .^{7}$

Etapa 1: Considerando as medidas indicadas na figura 6.14, bem como as pseudo-medidas supracitadas, caracterizando o Caso Base, obtém se a seguinte matriz $H^{t}$ (como mencionado na seção 6.1, o algoritmo proposto monta $H^{t}$ incluindo as colunas correspondente às pseudo-medidas):

\begin{tabular}{|c|c|c|c|c|c|c|c|c|c|c|c|c|c|c|c|c|c|c|}
\hline & $F(1-2)$ & $F(2-3)$ & $F(4-5)$ & $F(4-6)$ & $F(5-4)$ & I1 & 13 & 15 & 16 & $P(1-3)$ & $P(2-1)$ & $P(3-1)$ & $P(3-2)$ & $P(3-4)$ & $P(4-3)$ & $P(6-4)$ & P1 & P4 \\
\hline 0 & 1 & 0 & 0 & 0 & 0 & 2 & -1 & 0 & 0 & 1 & -1 & -1 & 0 & 0 & 0 & 0 & 2 & 0 \\
\hline 1 & -1 & 1 & 0 & 0 & 0 & -1 & -1 & 0 & 0 & 0 & 1 & 0 & -1 & 0 & 0 & 0 & -1 & 0 \\
\hline$H^{t}=$ & 0 & -1 & 0 & 0 & 0 & -1 & 3 & 0 & 0 & -1 & 0 & 1 & 1 & 1 & -1 & 0 & -1 & -1 \\
\hline 3 & 0 & 0 & 1 & 1 & -1 & 0 & -1 & -1 & -1 & 0 & 0 & 0 & 0 & -1 & 1 & -1 & 0 & 3 \\
\hline 4 & 0 & 0 & -1 & 0 & 1 & 0 & 0 & 1 & 0 & 0 & 0 & 0 & 0 & 0 & 0 & 0 & 0 & -1 \\
\hline 5 & 0 & 0 & 0 & -1 & 0 & 0 & 0 & 0 & 1 & 0 & 0 & 0 & 0 & 0 & 0 & 1 & 0 & -1 \\
\hline
\end{tabular}

Etapa 2: A matriz $H_{\Delta}{ }^{t}$ será:

\footnotetext{
${ }^{6} \mathrm{P}(\mathrm{i}-\mathrm{j})$ : Pseudo-medida de fluxo de potência da barra "i" para a barra "j".

${ }^{7} \mathrm{Pi}$ : Pseudo-medida de injeção de potência na barra "i".
} 


\begin{tabular}{|c|c|c|c|c|c|c|c|c|c|c|c|c|c|c|c|c|c|c|c|}
\hline & & $F(1-2)$ & $F(2-3)$ & 13 & $F(4-6)$ & $F(5-4)$ & 11 & $F(4-5)$ & 15 & 16 & $P(1-3)$ & $P(2-1)$ & $\mathbf{P}(3-1)$ & $\mathbf{P}(3-2)$ & $P(3-4)$ & $P(4-3)$ & $P(6-4)$ & P1 & P4 \\
\hline & D & 1 & 0 & 0 & 0 & 0 & 2 & 0 & 0 & 0 & 1 & -1 & -1 & 0 & 1 & -1 & 0 & 2 & -1 \\
\hline & 1 & 0 & 1 & 0 & 0 & 0 & 1 & 0 & 0 & 0 & 1 & 0 & -1 & -1 & 2 & -2 & 0 & 1 & -2 \\
\hline$H_{\Delta}^{t}=$ & 2 & 0 & 0 & 1 & 0 & 0 & 0 & 0 & 0 & 0 & 0 & 0 & 0 & 0 & & -1 & 0 & 0 & -1 \\
\hline & 3 & 0 & 0 & 0 & 1 & 0 & 0 & $\theta$ & 0 & -1 & 0 & 0 & 0 & 0 & 0 & 0 & -1 & 0 & 1 \\
\hline & 4 & 0 & 0 & 0 & 0 & 1 & 0 & -1 & 1 & 0 & 0 & 0 & 0 & 0 & 0 & 0 & 0 & 0 & -1 \\
\hline & 5 & 0 & 0 & 0 & 0 & 0 & 0 & 0 & 0 & 0 & 0 & 0 & 0 & 0 & 0 & 0 & 0 & 0 & 0 \\
\hline
\end{tabular}

Etapa 3: Através dos elementos não nulos da submatriz R, obtém-se 0 seguinte vetor contador:

$\mathrm{VC}=\begin{aligned} & 0 \\ & 1 \\ & 2 \\ & 3 \\ & 4\end{aligned}\left[\begin{array}{l}1 \\ 1 \\ 0 \\ 1 \\ 2\end{array}\right]$

Analisando as linhas de VC, obtém-se:

$\checkmark \mathrm{VC}[2]=0$, Medida Básica 13 é crítica, pois, essa medida é a única que fornece informação do estado equivalente correspondente à linha 2;

VC[0], $\mathrm{VC}[1]$ e $\mathrm{VC}[3]$ são iguais a 1. Logo identificam-se três pares críticos: (i) $[F(1-2)$, I1]; (ii) $[F(2-3), 11]$ e (iii) $[F(5-4), 16]$.

O algoritmo percorre os pares críticos formados selecionando aqueles que possuem pelo menos uma Medida Suplementar em comum. Como resultado apresenta-se: $[F(1-2), F[2-3], 11]$ e $[F(4-6), 16]$. Como pode ser visualizado na figura 6.15 .

\section{Pares Críticos}

\begin{tabular}{|l|l|}
\hline$F(1-2)$ & 11 \\
\hline$F(2-3)$ & 11 \\
\hline$F(4-6)$ & 16 \\
\hline
\end{tabular}

Conjuntos Críticos

\begin{tabular}{|l|l|l|}
\hline$F(1-2)$ & $F(2-3)$ & 11
\end{tabular}

$\mathrm{F}(4-6) \quad 16$

Figura 6.15 - Identificação dos Conjuntos Críticos a partir dos Pares Críticos do Exemplo

Etapa 4: Através das medidas críticas e conjuntos críticos apresentados na etapa anterior, obtém-se o seguinte vetor "Status": 
0
1
Status $=$
2
3
4 $\left[\begin{array}{l}x \\ x \\ x \\ x\end{array}\right]$

Analisando as linhas do vetor "Status", obtém-se:

Status[4] $\neq$ " $x "$ ", Medida Básica $F(5-4)$ não é crítica e não apareceu nos conjuntos críticos identificados anteriormente;

$>\mathrm{CP}=6$, o algoritmo inicializa o processo para obter os fatores triangulares necessários para transformar a coluna "6" da SubMatriz R em uma coluna formada apenas por zeros, com exceção do elemento da linha "4", que deve ser feito igual a 1. Atualizando o vetor VCA, obtém-se:

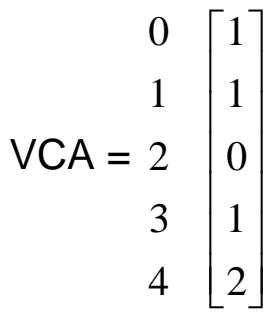

Analisando as linhas do vetor VCA, verifica-se que nenhum dos elementos não nulos se tornaram nulos. Portanto a Medida Básica $F(4-5)$ não faz parte de nenhum conjunto crítico. Não encontrando mais nenhuma posição no vetor Status = "X", a análise está encerrada.

O programa informa, então, os seguintes dados:

Medida Crítica: 13

$>$ Pares Críticos: [F(1-2), I1]; [F(2-3), I1]; [F(4-6), I6]

$>$ Conjuntos Críticos: [11, F(1-2), F(2-3)]; [F(4-6), I6]

Etapa 5: O algoritmo permitirá a análise das seguintes situações de emergência: (i) Perda das medidas I1 e I6; (ii) Perda das medidas F(4-6) e 16.

Situação 1: Foram perdidas as medidas I1 e 16:

O algoritmo verifica que não houve perda de Medidas Básicas. O sistema por sua vez continua observável. Removendo as colunas de $H_{\Delta}{ }^{t}$ correspondentes às medidas perdidas, apresenta-se: 


\begin{tabular}{|c|c|c|c|c|c|c|c|c|c|c|c|c|c|c|c|c|}
\hline & $F[1-2]$ & $F(2-3)$ & 13 & $F(4-6)$ & $F(5-4)$ & $F(4-5)$ & 15 & $\mathrm{P}[1,3]$ & $P(2-1)$ & $P(3-1)$ & $\mathrm{P}[3-2]$ & $P(3-4)$ & $P(4-3)$ & $P(6-4)$ & P1 & P4 \\
\hline \multirow{6}{*}{$H_{B}^{t}=$} & 1 & 0 & 0 & 0 & 0 & 0 & 0 & 1 & -1 & -1 & 0 & 1 & -1 & 0 & 2 & -1 \\
\hline & 0 & 1 & 0 & 0 & 0 & 0 & & 1 & 0 & -1 & -1 & 2 & -2 & 0 & 1 & -2 \\
\hline & 0 & 0 & 1 & 0 & 0 & 0 & & 0 & 0 & 0 & 0 & 1 & -1 & 0 & 0 & -1 \\
\hline & 0 & 0 & 0 & 1 & 0 & 0 & a & 0 & 0 & 0 & 0 & 0 & 0 & -1 & 0 & 1 \\
\hline & 0 & 0 & 0 & 0 & 1 & -1 & 1 & 0 & 0 & 0 & 0 & 0 & 0 & 0 & 0 & -1 \\
\hline & 0 & 0 & 0 & 0 & 0 & 0 & 0 & 0 & 0 & 0 & 0 & 0 & 0 & 0 & 0 & 0 \\
\hline
\end{tabular}

O algoritmo atualiza as características qualitativas do conjunto de medidas fornecendo a seguinte informação: Medidas críticas: F(1-2), F(2-3), I3, F(4-5).

Situação 2: Foram perdidas as medidas $F(4-6)$ e 16.

Dentre as medidas perdidas, verifica-se a perda da Medida Básica F(4-6). Conseqüentemente o sistema pode ter perdido a observabilidade. O VC é decrementado de acordo com a eliminação das colunas correspondente à Medida Suplementar 16, tornando-se:

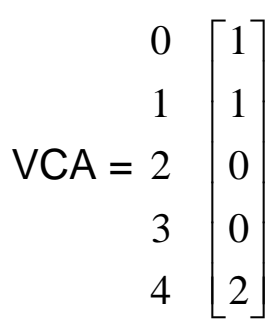

LP $=3$ e a coluna da matriz $H_{\Delta}{ }^{t}$ correspondente a Medida Básica F(4-6) é eliminada. $\mathrm{VC}[3]=0$, não há medida ainda disponível fornecendo informação do estado equivalente correspondente à linha 3. O algoritmo percorre as colunas da Submatriz $P$ encontrando a pseudomedida $P(6-4)$, que fornece informação do estado equivalente correspondente à linha "LP". O algoritmo troca as posições das colunas da matriz $H_{\Delta}{ }^{t}$, fazendo com que a pseudomedida $\mathrm{P}(6-4)$ seja armazenada na coluna LP da matriz $H_{\Delta}{ }^{t}$. Em seguida, através de fatoração triangular, é obtida a nova matriz $H_{\Delta}{ }^{t}$ (veja figura 6.16). 

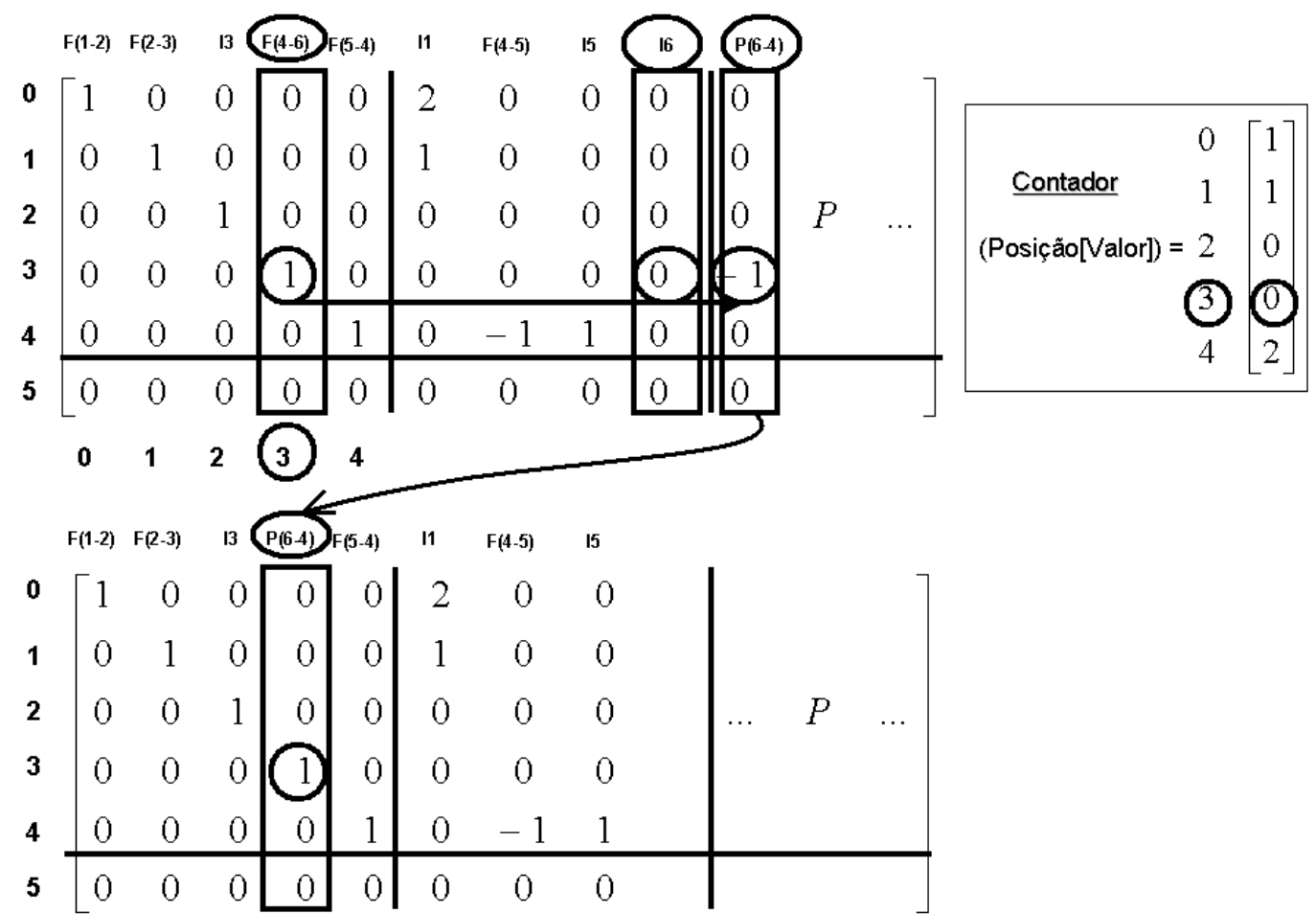

Figura 6.16 - Exemplo: Perda de Conjunto P-Crítico [F(4-6), I6]

Verificando a criticalidade das medidas ainda disponíveis, apresentam-se as seguintes informações:

Pares críticos: [F(1-2), I1]; [F(2-3), I1].

$>$ Medidas críticas: $13, \mathrm{P}(6-4)$.

$>$ Conjuntos críticos: [I1, F(1-2), F(2-3)].

\subsection{Análise comparativa entre os algoritmos desenvolvidos em London Jr. et al (2004) e os algoritmos propostos}

Embora as principais diferenças entre os algoritmos desenvolvidos em London Jr. et al (2004) e os algoritmos aqui propostos já tenham sido mencionadas neste capítulo, nesta seção tais diferenças serão novamente destacadas, para evidenciar as vantagens, em termos de rapidez de processamento, dos algoritmos aqui propostos:

$>$ Concorde seção 6.1, para o armazenamento da matriz $H^{t}$, que será fatorada, o algoritmo proposto já inclui as colunas correspondentes às pseudo-medidas, minimizando a quantidade de cálculos necessários para restauração da observabilidade. Pois, no algoritmo proposto em 
London Jr. et al (2004), em razão de as pseudo-medidas não serem armazenadas na matriz $H^{t}$, associada ao caso base, no instante em que se exige a restauração da observabilidade torna-se necessário aplicar os fatores triangulares, responsáveis pela obtenção da $H_{\Delta}{ }^{t}$, em uma por uma das pseudo-medidas disponíveis, até se encontrar aquela que permite a restauração da observabilidade. Em razão de a estrutura de armazenamento aqui proposta já incluir as pseudo-medidas na matriz $H^{t}$, associada ao caso base, no instante em que se exige a restauração da observabilidade, não se faz necessário cálculo algum para a determinação da pseudo-medida necessária, basta uma busca por elementos não nulos nas colunas da matriz $H_{\Delta}{ }^{t}$ correspondentes às pseudo-medidas. Isto porque essas colunas já foram consideradas no processo de fatoração triangular da matriz $H^{t}$, que resulta na obtenção da matriz $H_{\Delta}{ }^{t}$.

$>$ Conforme exposto na seção 6.4 .1 página 72 , para identificar os conjuntos críticos formados por mais de 1 medida Básica, o algoritmo desenvolvido em London Jr. et al (2004) requer um processo iterativo que consiste em eliminação daquelas Medidas Básicas e re-fatorações parciais da matriz $H_{\Delta}{ }^{t}$. Por outro lado, para aumentar a eficiência do algoritmo proposto, em termos de tempo de execução, o mesmo possibilita tal análise "simulando" re-fatorações parciais apenas na submatriz $R$, isto é, não se altera efetivamente o valor de nenhum elemento da submatriz R. 


\subsection{Interface gráfica}

A interface gráfica deve ser útil, maleável e ubíqua, permitindo uma visualização global do comportamento de todo o algoritmo implementado.

O programa inicia por meio de uma janela principal do tipo Tform, apresentando barra de título, ícones de maximização e minimização à direita da barra de título, uma barra de menu e uma moldura para a alteração do tamanho da janela.

Pode-se observar a sua estrutura na figura 6.17:

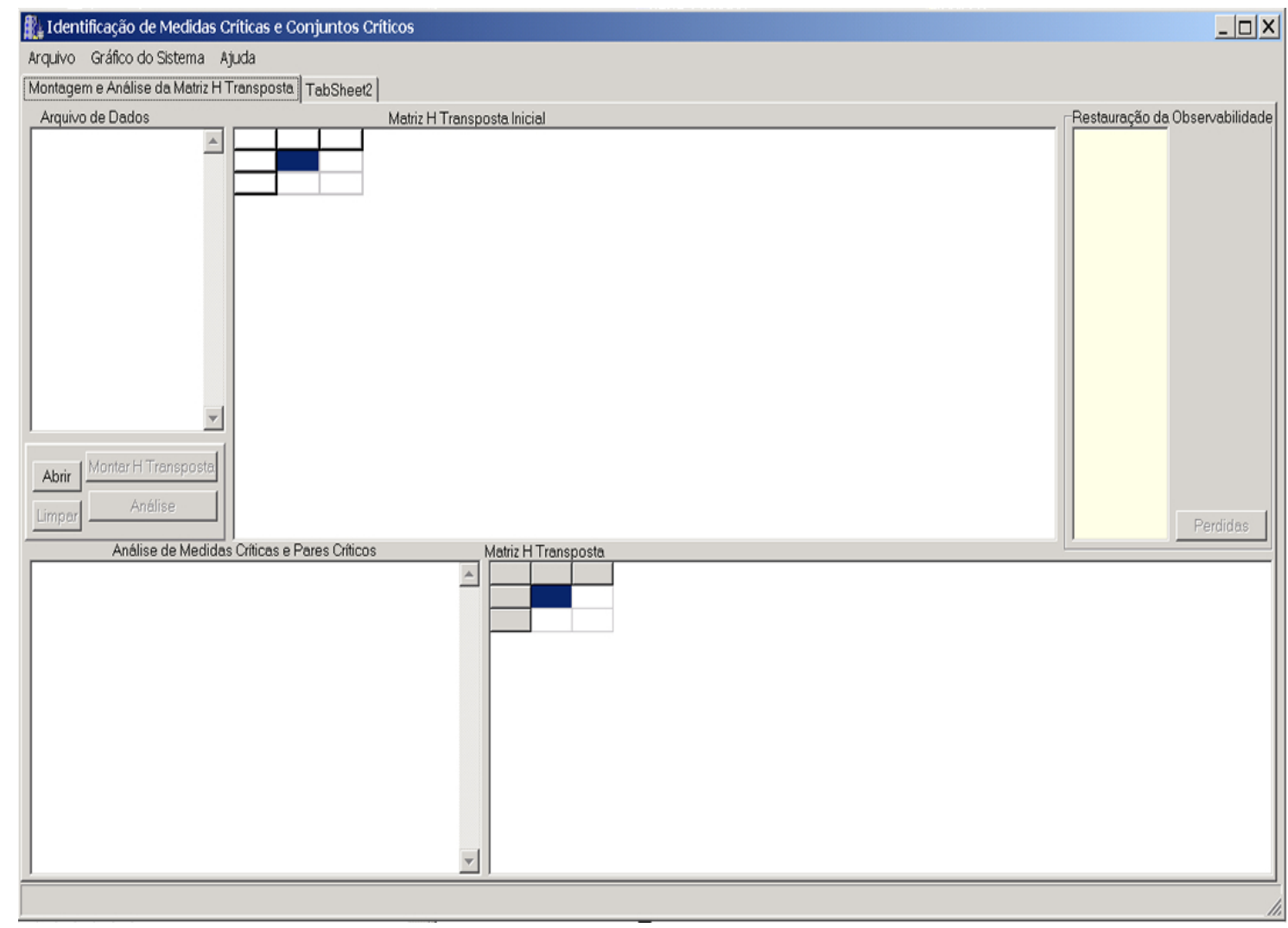

Figura $6.17-$ Tela 1

A partir da janela principal são gerenciados todos os processos do programa, como: abrir arquivo, salvar arquivo, sair do programa, alterar dados do banco de dados e visualizar resultados.

O programa permite que o usuário crie um banco de dados do sistema desejado. Este banco de dados deve conter informações da topologia do sistema e do tipo e localização das medidas disponíveis no mesmo. A figura 6.18 representa a janela responsável pela criação do banco de dados. 


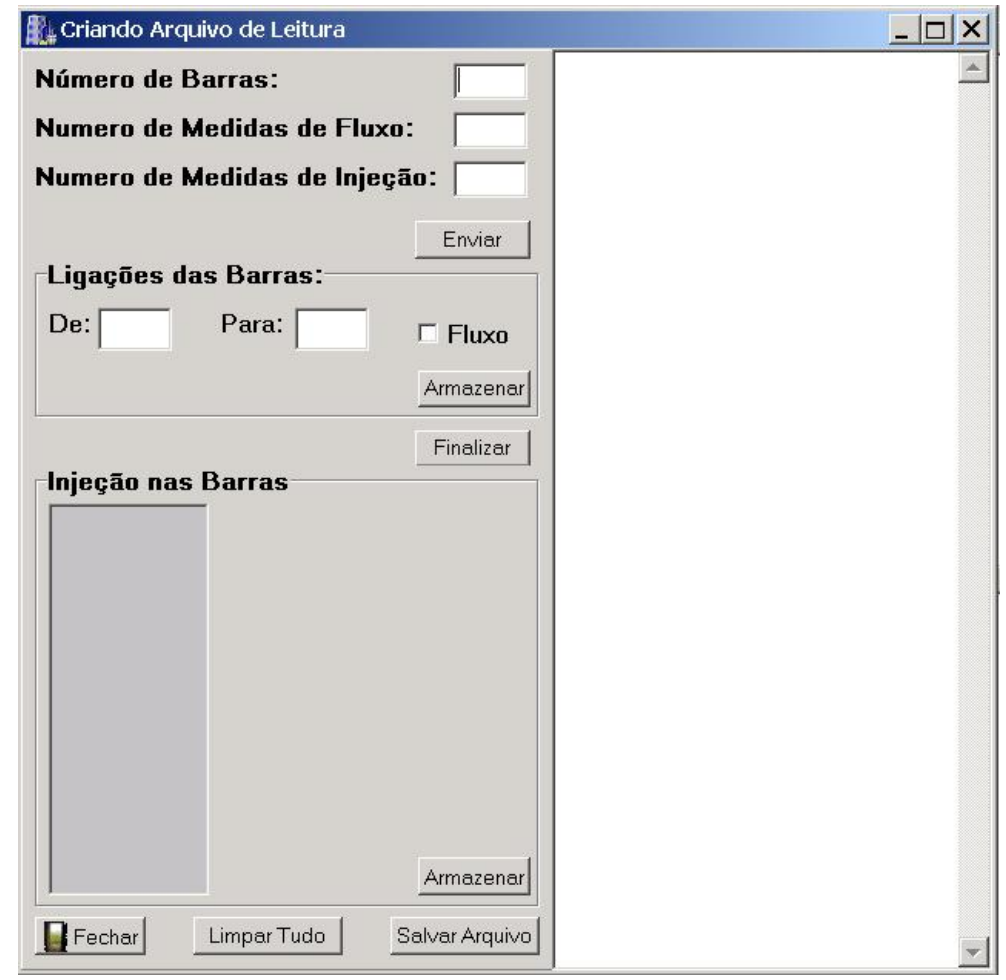

Figura 6.18 - Criando arquivo de Leitura (banco de dados)

O programa também permite que o usuário escolha um banco de dados já existente. Para isto nos itens de arquivo, são utilizados quadros de diálogos TopenDialog do builder, que representam, para o sistema Windows, uma maneira padrão de receber entrada de controle de usuário (veja figura 6.19).

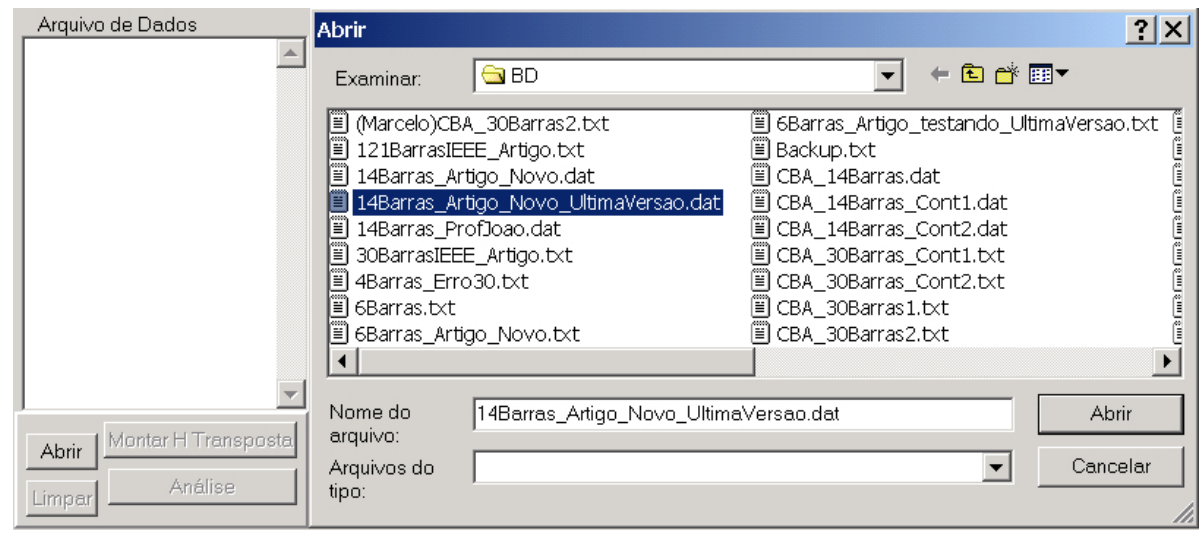

Figura 6.19 - Abrindo arquivo de Leitura (banco de dados)

É possível verificar na figura 6.20 que foi utilizado dois objetos do tipo StringGrid, chamado em momentos diferentes do algoritmo. O primeiro para a visualização da Matriz $H^{t}$, e o segundo para visualizar as mudanças que 
ocorrem na matriz durante o processo de identificação de medidas críticas e de conjuntos críticos.

A função desenvolvida "MontaMatriz" é a responsável pela visualização da matriz esparsa, no componente TStringGrid do builder.

Os parâmetros para requisitar a função "MontaMatriz" são dados por:

MontaMatriz(MatrizEsparsa *Source, int Row, int Col, TStringGrid *Target)

Onde Source é um ponteiro para a estrutura armazenada da Matriz Esparsa, Row e Col são variáveis do tipo inteiro que definem a dimensão da matriz e Target é um ponteiro do tipo TStringGrid para visualização da matriz no momento desejado.

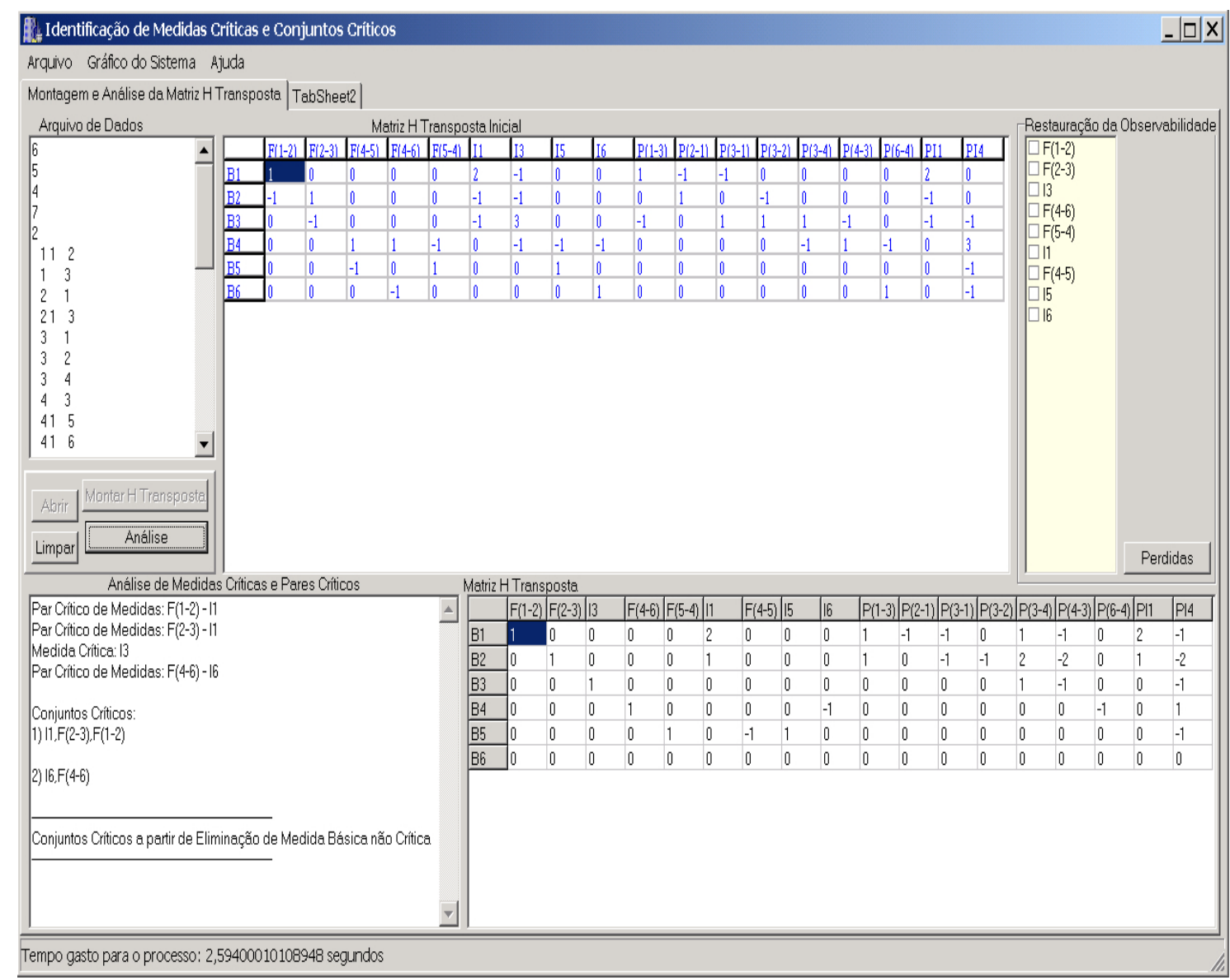

Figura 6.20 - Tela 2

Nota-se na figura 6.20, ou com mais detalhes na figura 6.21 , no canto superior direito da janela, a utilização de um componente CheckListBox, que 
informa ao programa as medidas que foram perdidas dando início ao processo de atualização das características qualitativas do novo conjunto de medidas.

Todas as informações necessárias do sistema que está sendo analisado são visualizadas em um componente memo, com a possibilidade de gravar essas informações ou imprimir para uma análise mais detalhada. A figura 6.21 mostra a situação do Caso Base, informando, no componente memo, as características qualitativas de conjunto de medidas.

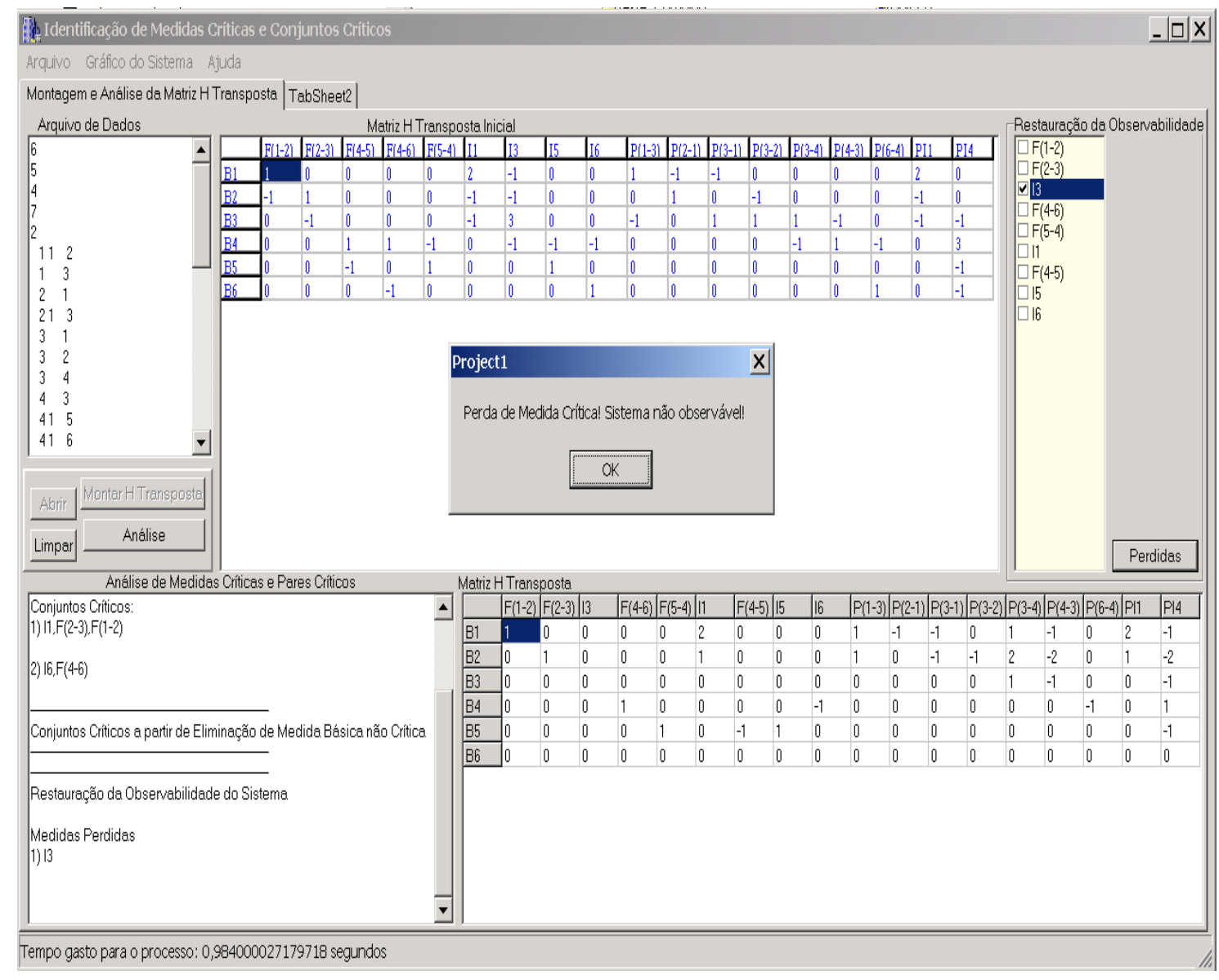

Figura $6.21-$ Tela 3

Optando em realizar testes a partir de perda de medidas, o programa atualiza as características qualitativas do conjunto de medidas e apresenta essas novas informações no componente memo. 


\section{Capítulo 5}

\section{Técnicas para desenvolvimento de programas computacionais}

Neste capítulo serão apresentadas algumas técnicas utilizadas para desenvolvimento de programas computacionais.

\subsection{Programação Orientada a Objetos}

Segundo Almeida (2003), a Programação Orientada a Objetos (OO) é uma extensão da programação modular $^{1}$. Linguagens que suportam conceitos de OO tornam mais fácil a criação de módulos reutilizáveis.

A Programação OO é uma técnica (tanto a nível de análise quanto de projeto e programação) que possibilita a criação de programas mais robustos, flexíveis e fáceis de se dar manutenção.

A primeira linguagem considerada como sendo orientada a objetos foi a Simula-68, criada em 1968. Entretanto, OO só se tornou uma técnica popular no início dos anos 80.

\footnotetext{
${ }^{1}$ Programação modular é também conhecida como método de programação de baixo para cima (bottomup). Ao invés de começar com o problema principal que se está tentando resolver e decompô-lo em rotinas menores, consiste na criação de pequenos módulos que são completamente independentes uns dos outros. Isto faz com que os códigos sejam escritos com o propósito de serem reutilizados.
} 
Linguagens mais tradicionais (Pascal e C) Ihe permitem criar estruturas de dados (matrizes, registros, etc.) e rotinas separadas (funções e procedimentos) que trabalham com os dados. Assim, sempre há uma separação entre os dados e as tarefas executadas com os mesmos.

Objetos lhe permitem armazenar dados e tarefas dentro da mesma estrutura de dados. Um objeto em C++ é essencialmente uma estrutura dentro da qual é possível definir procedimentos e funções como também tipos de campos. É possível pensar em um objeto como sendo um recipiente não só para os dados (os campos), mas também para as tarefas (as sub-rotinas).

A programação $O O$ tem como principais objetivos reduzir a complexidade no desenvolvimento de softwares e aumentar sua produtividade. Análise, projeto e programação $\mathrm{OO}$, são as respostas para o aumento da complexidade dos ambientes computacionais, que se caracterizam por sistemas heterogêneos, distribuídos em redes, em camadas, e baseados em interfaces gráficas.

No programa desenvolvido neste trabalho, o armazenamento da matriz é implementado como objeto, utilizando as técnicas de esparsidade citadas no capítulo 4, o que permite utilizar o armazenamento da matriz como uma caixa preta, ou seja, não é importante nesse momento compreender como ocorre o funcionamento interno do objeto, apenas conhecer as operações de consulta e atribuição de valor na matriz, pois o funcionamento interno do objeto não altera as estruturas das outras funções.

Exemplo 1:

Para armazenar um elemento de uma matriz numa variável:

$$
\text { Variável = matriz[i][j]; }
$$

Para armazenar um elemento da matriz esparsa desenvolvida como objeto numa variável:

$$
\text { Variável = matriz->Consul(i,j); }
$$

Exemplo 2:

Para inserir uma informação em uma posição da matriz:

$>$ Matriz[i][j] = informacao;

Para inserir uma informação na matriz esparsa desenvolvida como objeto: 
Com esse paradigma, é possível alterar as estruturas de dados utilizadas para o armazenamento da matriz esparsa, sem alterar o código dos cálculos necessários.

\subsection{Modelando Sistemas com a Linguagem de Modelagem Unificada}

Antes da elaboração de um programa computacional que represente um sistema real, deve-se ter um amplo conhecimento do domínio desse sistema, ou seja, cumpre analisá-lo. A análise será bastante proveitosa se resultar na construção de modelos, pois os mesmos permitem uma interação com o problema, e, conseqüentemente, o seu conhecimento mais amplo. Segundo Booch et al. (1997), isso se deve ao grau de abstração que os modelos apresentam, por traduzirem uma representação simplificada de algo real, levando os seus autores a focalizarem a atenção a partes relevantes do problema, deixando detalhes de implementação de lado. Esta característica é muito importante, porquanto, fazendo uso de modelos, simplifica-se inteligentemente o problema, dividindo-o em partes elementares e desfazendoIhe a complexidade, tornando assim mais fácil a sua compreensão total.

A modelagem servirá, não apenas para o entendimento do sistema e sua visualização, mas ao próprio comportamento. Seus modelos serão também os guias na implementação do projeto e usados para a documentação do resultado final.

Os modelos permitem que erros sejam visualizados antes da codificação do programa computacional, reduzindo destarte os riscos de implementação. É evidente que sistemas extremamente pequenos estejam sujeitos a riscos bem menores que sistemas maiores. Contudo, não se deve pensar que esses sistemas pequenos não necessitem de modelagem, pois, segundo Booch et al. (2000), há uma tendência natural de que sistemas pequenos se transformem em algo complexo, ao longo do tempo. Dessa maneira, uma documentação produzida por uma modelagem seria de grande valia em alterações futuras do sistema.

Para elaborar bons modelos, deve-se utilizar uma linguagem de modelagem dotada de diagramas que permitam a representação de sistemas simples ou complexos, sob diferentes vistas, pois isto facilita o entendimento. É 
a padronização, relativamente à comunicação entre as partes e a organização do problema.

A Linguagem de Modelagem Unificada (UML) vem tornando-se um padrão para modelagem de sistemas orientados a objeto [Larmann (2000)]. Esta linguagem é caracterizada por seus nove diagramas, que permitem visualizar um sistema sob diferentes perspectivas.

O primeiro requisito na construção de um sistema é a sua compreensão, sendo que para este objetivo é de grande valia a confecção de modelos. Entretanto, é importante evidenciar que nunca existirá um só modelo, que represente a totalidade de um sistema. Em verdade, a modelagem deverá consistir em um conjunto de modelos que se relacionem e representem individualmente o sistema, sob determinadas perspectivas. É o caso, por exemplo, da UML, segundo a qual um problema pode ser modelado de acordo com várias visões: a visão dos casos de uso, a visão de projeto, a visão de processo, a visão de implementação e a visão de implantação.

Para representar o sistema sob as várias visões, a UML dispõe de nove diagramas: diagrama de classes, diagrama de objetos, diagrama de componentes, diagrama de implantação, diagrama de caso de uso, diagrama de seqüência, diagrama de colaboração, diagrama de estados e diagrama de atividades.

Segundo Furlan (1998), os diagramas da UML possuem uma notação padrão e bastante compreensível, que permite a abstração de certos aspectos do sistema, ficando o mesmo, assim, fácil de ser entendido através de suas partes. Ao final da modelagem, essas partes se completam e representam o sistema em sua totalidade.

O conjunto de modelos constitui a proposta de uma solução para o problema, oriundo da necessidade de construir-se um sistema. Essa proposta poderá ser viável ou não. Assim, o modelo deverá ser estudado, até se chegar a uma conclusão aceitável. Durante esse estudo, o modelo poderá sofrer algumas alterações, a fim de corresponder aos requisitos do sistema.

$\mathrm{Na}$ fase de implementação, os modelos são muito consultados pela equipe do projeto, pois é a partir deles que se construirá o programa computacional, ou seja, os modelos são os guias na codificação. Fowler e Scott (2000) afirmam que é muito fácil esquecer detalhes em um projeto, mas, com 
uma pequena consulta a alguns diagramas, torna-se simples encontrar o caminho no programa computacional.

As fases iniciais de desenvolvimento de um software são as mais conflitantes, havendo sempre falta de entendimento entre os membros da equipe de desenvolvimento, assim também entre estes e os usuários do sistema (clientes). Isto se deve, na maioria das vezes, à falta de um vocabulário de comunicação entre as partes, e quase sempre, os próprios clientes ou usuários do sistema têm dificuldades em explicitar seus requisitos. Por esta razão, impõe-se-nos a definição de uma notação padrão, necessária nas fases de análise de requisitos e modelagem do sistema. Para tanto é proposto a $U M L$, que já se tornou, de fato, um padrão formalizado pela $O M G$ (Object Management Group), tendo, a cada dia que passa, um incremento na comunidade de seus adeptos.

\subsection{Linguagem de Programação}

O programa proposto foi implementado em linguagem $\mathrm{C}++$, que, hodiernamente, podemos encontrar em diversos programas, como fonte importante para a programação. O compilador usado é o C++ Builder.

Segundo Leão (1998), a linguagem C++ foi uma das pioneiras na implementação do conceito de programação 00 , estendendo as potencialidades da linguagem $\mathrm{C}$. Entretanto, ao contrário do que ocorre com a linguagem $\mathrm{C}$, que tem um padrão denominado ANSI-C, a flexibilidade da programação OO fez com que surgissem, no mercado, diversos "dialetos" do $\mathrm{C}++$, desenvolvidos por empresas como Microsoft, Borland, PowerSoft, etc.

Essas diferenças, no entanto, são uma conseqüência da implementação de diversas bibliotecas de classes, criadas para facilitar o trabalho do programador no desenvolvimento das suas aplicações. Como exemplo de biblioteca de classes podem-se destacar a Microsoft Foundation Classes (MFC), da Microsoft, e a Object Windows Library (OWL), da Borland, usadas no desenvolvimento de aplicações para o ambiente Windows. 
Essas bibliotecas, embora facilitassem a criação da interface do programa com o usuário, não ofereciam a simplicidade existente em linguagens de programação como o Visual Basic e o Borland Delphi².

A fim de preencher essa lacuna e considerando o sucesso indiscutível obtido pelo Borland Delphi, a Borland resolveu lançar um novo compilador: o C++ Builder.

O C++ Builder alia o poder da linguagem $\mathrm{C}++$ a um ambiente de desenvolvimento integrado, que permite o desenvolvimento da interface visual do aplicativo de uma forma simples e rápida, utilizando a Visual Component Library (VCL) - a biblioteca de componentes desenvolvida para ser usada, inicialmente, pelo Delphi.

Com o C++ Builder é possível desenvolver aplicações para o ambiente Windows e aplicações do tipo console.

As aplicações do tipo console, se criadas utilizando apenas os tipos e operadores básicos da linguagem $\mathrm{C}++$ (comuns à maioria dos compiladores), têm a vantagem da portabilidade, isto é, podem ser recompiladas em outras plataformas.

O C++ Builder utiliza os conceitos de programação visual e dirigida por eventos para proporcionar uma ferramenta RAD (Rapid Application Development), que permite desenvolver aplicações eficientes rapidamente. Algumas de suas características são:

> Uso de bibliotecas de componentes visuais, a VCL (Visual Components Library), desenvolvida originalmente para o Delphi.

$>$ Possui um excelente ambiente de desenvolvimento (IDE) com ferramentas de produtividade que auxiliam a programação, além de um ótimo depurador (debugger).

Ferramentas para o desenvolvimento em equipes de programadores e controle de versões.

> Grande escalabilidade no acesso a banco de dados: pode acessar tabelas locais dBase e Paradox, assim como SGBDs (Sistema de Gerenciador de Banco de Dados) como Oracle, Informix, Sybase, Microsoft SQL Server e Interbase.

\footnotetext{
${ }^{2}$ Compilador produzido pela Borland com características semelhantes ao C++ Builder, só que utilizando a linguagem Object Pascal como linguagem base.
} 


\subsection{Tipos e Estruturas de Dados}

Outro passo importante para o desenvolvimento de um programa computacional eficiente é a determinação da estrutura de dados mais adequada.

Há diversas estruturas de dados destinadas ao desenvolvimento de um algoritmo consistente nas operações, propiciando rápido desempenho, sendo que cada uma apresenta suas vantagens e desvantagens.

No programa proposto, foi necessário estudar um tipo de estrutura de dados para o armazenamento da matriz esparsa, ou seja, para facilitar o armazenamento apenas dos elementos não nulos da matriz.

Em vista disto, utilizamos uma estrutura de dados do tipo lista para este armazenamento.

I. Listas

Uma lista linear é uma coleção ordenada de elementos de um mesmo tipo. A palavra ordenada implica que dado um conjunto de elementos, é possível identificar o elemento antecessor e predecessor de qualquer elemento.

Juntamente com essa definição de lista, é possível tratar das operações que serão executadas nestas listas, como operações de inicialização da lista e de exclusão, inclusão e busca de elementos ou dados na lista.

Existem então, dois tipos de listas:

Listas seqüenciais: onde o sucessor como o predecessor ocupam as posições físicas do elemento. Ex.: um vetor.

Vantagens:

o rapidez de acesso à posição do elemento que se deseja.

o facilidade em alterar os elementos.

Desvantagens:

o Definição prévia do tamanho do vetor.

o Aumento da complexidade do algoritmo para inserir ou remover um elemento entre dois já existentes. 
Listas encadeadas: elementos consecutivos na lista não implicam em elementos consecutivos na representação, ou seja, a ordem é lógica.
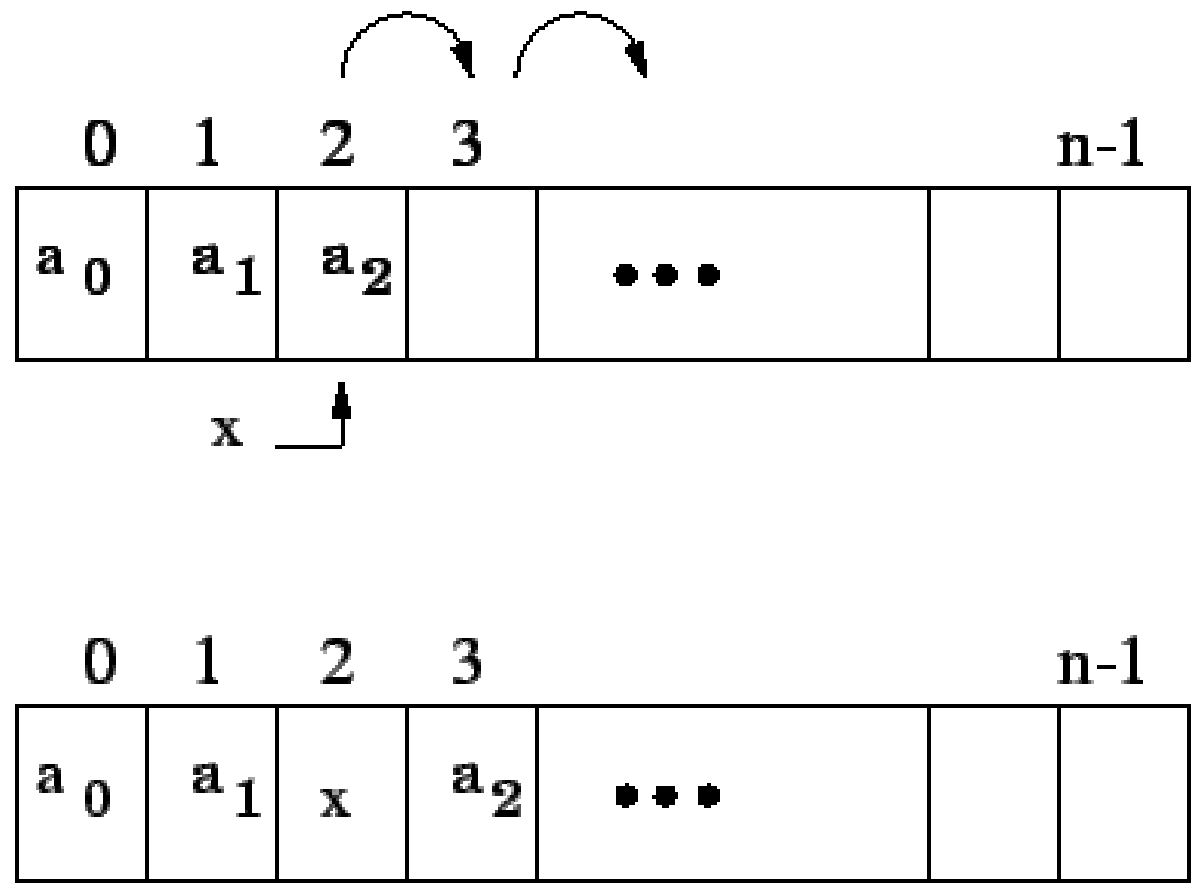

Figura 5.1 - Listas estáticas

Existem duas formas de se representar listas encadeadas através de vetores, chamadas de listas estáticas, como pode ser visto na figura 5.1, ou por ponteiros $^{3}$, chamadas listas dinâmicas, apresentada na figura 5.2.

\footnotetext{
${ }^{3}$ Ponteiros são variáveis que indicam algum endereço de memória. São usados para alocação dinâmica de espaço em memória, ou seja, alocação de espaço de memória que ocorre no intervalo de tempo de execução dos programas.
} 

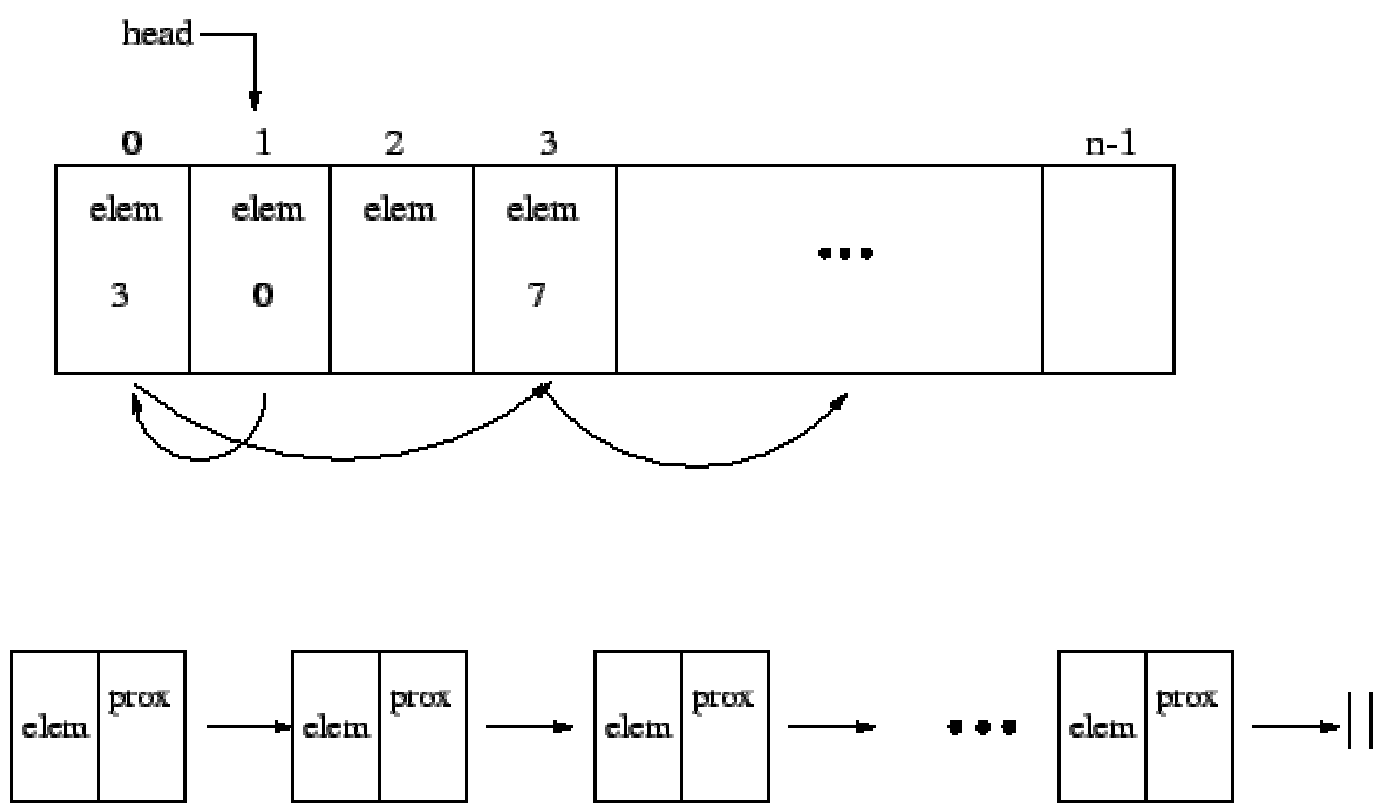
head

Figura 5.2 - Listas Dinâmicas

Vantagens:

o Eliminação do problema dos deslocamentos dos nós ${ }^{4}$.

o No caso de listas dinâmicas, não é necessário saber previamente o número de elementos a serem armazenados.

Desvantagens:

o Não é possível acessar os elementos da lista em tempo constante.

o Número excessivo de operações para manter a integridade dos dados.

É possível dividir as listas encadeadas em:

$>$.Unicamente ou simplesmente encadeada:

Cada elemento possui apenas informação de quem é o seu sucessor. É necessário armazenar a informação do primeiro elemento da lista. Os principais problemas são a impossibilidade de retornar

\footnotetext{
${ }^{4}$ Área na memória reservada por variáveis que são ligadas através de ponteiros.
} 
ao elemento anterior e a necessidade de armazenar a informação do elemento anterior para a realização de alguma operação.

\section{Duplamente encadeada:}

Cada elemento possui a informação de seus respectivos sucessor e antecessor. Por isso, esta estrutura permite caminhar nas duas direções, sendo mais fácil a inclusão e a remoção de elementos. Todavia, esta estrutura exige mais espaço para o armazenamento e a manipulação de um ponteiro extra.

\section{Circular:}

Uma lista circular pode ser simples ou duplamente encadeada. O que caracteriza as listas circulares é o fato do sucessor do último elemento ser o primeiro elemento da lista.

\subsection{Interface gráfica}

A interface de um software é um meio de contato predominantemente cognitivo que utiliza aspectos léxicos (funcionais), sintáticos (estruturais) e semânticos (conteúdos).

Segundo Normam (1990), para o bom projeto de interfaces, normalmente se consideram as seguintes características:

- Mapeamento Natural: uso de padrões e símbolos bem estabelecidos e conhecidos;

- Visibilidade dos Controles: considera o tamanho e a quantidade dos controles, bem como a proporção referente ao espaço disponível;

- Reconhecimento versus Recordação: baseado na tendência freqüente apresentada por diversos usuários de descobrirem como uma interface funciona por tentativa e erro;

- Feedback: considera o resultado das ações do usuário, à medida que utiliza o sistema; 
- Affordance: exploração das propriedades perceptíveis dos objetos. Reúne todas as outras características.

Nota-se a importância do desenvolvimento da interface neste trabalho, cujo objetivo é permitir que os usuários tenham total acesso às informações do programa, entendendo com rapidez, através da interface, o funcionamento do seu algoritmo, o que Ihes há de proporcionar considerável auxílio em seus estudos e projetos. 


\section{Capítulo 4}

\section{$4 \quad$ Técnicas de Esparsidade}

\subsection{Introdução}

Várias das etapas do processo de estimação de estado, em SEP, envolvem a solução de sistemas algébricos lineares, que podem ser representados da seguinte forma:

$$
\text { A. } \underline{x}=\underline{b}
$$

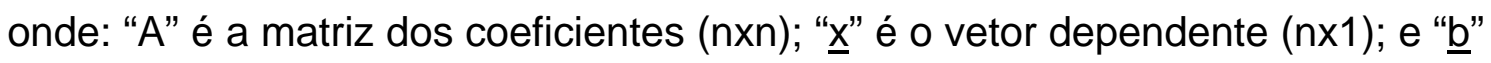
é o vetor independente $(\mathrm{n} \times 1)$.

Devido à grande dimensão dos SEP e do grande número de medidas que se realizam, os sistemas envolvidos no processo de estimação de estado do tipo "A. $\underline{x}=\underline{b}$ " são de grandes dimensões, mas com matrizes altamente esparsas. Em razão disso, a solução de tais sistemas, através do cálculo da inversa da matriz dos coeficientes, é impraticável e computacionalmente inviável, porquanto, apesar da matriz "A" ser esparsa, a sua inversa é geralmente cheia. Assim, a obtenção da inversa da matriz " $A$ " acarretaria uma grande quantidade de cálculos, tornando o processo lento e aumentando, assim, a possibilidade de problemas numéricos, inerentes ao processo de inversão de matriz. 
O grau de esparsidade (GE) de uma matriz é definido como a porcentagem de elementos nulos dessa matriz, isto é:

$$
G E=\frac{n^{o} \text { Elementos_Nulos }}{n^{o} \text { Total_Elementos }} .100 \%
$$

Uma matriz é considerada esparsa se GE $\geq 95 \%$.

As técnicas de esparsidade possibilitam a solução do sistema do tipo A. $\underline{x}=\underline{b}$, diminuindo a quantidade de dados a serem armazenados, bem como o montante de cálculos necessários.

De uma forma geral, as técnicas que serão aplicadas, para 0 desenvolvimento do programa proposto, são as seguintes:

1. Estrutura compacta e dinâmica, para o armazenamento de matrizes esparsas: para solucionar um sistema do tipo "A. $\underline{x}=\underline{b}$ ", através dos fatores triangulares, técnica que será aqui apresentada, basta conhecer os elementos não nulos da matriz dos coeficientes, bem como os "fill-in's" (elementos não nulos que surgem durante a fatoração da matriz). Em razão disso, para armazenar as matrizes esparsas, Zollenkopf (1971) desenvolveu uma estrutura compacta e dinâmica. Compacta porque são armazenados apenas os elementos não nulos das matrizes e dinâmica por permitir a locação dos "fill-in's";

2. Solução do sistema, através dos fatores triangulares: Segundo Monticelli (1983), a partir da chamada decomposição "L.D.U." da matriz dos coeficientes, determinam-se os fatores triangulares necessários à solução do sistema "A. $\underline{x}=\underline{b}$ ", sem a necessidade do cálculo da inversa da matriz "A";

3. Esquemas de ordenação: através de um conveniente esquema de ordenação da fatoração de uma matriz, isto é, da seqüência em que as suas colunas são fatoradas, é possível diminuir o número de "fill-in's";

4. Método dos vetores esparsos: Segundo Tinney et al. (1985), em muitos dos problemas de análise de sistemas elétricos de potência, além da matriz dos coeficientes, os vetores também são esparsos. A solução desses problemas torna-se ainda mais eficiente, através da utilização deste método. 


\subsection{Estrutura para o armazenamento de matrizes esparsas}

Dentre as estruturas desenvolvidas para armazenamento de matrizes esparsas, as primeiras desenvolvidas para aplicação em SEP foram propostas por Zollenkopf (1971). Atualmente, com o advento da alocação dinâmica, listas encadeadas, as estruturas de Zollenkopf (1971) deixaram de ser utilizadas. Entretanto, as mesmas servem ainda como modelo para o desenvolvimento de estruturas mais eficientes.

Face ao exposto, apresentam-se, a seguir, as estruturas de armazenamento propostas por Zollenkopf (1971).

1) Estrutura 1 - Para matrizes simétricas em estrutura e valor:

Armazena a matriz através de duas tabelas, sendo:

Tabela 1 (possui duas colunas)

- Coluna 1 - LCOL: Indica a linha da tabela 2 onde foi armazenado o primeiro elemento não nulo de uma determinada coluna;

- Coluna 2 - NOZE: número total de elementos não nulos de uma determinada coluna, caso seja "0", indica "fim de elementos".

Tabela 2 (possui três colunas)

- Coluna 1 - ITAG: Indica a linha (na matriz) do elemento que está sendo armazenado;

- Coluna 2 - LNEXT: indica a posição (linha da Tabela 2) onde foi armazenado o próximo elemento de uma determinada coluna;

- Coluna 3 - CE: Indica o valor real do elemento armazenado na posição da matriz.

2) Estrutura 2 - Para matrizes simétricas em estrutura, mas não simétricas em valor:

As diferenças desta estrutura em relação à Estrutura 1 é:

- Tabela 1 - Inclui-se a coluna "DE" para armazenar o valor dos elementos da diagonal principal.

- Tabela 2: Inclui-se a coluna "RE", que irá armazenar os valores de elementos simétricos aos elementos armazenados na coluna "CE". 


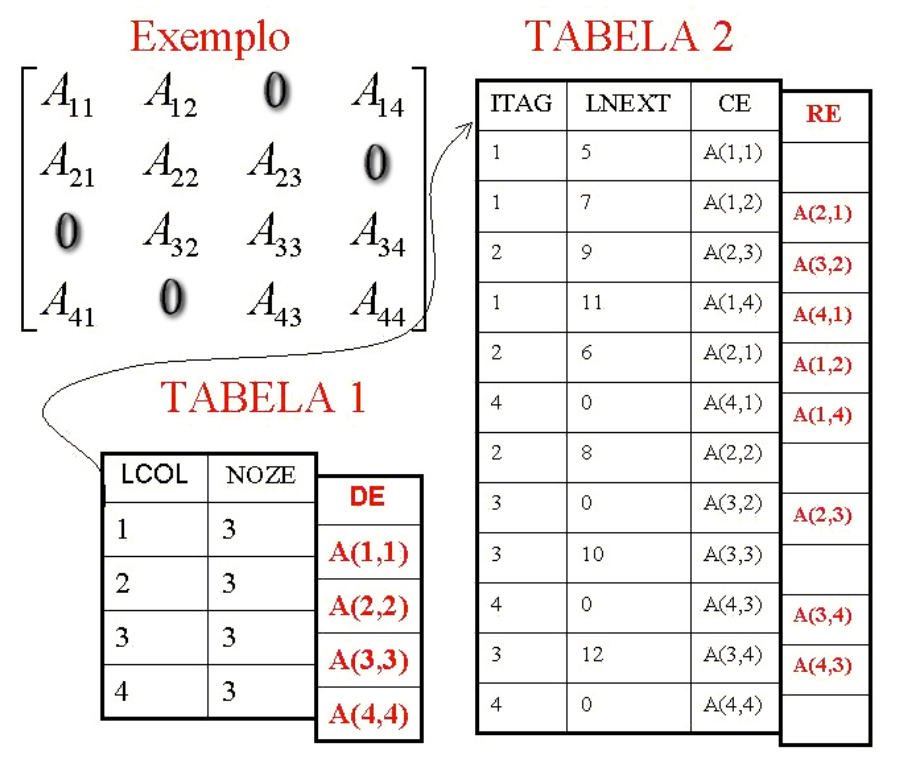

Figura 4.1 - Exemplo do armazenamento de Zollenkopf

A figura 4.1 demonstra como pode ser visualizada a implementação da estrutura de Zollenkopf (1971).

\subsection{Solução via fatores triangulares}

Em razão de o processo de solução via fatores triangulares basear-se no método de Eliminação de Gauss, apresentam-se, então, as principais etapas do método. A eliminação de Gauss consiste em transformar o sistema linear original em um sistema equivalente onde a matriz dos coeficientes é uma matriz Identidade. O método de eliminação de Gauss consiste das seguintes Etapas:

Etapa "Forward": Como pode ser visto na figura 4.2, a etapa "forward" consiste em eliminar os elementos não nulos, abaixo da diagonal principal. Calculam-se então, os fatores necessários para essa eliminação. Por exemplo:

$F_{i j}$ é o fator que vai eliminar o elemento $A_{i j}$. Logo, $F_{i j}=-\frac{A_{i j}}{A_{j j}}$. A linha "i" da nova matriz "A", será igual ao somatório da própria linha i, da matriz original, pela linha "j", da matriz original, multiplicada pelo fator $F_{i j}$. 
Na figura 2, o fator que irá zerar o elemento $A_{21}$, será aplicado em toda linha, retornando um novo elemento em $A_{22}$ e $A_{23}$. Esse processo é iterativo, calculando novos fatores, até zerar todos os elementos não nulos do triangulo inferior da matriz $A$.

$$
\begin{aligned}
& \text { Etapa Forward } \\
& A=\left[\begin{array}{lll}
A_{11} & A_{12} & A_{13} \\
A_{21} & A_{22} & A_{23} \\
A_{31} & A_{32} & A_{33}
\end{array}\right] \quad A^{1}=\left[\begin{array}{ccc}
A_{11} & A_{12} & A_{13} \\
0 & A_{22}{ }^{1} & A_{23}{ }^{1} \\
0 & A_{32}{ }^{1} & A_{33}{ }^{1}
\end{array}\right] \\
& F_{21}=\frac{-A_{21}}{A_{11}} \quad F_{31}=\frac{-A_{31}}{A_{11}} \\
& A_{21}{ }^{1}=F_{21} \cdot A_{11}+A_{21}=0 \quad A_{31}{ }^{1}=F_{31} \cdot A_{11}+A_{31}=0 \\
& A_{22}{ }^{1}=F_{21} \cdot A_{12}+A_{22} \quad A_{32}{ }^{1}=F_{31} \cdot A_{12}+A_{32} \\
& A_{23}{ }^{1}=F_{21} \cdot A_{13}+A_{23} \quad A_{33}{ }^{1}=F_{31} \cdot A_{13}+A_{31} \\
& \sqrt{5}
\end{aligned}
$$

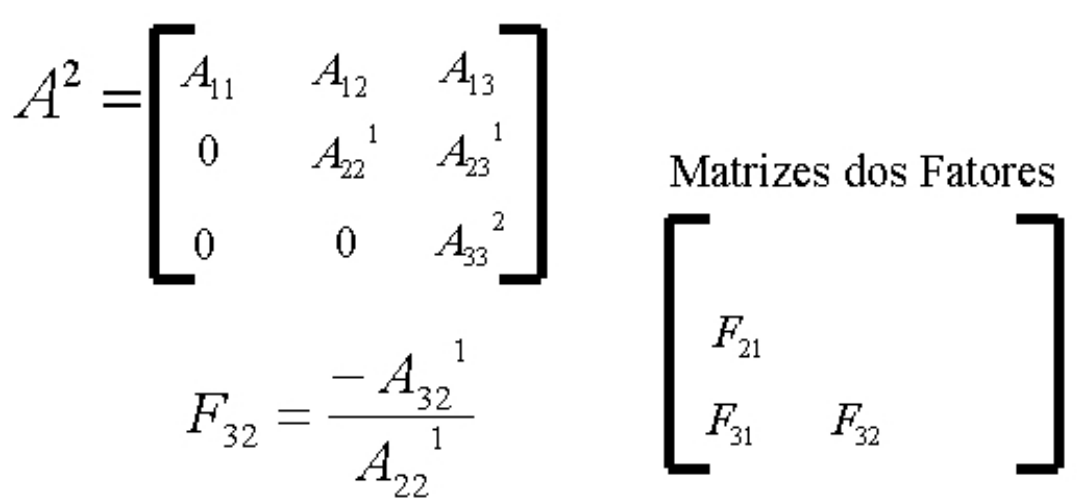

Figura 4.2 - Etapa "Forward" na matriz A

Etapa Diagonalização: Fazem-se os elementos da diagonal principal igual a 1(um), dividindo-se, cada equação, pelo elemento correspondente da diagonal principal da matriz dos coeficientes obtida no passo anterior. Assim 
são obtidos os fatores da diagonalização. Na figura 4.3 verifica-se o seguinte fator:

O fator $D_{11}$ é utilizado para fazer o elemento $A_{11}$ igual a 1 , na matriz original. Assim, este fator será aplicado a toda linha 1.

$$
\begin{aligned}
& \text { Etapa Diagonalização }
\end{aligned}
$$

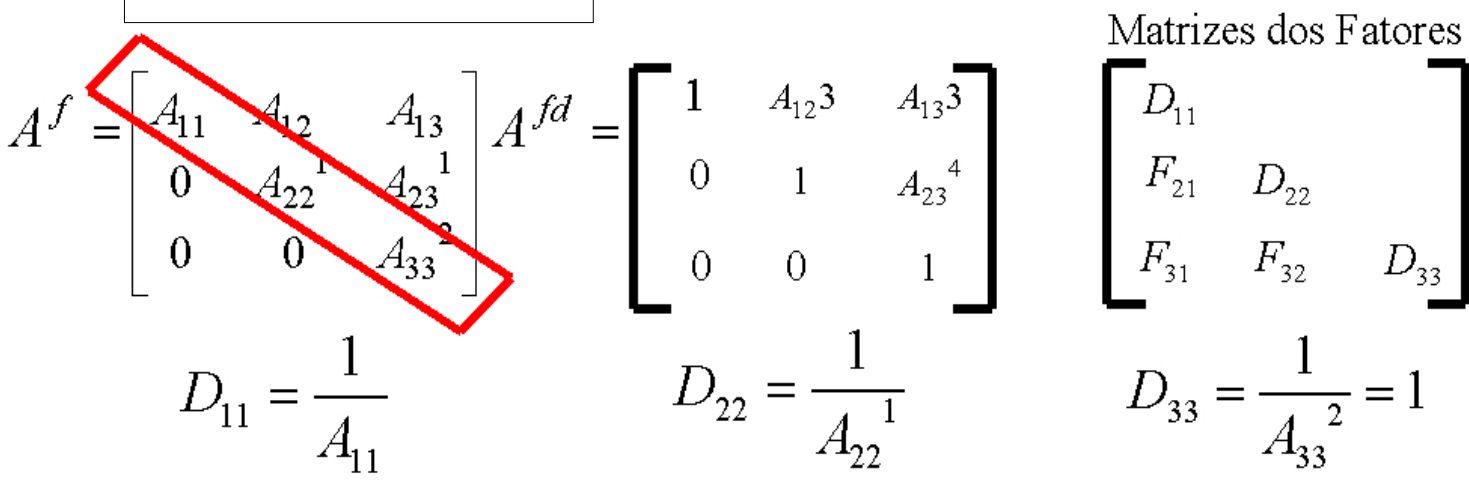

$$
\begin{aligned}
& A_{11}{ }^{3}=D^{1} \cdot A_{11}=1 \quad A_{22}{ }^{4}=D_{22}{ }^{1} \cdot A_{22}{ }^{1}=1 \\
& A_{12}{ }^{3}=D_{11} \cdot A_{12} \quad A_{23}{ }^{4}=D_{22}{ }^{1} \cdot A_{23}{ }^{1} \\
& A_{13}{ }^{3}=D_{11} \cdot A_{13}
\end{aligned}
$$

Figura 4.3 - Etapa Diagonalização na matriz A

Etapa "Backward": Zeram-se agora os elementos do triângulo superior (também através de combinações lineares) transformando, ao final do processo, a matriz dos coeficientes numa matriz identidade.

$$
\begin{aligned}
& \text { Etapa Backward } \\
& A^{2}=\left[\begin{array}{ccc}
1 & A_{12}{ }^{3} & A_{13}{ }^{3} \\
0 & 1 & A_{23}^{4} \\
0 & 0 & 1
\end{array}\right] A^{3}=\left[\begin{array}{ccc}
1 & 0 & 0 \\
0 & 1 & 0 \\
0 & 0 & 1
\end{array}\right]\left[\begin{array}{ccc}
D_{11} & B_{12} & B_{13} \\
F_{21} & D_{22} & B_{23} \\
F_{31} & F_{32} & D_{33}
\end{array}\right] \\
& B_{23}=-A_{23}{ }^{4} \quad B_{13}=-A_{13}{ }^{3} \quad B_{12}=-A_{12}{ }^{3} \\
& A_{23}{ }^{5}=B_{23} \cdot 1+A_{23}{ }^{4}=0 \quad A_{13}{ }^{6}=B_{13} \cdot 1+A_{13}{ }^{3}=0 \quad A_{12}{ }^{6}=B_{12} \cdot 1+A_{12}{ }^{3}=0
\end{aligned}
$$


Como pode ser visto na figura 4.4, na etapa "Backward", o processo é o inverso da etapa "forward", mas como os elementos da diagonal principal, da matriz dos coeficientes, resultante das etapas anteriores, são iguais a 1 , os fatores são o negativo dos elementos a serem eliminados.

É necessário ressaltar que todas as operações efetuadas sobre a matriz dos coeficientes devem ser efetuadas sobre o vetor independente. Portanto, o vetor independente resultante será a solução do sistema, conforme pode ser visto na figura 4.5 .

apa "Forward"

$$
\left[\begin{array}{lll}
D_{11} & B_{12} & B_{13} \\
\left(N_{2}\right. & D_{22} & B_{23} \\
N_{2} & D_{33}
\end{array}\right]
$$$$
\text { A. } \underline{x}=\underline{b}
$$

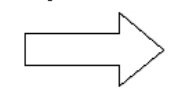

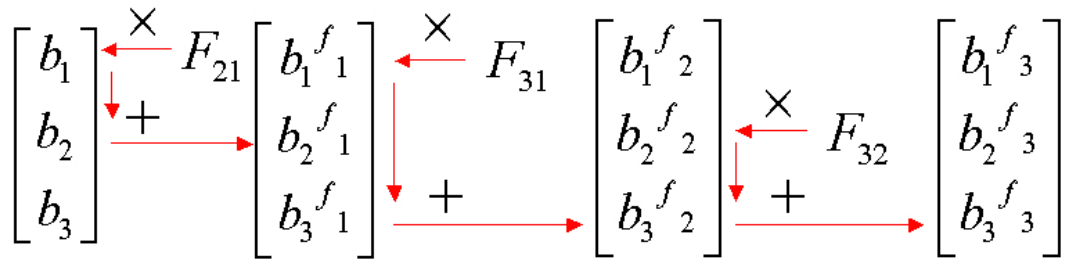

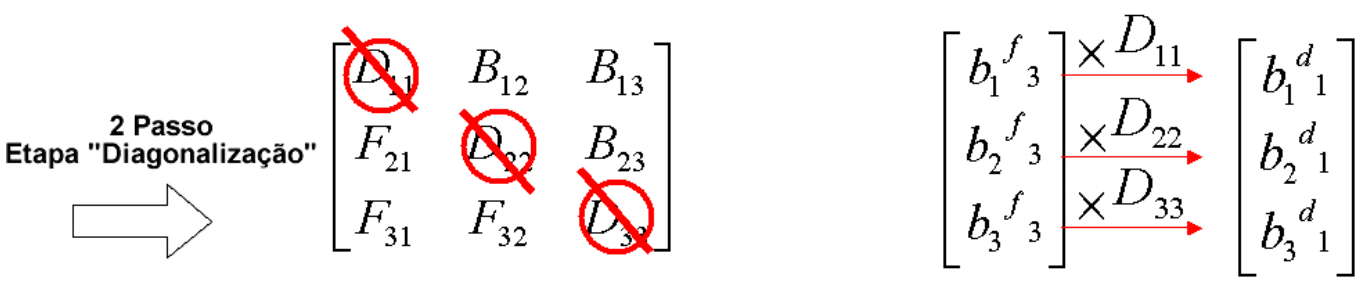

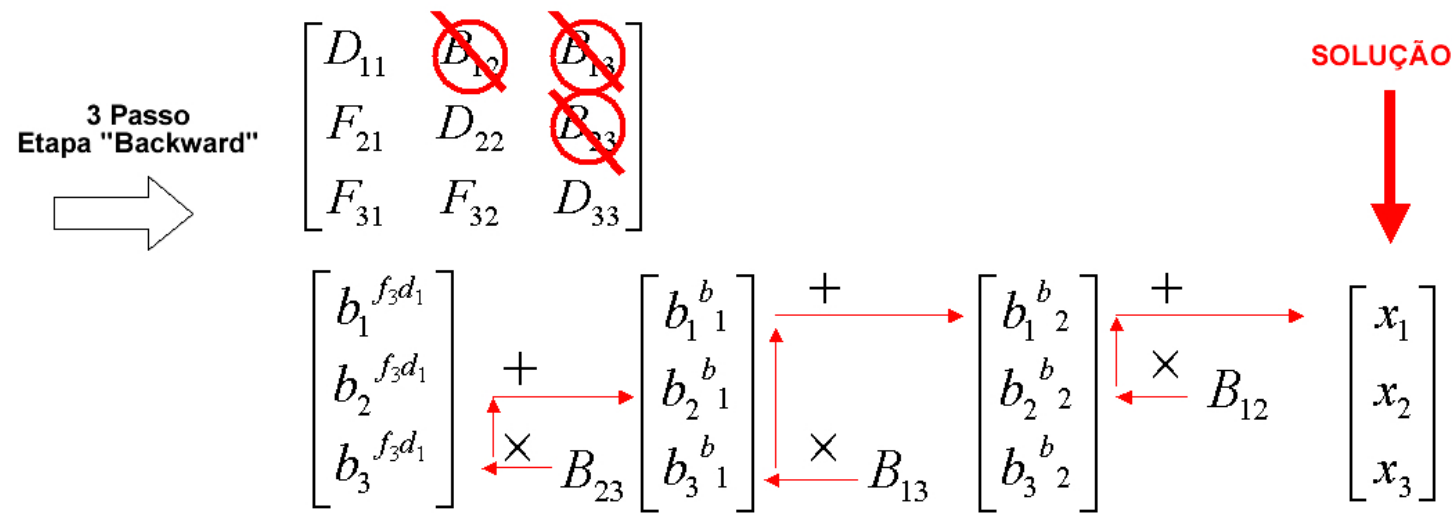

Figura 4.5 - Etapas aplicadas no vetor $\underline{b}$ 


\subsection{Esquemas de Ordenação}

O objetivo dos esquemas de ordenação é minimizar o aparecimento dos "fill-in's" durante a fatoração de uma matriz.

Para se ter noção da importância da seqüência em que as colunas são fatoradas, visualiza-se, na figura 4.6, que mudando a seqüência em que as colunas da matriz "A" são fatoradas, não aparecem nenhum "fill-ins".

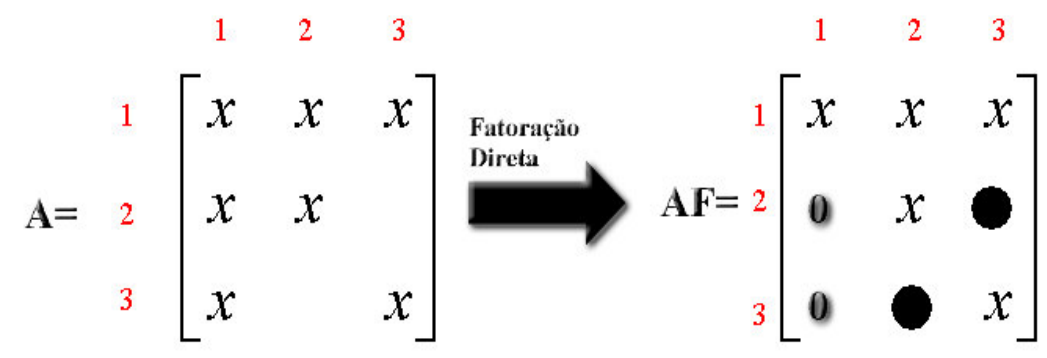

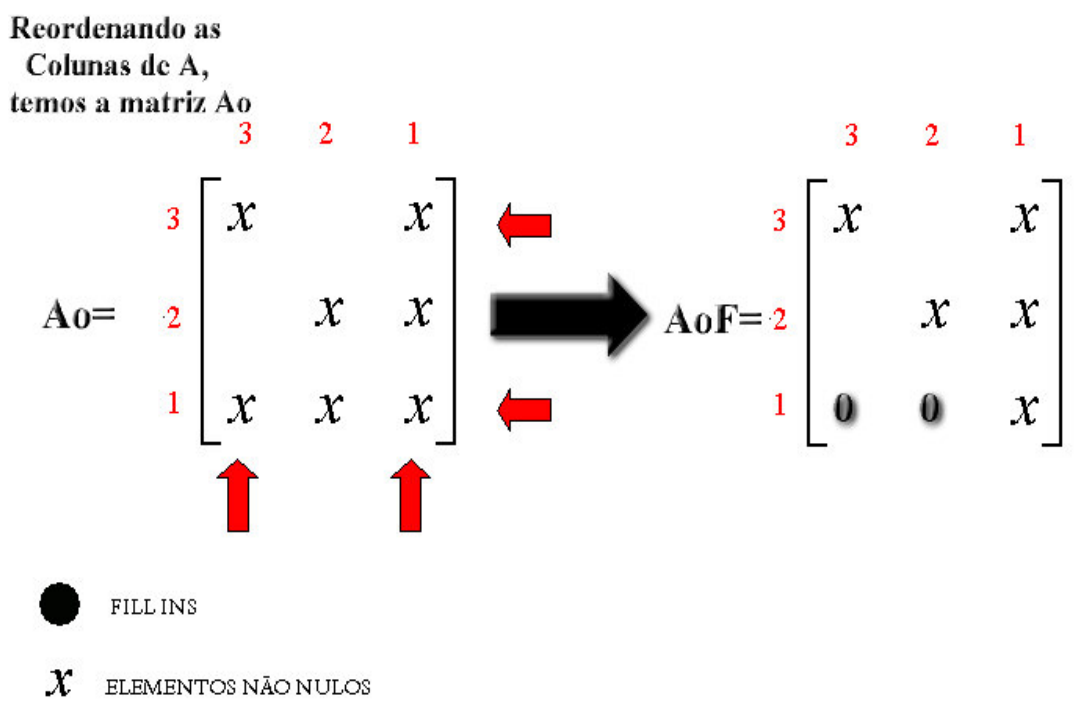

Figura 4.6 - "Fill-ins" durante a fatoração

A seguir são apresentados, em ordem de complexidade, os três esquemas de ordenação propostos por Tinney et al. (1985):

- TINNEY I (Estático): Fatorar a matriz na ordem inversa do grau ${ }^{1}$ dos nós, ou seja, as colunas com menos elementos não-nulos, na matriz original, são fatoradas primeiro.

o Vantagem: simplicidade;

o Desvantagem: não considera o aparecimento de "fill-ins".

- TINNEY II (Dinâmico): A cada estágio fatora-se a coluna com menos elementos não-nulos

\footnotetext{
${ }^{1}$ Quantidade de elemento não nulo.
} 
o Vantagem: minimiza o aparecimento de "fill-ins";

o Desvantagem: maior complexidade.

- TINNEY III ("Ótimo"): A cada estágio simula-se a fatoração de todas colunas ainda restantes e torna-se aquela que gerar o menor número de "fill-in's".

o Vantagem: minimiza, em relação ao TINNEY II, o aparecimento de "fill-ins";

o Desvantagem: ordenação mais lenta diante de suas simulações.

\subsection{Método dos vetores esparsos}

O Método dos vetores esparsos é útil para solução de sistemas do tipo A. $\underline{x}=\underline{b}$, onde além da matriz "A" ser esparsa, também são esparsos os vetores

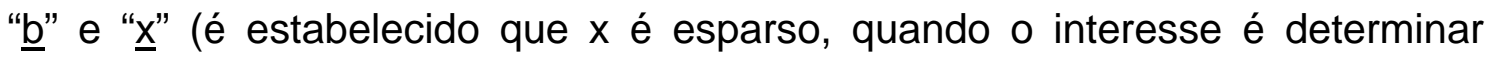
apenas alguns dos elementos do vetor $x$ ).

Assim, para b-esparso, o método possibilita a determinação dos fatores triangulares necessários para a etapa "Forward". E, para x-esparso, o método possibilita a determinação de quais os fatores triangulares necessários para a fase "Backward".

O método identifica os fatores necessários analisando o "caminho de fatoração".

Na figura 4.7, é visualizada a matriz dos fatores triangulares e, como o primeiro elemento não nulo do vetor $\underline{b}$ está na linha 1, os fatores necessários para a etapa "forward" são apenas os que se encontram no caminho de fatoração associado a esse vetor. Na figura 4.7, esses fatores estão dentro dos quadrados. 


\section{Caminhos de Fatoracão - Forward}

\begin{tabular}{|l|l|l|l|l|}
\hline & 1 & 2 & 3 & 4 \\
\hline 1 & $\mathrm{D}_{11}$ & $\mathrm{~B}_{12}$ & & $\mathrm{~B}_{14}$ \\
\hline 2 & $\mathrm{~F}_{21}$ & $\mathrm{D}_{22}$ & & $\mathrm{~B}_{24}$ \\
\hline 3 & & & $\mathrm{D}_{33}$ & $\mathrm{~B}_{34}$ \\
\hline 4 & $\mathrm{~F}_{41}$ & $\mathrm{~F}_{42}$ & $\mathrm{~F}_{43}$ & $\mathrm{D}_{44}$ \\
\hline
\end{tabular}
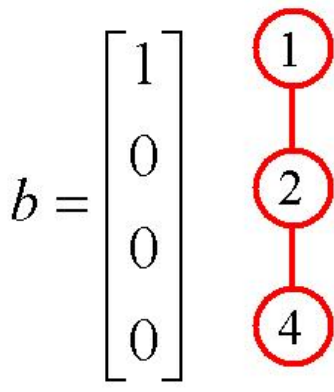

Figura 4.7 - Exemplo de caminhos de fatoração para "Forward"

Na figura 4.8 é visualizada a matriz dos fatores triangulares, e como no vetor $\underline{x}$, o único elemento que precisa determinar é $0 \times 3$, o elemento utilizado para as operações necessárias na etapa "Backward" é apenas o fator B 34 .

\section{Caminhos de Fatoracão - Backward}

\begin{tabular}{|l|l|l|l|l|}
\hline & 1 & 2 & 3 & 4 \\
\hline 1 & $\mathbf{D}_{\mathbf{1 1}}$ & $\mathbf{B}_{\mathbf{1 2}}$ & & $\mathbf{B}_{\mathbf{1 4}}$ \\
\hline 2 & $\mathbf{F}_{21}$ & $\mathbf{D}_{\mathbf{2 2}}$ & & \\
\hline 3 & & & $\mathbf{D}_{\mathbf{3 3}}$ & $\mathbf{D}_{\mathbf{3 4}}$ \\
\hline 4 & $\mathbf{F}_{\mathbf{4 1}}$ & & $\mathbf{F}_{\mathbf{4 3}}$ & $\mathbf{D}_{\mathbf{4 4}}$ \\
\hline
\end{tabular}

$$
x=\left[\begin{array}{l}
x 1 \\
x 2 \\
x 3 \\
x 4
\end{array}\right], x 3
$$

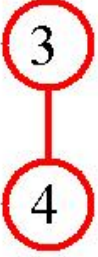

Figura 4.8 - Exemplo de caminhos de fatoração para "Backward" 


\section{Capítulo 3}

\section{Algoritmos para o Tratamento das Características Qualitativas de Conjuntos de Medidas, para efeito de Estimação de Estado em Sistemas Elétricos de Potência}

Neste capítulo serão apresentados, detalhadamente, os dois algoritmos desenvolvidos por London Jr. et al (2004). Vale lembrar que o primeiro algoritmo permite a identificação de medidas críticas e de conjuntos críticos de medidas, de uma forma direta e simples. O segundo tem por objetivo a atualização das características qualitativas do conjunto de medidas (análise e restauração da observabilidade e identificação de medidas críticas e de conjuntos críticos de medidas) após a perda de medidas.

\subsection{Introdução}

Como mencionado no capítulo 1, visando a uma estimação de estado confiável, os SEP devem ser projetados para serem observáveis e possuírem um nível de redundância que garanta a ausência de medidas críticas e de conjuntos críticos de medidas. Entretanto, durante a operação de um SEP, podem ocorrer problemas no sistema de aquisição de dados (sistema de 
telemedição). Tais problemas podem acarretar a perda de uma ou mais medidas, podendo dificultar a operação do sistema.

Em situações como essa, para tornar ainda possível uma operação em tempo real confiável, é necessário que o operador obtenha as seguintes informações: (i) Se o sistema em análise continua observável; (ii) Caso continue observável, quais as características qualitativas, em termos de redundância de medidas, do conjunto de medidas disponíveis naquele momento (presença de medidas críticas e de conjuntos críticos de medidas); (iii) Caso o sistema tenha perdido a observabilidade, quais as pseudo-medidas necessárias à restauração da observabilidade.

Em London Jr. et al (2004) foram propostos dois algoritmos para a solução do problema mencionado, através dos quais possa o operador de um sistema de potência cientificar-se, de forma rápida e simples, daquelas informações. Para isto, tais algoritmos permitem identificar, primeiramente, os chamados conjuntos $p$-críticos.

Definição 3.1: Conjuntos p-críticos de medidas são conjuntos de " $p$ " medidas $(p \geq 1)$, associadas a um SEP observável, medidas essas que, caso perdidas tornam tal sistema não observável (a remoção de qualquer conjunto de $k$ medidas, pertencentes a um conjunto $p$-crítico, com $k<p$, não causa a perda da observabilidade do sistema).

Assim, como descrito em London Jr. et al (2001), podemos verificar que:

$>$ Para $p=1$, o conjunto $p$-crítico é a medida crítica;

$>$ Para $p=2$, par crítico de medidas;

$>$ Para $p=3$, trio crítico; e assim por diante.

Definição 3.2: Uma medida tem Nível de Redundância (NR) igual a ( $p-1)$, se o conjunto $p$-crítico com menor número de medidas a que ela pertencer possuir $p$ medidas.

Considerando essa definição, a medida crítica tem NR = 0. Já uma medida não-crítica, que aparece em pelo menos um par crítico de medidas, tem NR $=1$, e assim por diante.

Vale destacar que conjunto $p$-crítico não é, por definição, o mesmo que conjunto crítico de medidas, pois, de acordo com a sua definição, conjunto crítico de medidas é aquele constituído por medidas não críticas, em que a 
eliminação de uma medida qualquer, a ele pertencente, torna as demais medidas críticas [Korres e Contaxis (1991)]. Assim, observa-se que um conjunto $p$-crítico será igual a um conjunto crítico, somente se ambos possuírem duas medidas, porquanto, a retirada de uma das medidas de um par crítico torna a outra crítica. Verifica-se também que as medidas de um par crítico, assim como as medidas de um conjunto crítico, possuem resíduos normalizados iguais [Mili et al (1984)].

Entretanto, os conjuntos $p$-críticos, com $p \neq 2$, não constituem conjuntos críticos de medidas. Por exemplo, o conjunto $p$-crítico, $\operatorname{com} p=1$, é a própria medida crítica; já em um conjunto $p$-crítico, $\operatorname{com} p=3$, verifica-se que a retirada de uma das suas medidas não torna as demais medidas críticas. Vale ressaltar também que as medidas que pertencem a esses conjuntos $p$-críticos, com $p \neq 2$, em geral não apresentam os mesmos resíduos normalizados.

Para identificar os conjuntos $p$-críticos, os algoritmos baseiam-se nas relações de dependência linear das linhas da matriz Jacobiana. Para determinar essas relações, uma conveniente mudança de base no espaço das variáveis de estado é realizada. A finalidade dessa mudança de base é encontrar variáveis de estado equivalentes, cujo relacionamento com as medidas seja mais direto. Logo, a identificação dessas relações torna-se simples e direta.

Em razão de os algoritmos propostos em London Jr. et al (2004) ser inteiramente baseado na matriz Jacobiana, apresentaremos, na próxima seção, algumas características dessa matriz, que são importantes para a compreensão do mesmo.

\subsection{A Matriz Jacobiana}

A matriz Jacobiana $H$, dada pela equação (2.9), relaciona as medidas com as variáveis de estado do sistema. As variáveis de estado são os ângulos de fase $(\underline{\theta})$ e as magnitudes de tensão $(\underline{V})$, nas barras do sistema; usualmente as medidas são: 
$P_{k l} \Rightarrow$ fluxo de potência ativa nas linhas;

$\mathrm{Q}_{\mathrm{kl}} \Rightarrow$ fluxo de potência reativa nas linhas;

$\mathrm{P}_{\mathrm{k}} \Rightarrow$ injeção de potência ativa nas barras;

$\mathrm{Q}_{\mathrm{k}} \Rightarrow$ injeção de potência reativa nas barras;

$\mathrm{V}_{\mathrm{k}} \Rightarrow$ magnitude de tensão nas barras;

Assim, podemos representar a matriz Jacobiana da seguinte forma:

$$
H=\left[\begin{array}{cc}
\frac{\partial P_{k l}}{\partial \underline{\theta}} & \frac{\partial P_{k l}}{\partial \underline{V}} \\
\frac{\partial Q_{k l}}{\partial \underline{\theta}} & \frac{\partial Q_{k l}}{\partial \underline{V}} \\
\frac{\partial P_{k}}{\partial \underline{\theta}} & \frac{\partial P_{k}}{\partial \underline{V}} \\
\frac{\partial Q_{k}}{\partial \underline{\theta}} & \frac{\partial Q_{k}}{\partial \underline{V}} \\
\frac{\partial V_{k}}{\partial \underline{\theta}} & \frac{\partial V_{k}}{\partial \underline{V}}
\end{array}\right]
$$

Através da definição de observabilidade algébrica, apresentado por Krumpholz et al. (1980), um sistema com $n$ barras é observável se: ${ }^{1}$

$$
\operatorname{Posto}(H)=2 n-1
$$

sendo (2n-1) a dimensão do vetor de variáveis de estado a ser estimado.

Através do desacoplamento $\underline{P \theta}-\underline{Q V}$, conhecido como desacoplamento do modelo, que é obtido considerando o fato de as sensibilidades $\frac{\partial \underline{P}}{\partial \underline{\theta}}$ e $\frac{\partial \underline{Q}}{\partial \underline{V}}$ serem mais intensas que as sensibilidades $\frac{\partial \underline{P}}{\partial \underline{V}}$ e $\frac{\partial \underline{Q}}{\partial \underline{\theta}}$ (este tipo de relação verifica-se principalmente para redes com a relação $X / R$ bem alta).

$$
(H)=\left[\begin{array}{cc}
H_{0} & 0 \\
0 & H_{v}
\end{array}\right]
$$

\footnotetext{
${ }^{1}$ Posto de uma matriz é a dimensão do espaço das colunas dessa matriz. Vale lembrar que para uma matriz A mxn, as dimensões do espaço das colunas e do espaço das linhas são iguais [Lay (1996].
} 
É possível realizar a análise de observabilidade algébrica separadamente, para cada um dos modelos. Desta forma, um sistema dir-se-á $\underline{P \theta}$ algebricamente observável, se:

$$
\operatorname{Posto}\left(H_{\underline{\theta}}\right)=n-1
$$

Onde:

$$
{ }^{H_{\underline{\theta}}}=\left[\begin{array}{ll}
\frac{\partial \underline{P}_{k l}}{\partial \underline{\theta}} & 0 \\
\frac{\partial \underline{P}_{k}}{\partial \underline{\theta}} & 0
\end{array}\right]
$$

sendo (n-1) o número de ângulos de fase a serem estimados, pois o ângulo de uma das barras é considerado como referência angular. Da mesma forma, um sistema é dito $\underline{Q V}$ algébricamente observável, se:

$$
\operatorname{Posto}\left(H_{\underline{V}}\right)=n
$$

Onde:

$$
H_{\underline{V}}=\left[\begin{array}{ll}
0 & \frac{\partial \underline{Q} k l}{\partial \underline{V}} \\
0 & \frac{\partial \underline{Q} k}{\partial \underline{V}} \\
0 & \frac{\partial \underline{\underline{V}} k}{\partial \underline{V}}
\end{array}\right]
$$

sendo $n$ o número de magnitudes de tensão a serem estimadas.

Considerando que as medições de potência ativa e reativa são realizadas aos pares e que existe apenas uma medida de magnitude de tensão, realizada na barra escolhida como referência angular, o número de variáveis de estado, a serem estimadas para o modelo $\underline{Q V}$, é igual ao do modelo $\underline{P \theta}$. Destarte, um sistema de potência sendo $\underline{P \theta}$ algebricamente observável, será também $Q V$ algebricamente observável [Krumpholz et al (1981); Monticelli \& Wu (1985a)]. Conseqüentemente, a análise de observabilidade algébrica poderá ser realizada considerando apenas (n-1) variáveis de estado a serem estimadas; a condição para a observabilidade algébrica será: 


$$
\operatorname{Posto}(H)=n-1
$$

\subsection{Metodologia}

Como a condição para a observabilidade algébrica é que o posto da matriz Jacobiana $H$ seja $n-1$, pode-se afirmar que as medidas críticas correspondem às linhas linearmente independentes dessa matriz. Seguindo o mesmo raciocínio, as $p$ medidas que constituem um conjunto $p$-crítico correspondem as $p$ linhas da matriz $H$, que, caso retiradas simultaneamente, fazem com que o posto da matriz $H$ diminua de uma unidade. Contudo, a retirada simultânea de quaisquer $(p-1)$ medidas desse conjunto não reduz o posto da matriz $H$.

Considerando essas propriedades, a idéia do método é analisar as relações de dependência linear entre as linhas da matriz $H$. Essas relações são de difícil análise, através da estrutura da matriz $H$, mas, com uma mudança conveniente de base, no espaço das variáveis de estado, essa análise é bastante simplificada. Sendo assim, pode-se enunciar o seguinte teorema:

Teorema 3.3.1 Considere a matriz Jacobiana $H$, associada a um SEP com $m$ medidas, sendo $m>(n-1)$. Se o sistema for observável $[\operatorname{Posto}(H)=(n-1)]$, então existe uma mudança de base $C$, no espaço das variáveis de estado, tal que, nesta nova base, a matriz $H$ apresentará a seguinte forma:

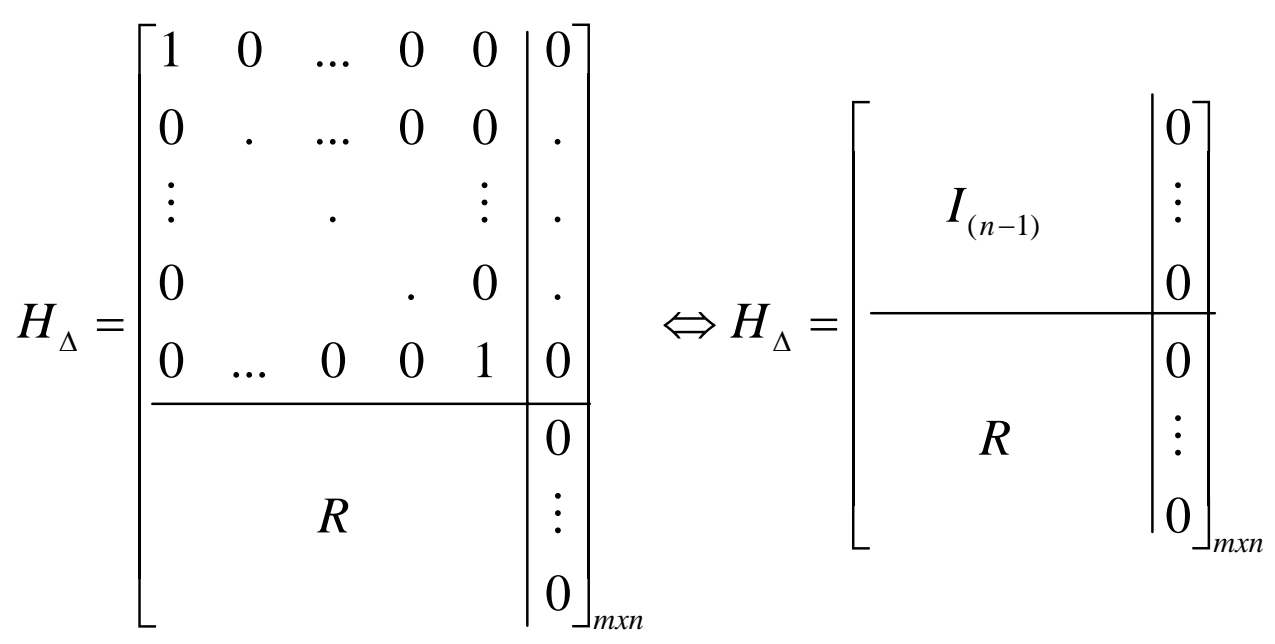


Sendo:
$H_{\Delta} \Rightarrow$
matriz $H$ na nova base;
$I \Rightarrow$
matriz Identidade de dimensão $(n-1) x(n-1)$;
$R \Rightarrow$
submatriz de dimensão $[m-(n-1)] x(n-1)$, composta por
linhas linearmente dependentes das linhas da submatriz $I_{(n-1)}$;

Observação 3.2: A última coluna da matriz $H_{\Delta}$ é constituída apenas por zeros, por corresponder à barra escolhida como referência angular.

Observação 3.3: A demonstração desse teorema é apresentada em London Jr. et al (2004).

A matriz $H_{\Delta}$ pode ser obtida mediante a solução de um sistema esparso de equações lineares, havendo dois caminhos para a sua determinação, através do processo de eliminação de Gauss.

1- Aplicando a eliminação de Gauss diretamente à matriz Jacobiana $H$. Isto, entretanto, apresenta o seguinte inconveniente: devido às peculiaridades dessa matriz e à exigência de a eliminação processar-se através de uma combinação entre as colunas correspondentes às variáveis de estado do sistema, exigir-se-iam muitas mudanças no processo de eliminação, como é o mesmo tradicionalmente realizado;

2- Aplicando a eliminação de Gauss à matriz Jacobiana transposta $H^{t}$, as suas linhas correspondem às variáveis de estado e as suas colunas às medidas. Desta forma, o processo de eliminação de Gauss pode aplicar-se a essa matriz, sem a exigência de muitos detalhes, que o diferenciem da forma como é tradicionalmente realizado, facilitando assim a sua implantação. Visando, pois, a esta facilidade de implantação do processo de eliminação de Gauss, escolheu-se esta segunda opção. Proceder-se-á então à triangulação da matriz $H^{t}$, que, por ser a transposta da matriz $H$, possui as mesmas propriedades da matriz $H$. Destarte, tudo o que foi apresentado em relação à matriz $H$, aplicar-se-á à matriz $H^{t}$. Desta forma, a matriz $H_{\Delta}{ }^{t}$, que será obtida para um sistema de potência observável, associado a um conjunto de "m" medidas [m > $(n-1)]$, vai possuir a seguinte forma: 


$$
H_{\Delta}{ }^{t}=\left[\begin{array}{ccc|c|c}
1 & & & & \\
& \ddots & & R & \\
& & 1 & & \\
\hline 0 & \ldots & & \ldots & 0
\end{array}\right] \Rightarrow H_{\Delta}{ }^{t}=\left[\begin{array}{cc|cc} 
& I_{(n-1)} & R & \\
\hline 0 & \ldots & \ldots & 0
\end{array}\right]
$$

Sendo:

$$
\begin{array}{ll}
H_{\Delta}{ }^{t} \Rightarrow & \text { matriz } H^{t} \text { na nova base; } \\
I_{(n-1)} \Rightarrow & \text { matriz Identidade de dimensão }(n-1) x(n-1) ; \\
R \Rightarrow & \text { submatriz de dimensão }(n-1) x[m-(n-1)], \text { composta por }
\end{array}
$$$$
\text { colunas linearmente dependentes das colunas da submatriz } I_{(n-1)} \text {; }
$$

Tendo em vista que a matriz $H_{\Delta}{ }^{t}$ é obtida através de um processo de fatoração triangular da matriz $H^{t}$, realizado através da combinação das linhas de $H^{t}$, verifica-se que a matriz $H_{\Delta}{ }^{t}$ relaciona as medidas com variáveis de estado equivalentes, que são combinações lineares das variáveis de estado do sistema ${ }^{2}$.

Analisando a estrutura da submatriz $I$, de $H_{\Delta}{ }^{t}$, verifica-se que as suas $(n-1)$ colunas são, isoladamente, linearmente independentes. Por esta razão, as medidas correspondentes a essas colunas serão chamadas de Medidas Básicas $^{3}$, pois essas medidas são suficientes para tornar o sistema em consideração observável. As outras medidas serão chamadas de Suplementares. Considerando a estrutura da matriz $H_{\Delta}{ }^{t}$, os seguintes lemas são formulados:

\section{Corolário 3.3.1}

Toda Medida Suplementar possui nível de redundância maior que 0.

\section{Lema 3.3.1}

Toda Medida crítica pertence ao conjunto de Medidas Básicas.

\section{Lema 3.3.2}

Todo conjunto p-crítico de medidas possui pelo menos uma Medida Básica.

\footnotetext{
${ }^{2}$ Para simplificar a notação usaremos simplesmente estados ao invés de variáveis de estado, e estados equivalentes ao invés de variáveis de estado equivalentes.

3 Denominação utilizada em Baran et al (1995). Já em Abur e Magnago (1999), essas medidas são chamadas de Essenciais.
} 
A busca pelos conjuntos $p$-críticos de medidas é dividida em duas fases:

(i) Identificação dos conjuntos $p$-críticos de medidas que contém apenas uma Medida Básica;

(ii) Identificação dos conjuntos p-críticos de medidas que contém mais de uma Medida Básica.

A seguir será mostrado que a segunda fase é uma aplicação recursiva da primeira. Considere-se então, o seguinte Teorema, cuja demonstração é apresentada em London Jr. et al (2004):

Teorema 3.3.2 As $p$ medidas, correspondentes às colunas dos $p$ elementos não nulos, que pertençam a uma mesma linha da matriz $H_{\Delta}{ }^{t}$, formam um conjunto p-crítico de medidas, contendo apenas uma Medida Básica.

Através do Teorema (3.3.2) verifica-se que, quando uma linha tem apenas um elemento não nulo, significa que a informação do estado equivalente, correspondente àquela linha, é fornecida apenas por uma medida, portanto, essa medida é crítica (tem NR igual a 0).

Para realizar a segunda fase da busca, utilizando as diretrizes do Teorema (3.3.2), elimina-se uma Medida Básica não-crítica da matriz $H_{\Delta}{ }^{t}$, para, em seqüência, proceder-se à obtenção da nova matriz $H_{\Delta}{ }^{t}$. Como a medida retirada é linearmente dependente de pelo menos uma Medida Suplementar, existe uma outra medida que pode substituí-la. Efetuando a substituição, obtém-se a nova matriz $H_{\Delta}{ }^{t}$. Analisando as linhas desta matriz, considerando o Teorema (3.3.2), conclui-se que as $p$ medidas, associadas aos novos conjuntos $p$-críticos identificados, constituem, juntamente com a Medida Básica que foi retirada, um conjunto $(p+1)$ - crítico de medidas.

Aplicando-se esse processo a todas as Medidas Básicas, com NR maior ou igual a 1 , identificam-se todos os conjuntos $p$-críticos, contendo duas Medidas Básicas. Continuando esse processo, eliminando conjuntos de " $b$ " Medidas Básicas, com NR maior ou igual a $b$, todos os conjuntos $p$-críticos de medidas, com $p \geq(b+1)$, contendo $(b+1)$ Medidas Básicas, serão identificados. 


\subsection{Algoritmo para identificação de medidas críticas e de conjuntos críticos de medidas}

Como mostrado na seção anterior, para identificar as medidas críticas, basta realizar uma busca das linhas de $H_{\Delta}{ }^{t}$, que possuem apenas um elemento não nulo, uma vez que as medidas correspondentes às colunas desses elementos são críticas.

Para realizar a identificação dos conjuntos críticos de medidas, as informações mais importantes que se obtêm, através das colunas de $H_{\Delta}{ }^{t}$, referem-se à identificação das medidas críticas e dos pares críticos de medidas, constituídos por uma Medida Básica e uma Medida Suplementar. Isto porque, para realizar a busca dos conjuntos críticos de medidas, primeiramente se faz necessário saber quais são as medidas críticas, pois, de acordo com a definição de conjunto crítico, apresentada na seção 3.1, essas medidas não devem ser consideradas naquela busca. A importância de conhecerem os pares críticos de medidas, é que, as duas medidas que constituem um par crítico pertencem ao mesmo conjunto crítico de medidas. Conseqüentemente, os pares críticos servem para guiar a busca pelos conjuntos críticos de medidas, minimizando-a.

Considerando o que foi discutido acima, a identificação dos conjuntos críticos de medidas, através da matriz $H_{\Delta}{ }^{t}$, realiza-se em três etapas:

$1^{\circ}$ Etapa: Mediante as medidas disponíveis, construa a matriz $H^{t}$, obtendo a matriz $H_{\Delta}{ }^{t}$. Em seguida identifique, através das linhas de $H_{\Delta}{ }^{t}$, as medidas críticas e os pares críticos de medidas, formados por apenas uma Medida Básica.

$2^{\circ}$ Etapa: Se for identificado pelo menos um par crítico de medidas, na primeira etapa, elimina-se da matriz $H_{\Delta}{ }^{t}$ uma Medida Suplementar, que apareça em pelo menos um par crítico. Analisando as colunas da nova matriz $H_{\Delta}{ }^{t}$, as Medidas Básicas, que agora são identificadas como críticas, constituem, juntamente com a Medida Suplementar eliminada, um conjunto crítico de medidas. 
Esta etapa é finalizada quando todas as Medidas Suplementares, pertencentes à pelo menos um par crítico de medidas, identificado na primeira etapa, tiverem sido consideradas. Entretanto, caso não se tenha identificado, na primeira etapa, nenhum par crítico de medidas, não se exigirá a realização desta segunda etapa. Isto porque a eliminação de qualquer uma das Medidas Suplementares não iria gerar nenhuma medida crítica nova, pois, para cada Medida Básica, haveria no mínimo duas Medidas Suplementares, dando a mesma informação.

$3^{0}$ Etapa: Se existir alguma Medida Básica não crítica, não pertencente aos conjuntos críticos já identificados, elimina-se da matriz $H_{\Delta}{ }^{t}$ tal medida. Em seguida, obtém-se a nova matriz $H_{\Delta}{ }^{t}$, e, analisando as linhas desta matriz, as Medidas Básicas, que agora são identificadas como críticas, constituirão, juntamente com a Medida Básica eliminada, um conjunto crítico de medidas.

Esta etapa é finalizada quando todas as Medidas Básicas não críticas, não pertencentes a conjuntos críticos já identificados, tiverem sido analisadas.

Na pior situação em termos de processamento, o algoritmo supracitado exigiria no máximo (n-1) fatorações parciais, acompanhadas de contagens de elementos não nulos em (n-1) matrizes. Tal situação ocorreria quando nenhum conjunto $p$-crítico, com $p \leq 2$, fosse identificado nas Etapas 1 e 2. O algoritmo topológico proposto por Simões-Costa et al (1991) exigiria, para mesma situação, que o algoritmo de identificação de medidas críticas, que se baseia numa busca por árvores de posto completo, fosse processado em torno de (m$\mathrm{N}$ ) vezes, sendo $\mathrm{m}$ o número de medidas disponíveis e $\mathrm{N}$ o número de variáveis de estado a serem estimadas ${ }^{4}$.

\subsubsection{Exemplo}

O algoritmo é aplicado ao sistema de 6 barras do IEEE associado com o conjunto de medidas ilustrado na figura 3.1.

\footnotetext{
${ }^{4}$ Para maiores informações sobre os métodos desenvolvidos para identificação de medidas críticas e de conjuntos críticos de medidas, consulte a seção 2.6, capítulo 2 .
} 


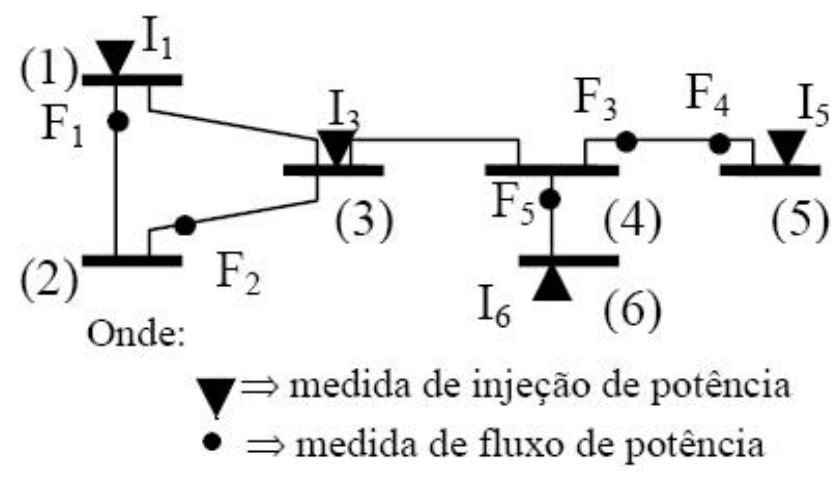

Figura 3.1 - Sistema teste de 6 barras IEEE

$1^{\circ}$ Etapa: Considerando as medidas indicadas na figura 3.1, obtém-se a seguinte matriz $H^{t}$ :

Observação 3.4: A matriz $H^{t}$ pode ser construído considerando o valor real das reatâncias das linhas, mas, como a redundância das medidas depende somente do número, tipo e localização das mesmas, não do valor real dos parâmetros da rede, a matriz $H^{t}$ será construída atribuindo-se às reatâncias de linha o valor 1.

\begin{tabular}{|c|c|c|c|c|c|c|c|c|c|}
\hline & F1 & L $\quad F$ & F3 & F4 & F5 & I1 & 13 & 15 & 16 \\
\hline 1 & 1 & 0 & 0 & 0 & 0 & 2 & -1 & 0 & 0 \\
\hline 2 & -1 & 1 & 0 & 0 & 0 & -1 & -1 & 0 & 0 \\
\hline 3 & 0 & -1 & 0 & 0 & 0 & -1 & 3 & 0 & 0 \\
\hline$H^{t}=$ & 0 & 0 & 1 & -1 & 1 & 0 & -1 & -1 & -1 \\
\hline 5 & 0 & 0 & -1 & 1 & 0 & 0 & 0 & 1 & 0 \\
\hline 6 & 0 & 0 & 0 & 0 & -1 & 0 & 0 & 0 & 1 \\
\hline
\end{tabular}

A matriz $H_{\Delta}{ }^{t}$ será:

\begin{tabular}{|c|c|c|c|c|c|c|c|c|c|c|}
\hline & & F1 & F2 & 13 & F4 & F5 & I1 & F3 & 15 & 16 \\
\hline & 1 & 1 & 0 & 0 & 0 & 0 & 2 & 0 & 0 & 0 \\
\hline & 2 & 0 & 1 & 0 & 0 & 0 & 1 & 0 & 0 & 0 \\
\hline$H^{t}=$ & 3 & 0 & 0 & 1 & 0 & 0 & 0 & 0 & 0 & 0 \\
\hline & 4 & 0 & 0 & 0 & 1 & 0 & 0 & -1 & 1 & 0 \\
\hline & 5 & 0 & 0 & 0 & 0 & 1 & 0 & 0 & 0 & -1 \\
\hline & 6 & 0 & 0 & 0 & 0 & 0 & 0 & 0 & 0 & 0 \\
\hline
\end{tabular}

Analisando as linhas desta matriz, identifica-se uma medida crítica, a medida 13, identificando-se ainda, três pares críticos de medidas: (i)[F1, I1]; (ii) $[F 2$, I1] e (iii) $[F 5, I 6]$. 
$2^{\circ}$ Etapa: A medida I1 aparece em dois pares críticos. Por conseguinte, retirando a coluna correspondente a essa medida de $H_{\Delta}{ }^{t}$, obtém-se:

\begin{tabular}{|c|c|c|c|c|c|c|c|c|c|}
\hline & & F1 & F2 & 13 & F4 & F5 & F3 & 15 & 16 \\
\hline & 1 & 1 & 0 & 0 & 0 & 0 & 0 & 0 & 0 \\
\hline & 2 & 0 & 1 & 0 & 0 & 0 & 0 & 0 & 0 \\
\hline$H_{\Delta}{ }^{t}=$ & 3 & 0 & 0 & 1 & 0 & 0 & 0 & 0 & 0 \\
\hline & 4 & 0 & 0 & 0 & 1 & 0 & -1 & 1 & 0 \\
\hline & 5 & 0 & 0 & 0 & 0 & 1 & 0 & 0 & -1 \\
\hline & 6 & 0 & 0 & 0 & 0 & 0 & 0 & 0 & 0 \\
\hline
\end{tabular}

Através das linhas da matriz, verifica-se que as medidas F1 e F2 tornaram-se críticas. Conseqüentemente, essas medidas constituem, juntamente com a medida I1, um conjunto crítico de medidas: [F1, F2, I1].

Realizando a mesma operação, considerando a Medida Suplementar 16, identifica-se mais um conjunto crítico de medidas: [F5, I6].

$3^{\circ}$ Etapa: F4 é a única Medida Básica não crítica, que não apareceu em nenhum conjunto crítico, identificado na etapa anterior. Assim, eliminando essa medida da matriz $H_{\Delta}{ }^{t}$, obtém-se:

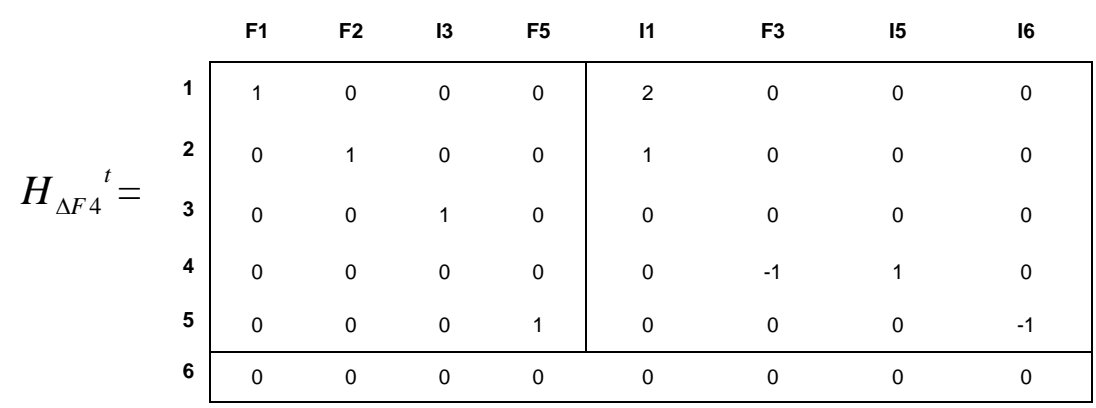

Trocando as posições das colunas dessa matriz, como se mostra a seguir, podemos obter a nova matriz $H_{\Delta}{ }^{t}$, que é a seguinte:

\begin{tabular}{|c|c|c|c|c|c|c|c|c|c|}
\hline & & F1 & F2 & 13 & F3 & F5 & I1 & 15 & 16 \\
\hline & 1 & 1 & 0 & 0 & 0 & 0 & 2 & 0 & 0 \\
\hline & 2 & 0 & 1 & 0 & 0 & 0 & 1 & 0 & 0 \\
\hline$H_{\Delta}{ }^{t}=$ & 3 & 0 & 0 & 1 & 0 & 0 & 0 & 0 & 0 \\
\hline & 4 & 0 & 0 & 0 & 1 & 0 & 0 & 1 & 0 \\
\hline & 5 & 0 & 0 & 0 & 0 & 1 & 0 & 0 & -1 \\
\hline & 6 & 0 & 0 & 0 & 0 & 0 & 0 & 0 & 0 \\
\hline
\end{tabular}


Através das linhas dessa matriz, com a análise, verifica-se que nenhuma Medida Básica tornou-se crítica. Logo, F4 não faz parte de nenhum conjunto crítico e a análise está encerrada.

Obtém-se assim o seguinte resultado:

$>$ Medida Crítica: 13

$>$ Conjuntos Críticos: [I1, F1, F2]; [F5, I6]

\subsection{Algortimo para atualização das características qualitativas de conjuntos de medidas, para efeito de estimação de estado em SEP}

Para possibilitar uma rápida atualização das características qualitativas de um conjunto de medidas ${ }^{5}$, quando há perda de uma ou mais medidas, o algoritmo proposto em London Jr. et al (2004) faz uma "pré-análise" dos dados antes de ser colocado em operação, isto é, antes de analisar uma amostragem de medidas que se torna disponível no centro de operação. A pré-análise dos dados realiza-se considerando que estejam disponíveis as medidas de todos os medidores instalados no sistema, bem como todas as medidas virtuais ${ }^{6}$. Esta situação inicial recebe o nome de Caso Base.

A análise do Caso Base consiste em:

(i) Construção da matriz $H^{t}$ e, em seguida, obtenção da matriz $H_{\Delta}{ }^{t}$, armazenando os fatores triangulares;

(ii) Identificação dos conjuntos p-críticos de medidas (através das linhas da matriz $H_{\Delta}{ }^{t}$ obtida no Passo 1);

(iii) Identificação das medidas críticas e dos conjuntos críticos de medidas (da forma apresentada na seção 3.4).

No momento em que uma amostragem de medidas se torna disponível no centro de operação, o algoritmo proposto em London Jr. et al (2004) realiza as seguintes análises:

\footnotetext{
${ }^{5}$ Análise e restauração da observabilidade, bem como identificação de medidas críticas e de conjuntos críticos de medidas.

${ }^{6}$ Medida de injeção zero em nó passivo.
} 
Passo 1: Se não houve perda de medidas, isto é, se as medidas disponíveis são exatamente as mesmas consideradas no Caso Base, nenhuma análise é necessária, pois as características qualitativas não se alteraram;

Passo 2: Se foram perdidas apenas Medidas Suplementares, o método indicará que o sistema continua observável, e, a seguir, verifica a "criticalidade" das medidas disponíveis, isto é, verifica a existência de medidas críticas e de conjuntos críticos de medidas (da forma apresentada na seção 3.4);

Passo 3: Se foi perdida pelo menos uma Medida Básica, o sistema pode ter se tornado não observável. Assim, antes de verificar a "criticalidade" das medidas disponíveis, é necessário fazer análise da observabilidade. Uma vez comprovada a perda da observabilidade, o método proposto identificará, através dos fatores triangulares responsáveis pela fatoração da matriz $H^{t}$, as pseudo-medidas necessárias para a restauração da observabilidade ${ }^{7}$.

\subsubsection{Algoritmo proposto em London Jr. et al (2004)}

A seguir serão apresentadas as variáveis utilizadas no algoritmo:

MDP: variável onde serão armazenadas as medidas do Caso Base (medidas provenientes de todos os medidores instalados e todas as medidas virtuais);

P: variável onde será armazenado o conjunto de medidas que foi perdido;

PA: indica o próximo passo a ser executado;

LV: indica a linha do pivô nulo;

NB: número de Medidas Básicas que foram perdidas (será decrementado durante o processamento do algoritmo);

np: informa a pseudo-medida a ser analisada.

Passo 1: Construir a matriz $H^{t}$, através das medidas armazenadas na variável MDP, obtendo depois a matriz $H_{\Delta}{ }^{t}$, armazenando os fatores triangulares, e, através dos elementos não nulos das linhas de $H_{\Delta}{ }^{t}$, identificar os conjuntos $p$ críticos de medidas, formados por apenas uma Medida Básica. Em seguida identificar os conjuntos críticos de medidas.

\footnotetext{
${ }^{7}$ No capítulo 4 apresenta-se o processo de solução de sistemas lineares via fatores triangulares.
} 
Observação 3.5: O processamento dos próximos passos só ocorrerá na presença de alguma falha no sistema de telemedição.

Passo 2: Armazene o conjunto de medidas que foi perdido na variável $\mathbf{P}$.

Passo 3: Se o conjunto de medidas armazenado em $\mathbf{P}$ for constituído apenas por Medidas Suplementares, informe ao operador de que o sistema continua observável e encaminhe ao Passo 9. Caso contrário vá para o próximo passo.

Passo 4: Se o conjunto de medidas armazenado em $\mathbf{P}$ possuir apenas uma Medida Básica, prosseguir para o próximo passo, ou, caso contrário, encaminhar para o Passo 10.

Passo 5: Se o conjunto de medidas armazenado em $\mathbf{P}$ for um conjunto $p$-crítico de medidas, identificado no Passo 1 , informe ao operador de que se há de exigir, para continuar operando o sistema, o uso de pseudo-medida; elimine da matriz $H_{\Delta}{ }^{t}$ as colunas correspondentes às medidas armazenadas em P; faça PA = 9 e encaminhe-se para o próximo passo. Caso contrário, indique ao operador que o sistema continua observável e dirija-se para o Passo 9.

Passo 6: Verifique qual a linha da matriz $H_{\Delta}{ }^{t}$, não considerando a última linha, é composta apenas por elementos nulos. Essa linha recebe o nome de linha "LV". Faça $\mathbf{n p}=0$ e prossiga para o próximo passo.

Passo 7: Faça $\mathbf{n p}=\mathbf{n p}+1$; selecione a $\mathbf{n p}$ pseudo-medida disponível no centro de operação; crie uma nova coluna na matriz $H_{\Delta}{ }^{t}$ para armazenar essa pseudo-medida e encaminhe-se para o próximo passo.

Passo 8: Aplique à coluna, onde foi armazenada a pseudo-medida em análise, os fatores triangulares obtidos até o momento, considerando a ordem adequada $^{8}$. Caso o elemento dessa coluna, pertencente à linha LV, não seja nulo, indique ao operador que a pseudo-medida de ordem np deve ser adicionada ao conjunto disponível de medidas, para restaurar a observabilidade do sistema em análise e direcione para o passo armazenado

\footnotetext{
${ }^{8}$ Primeiramente são considerados os fatores triangulares responsáveis pela obtenção, no Passo 1 , da matriz $H_{\Delta}{ }^{t}$. Depois, os fatores que possam ter sido necessários para tornar a matriz $H_{\Delta}{ }^{t}$ novamente triangular. Esta fatoração parcial é exigida sempre que se fizer necessária uma pseudo-medida, para a restauração da observabilidade do sistema (operação esta que se realizará no Passo 13), ou quando uma medida suplementar substituir uma Medida Básica eliminada (operação que será realizada no Passo 12).
} 
na variável PA. Caso contrário, elimine essa coluna de $H_{\Delta}{ }^{t}$ e volte para 0 Passo 7.

Passo 9: Elimine da matriz $H_{\Delta}{ }^{t}$ as colunas correspondentes às medidas armazenadas em P. Em seguida, verifique-se a criticalidade das medidas ainda disponíveis e Fim de processamento.

Passo 10: Caso existam Medidas Suplementares armazenadas em $\mathbf{P}$, elimine da matriz $H_{\Delta}{ }^{t}$ as colunas correspondentes a essas medidas; guarde o número de Medidas Básicas armazenadas em P na variável "NB" e prossiga ao próximo passo.

Passo 11: Se NB $\neq 0$, elimine da matriz $H_{\Delta}{ }^{t}$ uma coluna correspondente a uma das Medidas Básicas armazenadas em $\mathbf{P}$, mas, antes, verifique em que linha aparece o elemento não nulo dessa coluna. Faça $\mathbf{N B}=\mathbf{N B}-1 \mathrm{e}$ encaminhe-se para o próximo passo. Caso contrário, fim de processamento.

Passo 12: Em existindo algum elemento não nulo na linha de $H_{\Delta}{ }^{t}$, correspondente ao elemento não nulo da coluna eliminada no Passo 11, obtenha novamente a matriz $H_{\Delta}{ }^{t}$; armazene em seguida os novos fatores triangulares e volte ao Passo 11. Caso contrário, informe o operador de que, para continuar operando o sistema, exigir-se-á o uso de pseudo-medida; faça PA = 13 e encaminhe para o Passo 6.

Passo 13: Se NB $\neq 0$, obtenha a nova matriz $H_{\Delta}{ }^{t}$; armazene os novos fatores e volte ao Passo 11. Caso contrário, verifique a criticalidade das medidas ainda disponíveis e fim de processamento.

Observação 3.6: O algoritmo permite a análise de cada situação de falha, sem realizar nenhuma fatoração completa da matriz $\mathrm{H}^{t}$, pois, as fatorações necessárias, nos Passos 9, 12 e 13, são parciais, sendo que a fatoração necessária, no Passo 1, realiza-se antes da perda de medidas.

Observação 3.7: O algoritmo foi desenvolvido considerando estar sempre disponível, no centro de operação, a pseudo-medida necessária à restauração da observabilidade do sistema. 


\subsubsection{Exemplo}

O algoritmo proposto por London Jr. et al (2004) será aplicado ao sistema e ao conjunto de medidas apresentado na figura 3.1. Considerando ainda que, além das medidas indicadas, estejam também disponíveis, no centro de operação, as pseudo-medidas de fluxo de potência da barra 6 para a barra $4\left(P_{(6-4)}\right)$ e da barra 4 para a barra $3\left(P_{(4-3)}\right)$. O algoritmo permitirá a análise, uma por uma, das seguintes situações de emergência: (i) Perda das medidas F3 e 15; (ii) Perda das medidas F1 e F2.

Passo 1: Como a matriz $H^{t}$ já foi construída e fatorada, no exemplo apresentado na subseção 3.3.1, vamos apresentar diretamente a matriz $H_{\Delta}{ }^{t}$ :

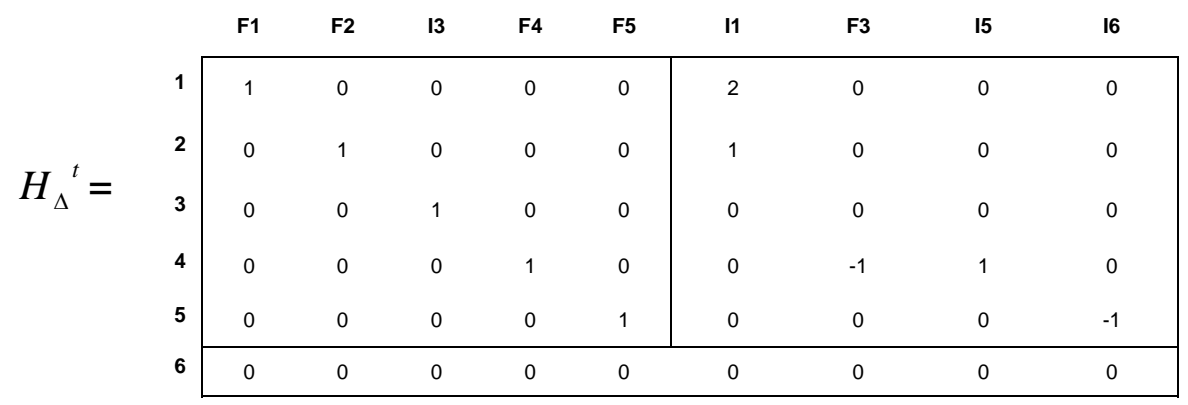

Onde a matriz dos fatores é:

\begin{tabular}{|c|c|c|c|c|c|c|}
\hline & & F1 & F2 & 13 & F4 & F5 \\
\hline & 1 & 1 & 0 & 1 & 0 & 0 \\
\hline & 2 & 1 & 1 & 2 & 0 & 0 \\
\hline & 3 & 0 & 1 & 1 & 0 & 0 \\
\hline & 4 & 0 & 0 & 1 & -1 & 1 \\
\hline & 5 & 0 & 0 & 0 & 1 & 1 \\
\hline & 6 & 0 & 0 & 0 & 0 & 1 \\
\hline
\end{tabular}

Analisando as linhas da matriz $H_{\Delta}{ }^{t}$, obtém-se:

$1^{\circ}$ Linha: $[F 1 ; 11]$ - par crítico;

$2^{\circ}$ Linha: [F2; I1] - par crítico;

$3^{\circ}$ Linha: [I3] - Medida Crítica;

$4^{\circ}$ Linha: [F4; F3; 15] - trio crítico;

$5^{\circ}$ Linha: [F5; I6] - par crítico;

Conjunto Crítico: [I1; F1; F2] e [F5; I6]. 
Situação 1: Foram perdidas as medidas F3 e 15.

Passo 2: $P=\{F 3 ; 15\}$

Passo 3: Como o conjunto de medidas armazenado em $\mathbf{P}$ é formado apenas por Medidas Suplementares, o algoritmo indicará ao operador que o sistema continua observável. Encaminhar para o Passo 9.

Passo 9: Eliminando da matriz $H_{\Delta}{ }^{t}$ as colunas correspondentes às medidas armazenadas em $\mathbf{P}$, e, aplicando o método apresentado na 3.4, identificam-se duas medidas críticas: I3 e F4; e dois conjuntos críticos: [F1; F2; I1] e [F5; I6]. Fim da análise.

\section{Situação 2: Foram perdidas as medidas F1 e F2.}

Lembrando que, no Passo 1, consideram-se todas as medidas disponíveis no sistema, isto é, aquelas indicadas na figura 3.1, o Passo 1, para esta situação, será o mesmo que o considerado para a situação 1.

Passo 2: $P=\{F 1 ; F 2\}$

Passo 3: O conjunto de medidas armazenado em $\mathbf{P}$ não possui Medida Suplementar.

Passo 4: O conjunto de medidas armazenado em $\mathbf{P}$ possui mais de uma Medida Básica.

Passo 10: Em P não existe nenhuma Medida Suplementar. NB = 2 (existem duas Medidas Básicas em P).

Passo 11: $\mathbf{N B}=2$. A coluna correspondente à medida F1 tem elemento não nulo na primeira linha; eliminando essa coluna de $H_{\Delta}{ }^{t}$ obtém-se:

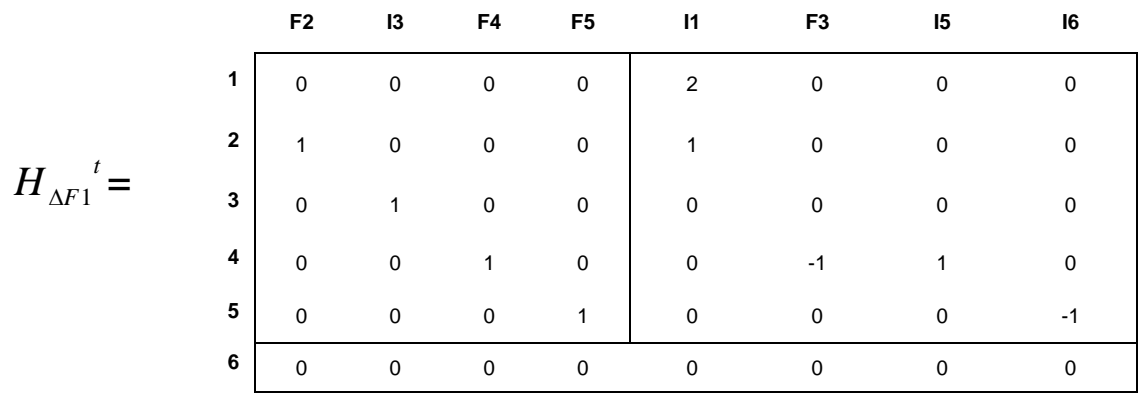

NB $=2-1=1$ 
Passo 12: Como $H_{\Delta F 1}{ }^{t}(1,5) \neq 0$, trocando-se as posições das colunas dessa matriz, como mostrado a seguir, pode obter-se novamente a matriz $H_{\Delta}{ }^{t}$, que será a seguinte:

\begin{tabular}{|c|c|c|c|c|c|c|c|c|c|}
\hline & & I1 & F2 & 13 & F4 & F5 & F3 & 15 & 16 \\
\hline \multirow{6}{*}{$H_{\Delta}{ }^{t}=$} & 1 & 1 & 0 & 0 & 0 & 0 & 0 & 0 & 0 \\
\hline & 2 & 0 & 1 & 0 & 0 & 0 & 0 & 0 & 0 \\
\hline & 3 & 0 & 0 & 1 & 0 & 0 & 0 & 0 & 0 \\
\hline & 4 & 0 & 0 & 0 & 1 & 0 & -1 & 1 & 0 \\
\hline & 5 & 0 & 0 & 0 & 0 & 1 & 0 & 0 & -1 \\
\hline & 6 & 0 & 0 & 0 & 0 & 0 & 0 & 0 & 0 \\
\hline
\end{tabular}

Considerando os fatores necessários para essa fatoração, a matriz dos fatores será:

\begin{tabular}{|c|c|c|c|c|c|c|c|}
\hline & & F1 & F2 & 13 & F & F5 & 11 \\
\hline & 1 & 1 & 0 & 1 & 0 & 0 & 0,5 \\
\hline \multirow{5}{*}{ Fatores= } & 2 & 1 & 1 & 2 & 0 & 0 & $-0,5$ \\
\hline & 3 & 0 & 1 & 1 & 0 & 0 & 0 \\
\hline & 4 & 0 & 0 & 1 & -1 & 1 & 0 \\
\hline & 5 & 0 & 0 & 0 & 1 & 1 & 0 \\
\hline & 6 & 0 & 0 & 0 & 0 & 1 & 0 \\
\hline
\end{tabular}

Observação 3.8: Na última coluna foram armazenados os fatores responsáveis pela triangulação realizada nesta etapa.

Voltar ao Passo 11.

Passo 11: NB = 1. A coluna correspondente à medida F2 tem elemento não nulo na segunda linha; eliminando essa coluna de $H_{\Delta}{ }^{t}$ obtém-se:

\begin{tabular}{|c|c|c|c|c|c|c|c|c|}
\hline & & I1 & 13 & F4 & F5 & F3 & 15 & 16 \\
\hline \multirow{6}{*}{$H_{\Delta F 2}{ }^{t}=$} & 1 & 1 & 0 & 0 & 0 & 0 & 0 & 0 \\
\hline & 2 & 0 & 0 & 0 & 0 & 0 & 0 & 0 \\
\hline & 3 & 0 & 1 & 0 & 0 & 0 & 0 & 0 \\
\hline & 4 & 0 & 0 & 1 & 0 & -1 & 1 & 0 \\
\hline & 5 & 0 & 0 & 0 & 1 & 0 & 0 & -1 \\
\hline & 6 & 0 & 0 & 0 & 0 & 0 & 0 & 0 \\
\hline
\end{tabular}


$\mathrm{NB}=1-1=0$.

Passo 12: Como a segunda linha dessa matriz é formada apenas por zeros, o algoritmo indicará ao operador que, para continuar operando o sistema, exigirse-á o uso de pseudo-medida; PA = 13. Encaminhar para o Passo 6.

Passo 6: $\mathbf{L V}=2 ; \mathbf{n p}=0$.

Passo 7: $\mathbf{n p}=\mathbf{n p}+1=1$. O algoritmo vai selecionar a primeira pseudo-medida disponível no centro de operação. É a pseudo-medida $P_{(6-4)}$. Será então criada a coluna 8, na matriz $H_{\Delta F 2}{ }^{t}$, onde será armazenada $P_{(6-4)}$. A matriz torna-se:

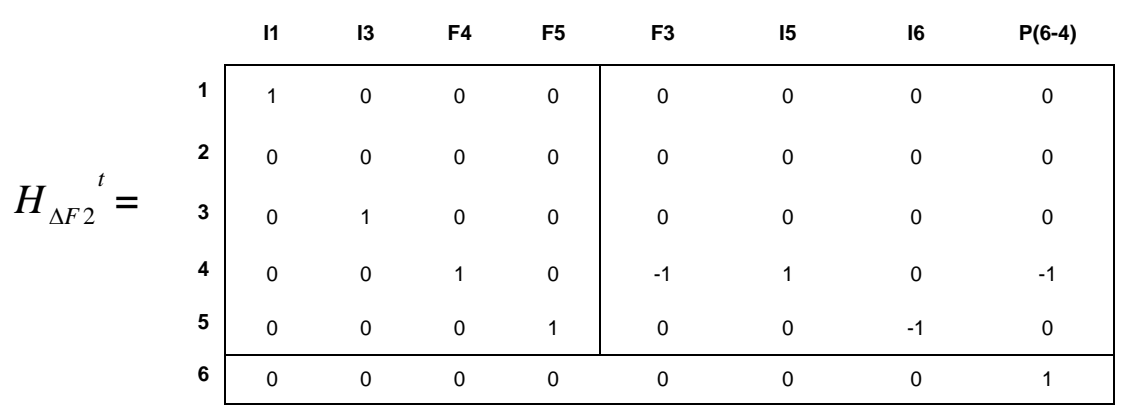

Passo 8: Aplicando os fatores triangulares, obtidos até o momento, à coluna 8 dessa matriz, verifica-se que $H_{\Delta F 2}{ }^{t}(2,8)=0$. Logo, essa pseudo-medida não serve para restaurar a observabilidade do sistema. Elimine a coluna 8 de $H_{\Delta F 2}{ }^{t}$ e volte ao Passo 7.

Passo 7: $\mathrm{np}=\mathrm{np}+1=2$. O algoritmo vai selecionar a segunda pseudo-medida disponível, no centro de operação. É a pseudo-medida $P_{(4-3)}$. Será então criada, novamente, a coluna 8 , na matriz $H_{\triangle F 2}{ }^{t}$, onde se armazenará $P_{(4-3)}$. Passo 8: Aplicando os fatores triangulares à nova coluna 8, obtém-se:

\begin{tabular}{|c|c|c|c|c|c|c|c|c|c|}
\hline & & 11 & 13 & F4 & F5 & F3 & 15 & 16 & $\mathrm{P}(4-3)$ \\
\hline & 1 & 1 & 0 & 0 & 0 & 0 & 0 & 0 & $-0,5$ \\
\hline & 2 & 0 & 0 & 0 & 0 & 0 & 0 & 0 & $-1,5$ \\
\hline$H_{\Delta F^{2}}=$ & 3 & 0 & 1 & 0 & 0 & 0 & 0 & 0 & -1 \\
\hline & 4 & 0 & 0 & 1 & 0 & -1 & 1 & 0 & 0 \\
\hline & 5 & 0 & 0 & 0 & 1 & 0 & 0 & -1 & 0 \\
\hline & 6 & 0 & 0 & 0 & 0 & 0 & 0 & 0 & 0 \\
\hline
\end{tabular}


Como $H_{\triangle F 2}{ }^{t}(2,8) \neq 0$, o algoritmo indica ao operador que a pseudo-medida $P_{(4-3)}$ deve ser adicionada ao conjunto disponível de medidas, para restaurar a observabilidade do sistema. Dirigir-se para o Passo 13.

Passo 13: Como NB = 0, através do método apresentado na seção 3.4 identificam-se 3 medidas críticas: $11, P_{(4-3)}$ e 13; e um conjunto crítico de medidas: [F5; 16]. Fim da análise. 


\section{Capítulo 2}

\section{Estimação de Estado em Sistemas Elétricos de Potência}

\subsection{Revisão Bibliográfica}

Com o objetivo de mostrar como foi o desenvolvimento das pesquisas relacionadas à estimação de estado, é apresentado, a seguir, um pequeno histórico salientando as contribuições mais relevantes.

Os trabalhos desenvolvidos em 1970, pelo professor Schweppe [Schweppe (1970); Schweppe e Douglas (1970); Schweppe e Wildes (1970)], mostraram a natureza geral do processo de estimação de estado, destacando a importância da observabilidade e da detecção e identificação de medidas com erros grosseiros. Desde então, várias pesquisas têm sido desenvolvidas, relacionadas aos problemas ligados ao processo de estimação de estado [Coutto Filho et al. (1990); Monticelli (1999); Abur e Expósito (2004)].

Reportando à análise de observabilidade, os métodos desenvolvidos podem ser divididos em dois grupos: os métodos topológicos e os numéricos. Os métodos topológicos caracterizam-se pela criação de rotinas específicas, que não exigem cálculos, mas que são de natureza combinatorial e complexas [Handschin e Bongers (1972); Krumpholz et al. (1980); Quintana et al. (1982); Nucera e Gilles (1991); Mori e Tsuzuki (1991)]. 
Os métodos numéricos, por sua vez, são mais simples, visando à utilização de rotinas já disponíveis nos programas de estimadores de estado. Entretanto, estão sujeitos a erros numéricos [Monticelli e Wu (1985a); Monticelli e Wu (1985b); Monticelli e Wu (1986)].

Em Monticelli et al. (1992), foram apresentados alguns problemas que podem aparecer nas análises de observabilidade, realizadas por métodos em que se consideram apenas informações topológicas.

Buscando um outro caminho para realizar a análise de observabilidade, Slutsker e Scudder (1987) idealizaram um método não combinatorial, que não requer cálculo, exigindo um tempo de computação relativamente baixo, baseado na redução simbólica da matriz jacobiana. Neste método, não se considera o valor real dos elementos da matriz Jacobiana, mas apenas a posição dos elementos não nulos dessa matriz. Posteriormente, Chen (1990) apresentou uma versão modificada do método, considerando valores inteiros para os elementos não nulos da matriz Jacobiana.

Utilizando em conjunto a análise topológica e numérica, Contaxis e Korres (1988) chegaram a uma nova metodologia para a análise de observabilidade, em que o tamanho da rede é diminuído através de processos topológicos, reduzindo assim a quantidade de cálculos necessários.

Em seqüência, Bretas (1996) desenvolveu um novo método para testar a observabilidade da rede e identificar ilhas observáveis, fundamentando-o na triangulação da matriz ganho e nos conceitos contidos nos caminhos de grafo. Tal método requer subrotinas já disponíveis nos programas de estimadores de estado e não exige solução de sistemas de equações algébricas, sendo assim de fácil implantação.

Quanto à estimação de estado, detecção e identificação de medidas com erros grosseiros, muitas pesquisas foram desenvolvidas durante as últimas décadas. Foram criados os estimadores desacoplados [Horisberger et al. (1976); Garcia et al. (1979); Monticelli e Garcia (1990); Roy e Mohamed (1997)]; os estimadores com técnicas mais robustas, que buscam reduzir problemas numéricos [Simões-Costa e Quintana (1981); Quintana et al. (1982); Gjelsvik et al. (1985); Monticelli et al. (1985); Mili et al. (1996); Gouvêa e Simões-Costa (1998); Pires et al. (1999)], além de métodos mais eficientes, para a detecção e identificação de medidas com erros grosseiros [Monticelli e 
Garcia (1983); Mili et al. (1984); Mili et al. (1985); Slutsker (1989); Cheniae (1996)].

Buscando uma nova proposição para os estimadores de estado, foram apresentados os estimadores com capacidade de previsão (FASE- Forecasting Aided State Estimators) [Leite da Silva et al. (1983); Leite da Silva et al. (1987); Coutto Filho et al. (1989); Rousseaux et al. (1990); Coutto Filho et al. (1993); Souza et al. (1996)], que são interessantes especialmente para o processamento de erros grosseiros em tempo real, pois as medidas são analisadas antes da etapa de filtragem.

Considerando a dinâmica do vetor de estado, algumas pesquisas buscaram algoritmos para a estimação dinâmica de estado. Algumas dessas pesquisas acompanham as mudanças das variáveis de estado com o tempo, valendo-se do chamado estimador "tracking" [Masiello e Schweppe (1971); Falcão et al. (1982)]; outras adicionaram aos estimadores "tracking" a teoria do filtro de Kalman [Debs e Larson (1970); Leite da Silva et al. (1987); Bretas (1989)].

Em razão da dificuldade para determinação da matriz transição de estado, cuja função é representar a dinâmica dos SEP, os estimadores estáticos são os mais utilizados.

Como foi enfatizado na introdução deste projeto, é impossível detectar erros grosseiros em medidas críticas, nem mesmo, identificar tais erros em medidas pertencentes a conjuntos críticos. Para contornar estas dificuldades, várias pesquisas foram realizadas, surgindo então os métodos para a identificação de medidas críticas e de conjuntos críticos de medidas [Clements et al. (1981); Ayres e Haley (1986); Crainic et al. (1990); Simões-Costa et al. (1990); Korres e Contaxis (1991b); Bretas e London Jr. (1998); Bretas et al. (2005)]; e os métodos para a análise da confiabilidade e planejamento de conjuntos de medidas [Clements et al. (1982); Lo et al. (1982); Clements et al. (1983); Aam et al. (1983); Park et al. (1988); Korres e Contaxis (1994); Abur e Magnago (1999); Mounir et al (2001); Coutto Filho et al. (2001); London Jr. et al (2003); Souza et al. (2005)].

Em razão de o processo de estimação de estado estar sujeito ainda aos erros topológicos e erros de parâmetros, definidos na introdução, pesquisas 
foram realizadas em busca de métodos para a análise desses erros [Monticelli (1999); Zarco e Expósito (2000); Abur e Expósito (2004)].

Buscando uma ferramenta, por assim dizer, para a análise mais completa da redundância das medidas, em London Jr. et al (2001) foi proposto um método que permite, além da identificação das medidas críticas, a identificação de conjuntos de duas, três, ..., p medidas, que, caso perdidas simultaneamente, fazem um sistema de potência observável tornar-se não observável. Através dessas informações, o método permite identificar o nível de redundância de cada medida disponível, para o processo de estimação de estado.

Importa destacar que o método supracitado [London Jr. et al (2001)] baseia-se nas relações de dependência linear das linhas da matriz Jacobiana. Através de uma mudança conveniente de base, no espaço das variáveis de estado, a identificação dessas relações tornam-se simples e direta. A finalidade dessa mudança de base é encontrar variáveis de estado equivalentes, cujo relacionamento com as medidas seja mais direto.

Utilizando a mudança de base proposta por London Jr. et al (2001), em London Jr. et al (2004) foram propostos algoritmos que permitem análise e restauração da observabilidade, identificação de medidas críticas e de conjuntos críticos de medidas, bem como uma rápida atualização dessas características qualitativas de um conjunto de medidas após a perda de medidas.

\subsection{Estimação Estática de Estado}

Como mencionado anteriormente, o estimador de estado pode ser dinâmico ou estático. Nesta seção, será dada uma introdução ao conceito de estimador estático de estado, o qual pode ser considerado como uma generalização do problema clássico de fluxo de carga ${ }^{1}$.

O termo estático refere-se ao fato de o modelo de rede utilizado ser estático, não se considerando as variações entre as grandezas e a variável tempo. Desta forma, serão usadas apenas equações algébricas, sem o

\footnotetext{
${ }^{1}$ Para o desenvolvimento desta seção utilizou-se a referência LONDON Jr. (2000).
} 
emprego de equações diferenciais, assim como é feito no estudo do fluxo de carga [Monticelli (1983)].

O estimador de estado consiste em encontrar uma forma de atingir-se a melhor estimativa das variáveis de estado desconhecidas. Tendo-se em vista esse objetivo, dos muitos critérios estatísticos existentes, o que tem sido mais utilizado para a estimação de estado em SEP, é o critério dos mínimos quadrados ponderados.

\subsubsection{Estimação de Estado baseado no Método de Mínimos Quadrados}

A estimação de estado, através dos mínimos quadrados, formula-se considerando:

$$
\underline{z}=\underline{h}\left(\underline{x}_{v}\right)+\underline{w}
$$

onde: $\underline{z}$ - vetor de medidas $(m \times 1) ; \underline{h}($.$) - vetor de funções não lineares,$ relacionando as medidas com as variáveis de estado $(\mathrm{m} \times 1) ; \underline{x}_{v}-$ vetor de variáveis de estado verdadeiras $(\mathrm{N} \times 1) ; \underline{w}$ - vetor aleatório dos erros das medidas ( $\mathrm{mx} 1$ ); $\mathrm{m}$ - número de medidas; $\mathrm{N}$ - número de variáveis de estado a serem estimadas.

De acordo com o critério de mínimos quadrados [Schweppe (1970)], a melhor estimativa do vetor de estado $\underline{x}_{v}$, designada por $\underline{\hat{x}}$, é o valor de $\underline{x}$ que torna mínimo o índice $J(\underline{x})$, dado por:

$$
J(\underline{x})=\underline{w}^{t} W^{-1} \underline{w}
$$

ou

$$
J(\underline{x})=[Z-h(\underline{x})]^{t} W^{-1}[\underline{Z}-h(\underline{x})]
$$

onde $W^{-1}$ é uma matriz de ponderação para as medidas; é o inverso da matriz covariância das mesmas. É uma matriz diagonal, cujos valores diferentes de zero são os inversos das variâncias de cada medida $\left(\sigma_{\mathrm{ii}}{ }^{-2}\right)$. Através dessa matriz, as medidas são ponderadas conforme suas qualidades e o estimador passa a ser chamada de Estimador de Mínimos Quadrados Ponderados (WLS - Weighted Least Squares).

Da equação (2.3) deduz-se que $J(\underline{x})$ é uma função quadrática. Considerando que $\underline{x}_{v}$ torna mínimo $J(\underline{x})$, podemos dizer que $J(\underline{x})$ é convexo nas 
proximidades de $\underline{x}_{v}$. Deste modo, para determinar $\underline{\hat{x}}$, que torne $J(\underline{x})$ mínimo, fazemos:

$$
\frac{\partial J(\underline{x})}{\partial \underline{x}}=0
$$

portanto

$$
2 H(\underline{\hat{x}})^{t} W^{-1}[\underline{z}-h(\underline{\hat{x}})]=0
$$

onde $H(\underline{\hat{x}})$ é o jacobiano, dado por:

$$
H(\underline{\hat{x}})=\frac{\Delta}{\partial \underline{x}} \mid \underline{x}
$$

A equação (2.5) relaciona o vetor de variáveis de estado estimadas $\underline{\hat{x}}$, mas, para determinar-se-lhe a solução, temos que recorrer a técnicas iterativas, porquanto, devido à não linearidade de $H(\underline{\hat{x}})$ e $h(\underline{\hat{x}})$, a solução direta daquela equação não é possível.

Tendo em vista o fato de $J(\underline{x})$ ser convexo nas proximidades de $\underline{x}_{v}, 0$ método de Newton-Raphson pode ser utilizado para obter-se o valor de $\underline{\hat{x}}$ que torna mínimo $J(\underline{x})$.

- Tornando linear $h(\underline{x})$, em torno de um ponto de operação $\underline{x}^{0}$, tem-se:

$$
\underline{h}(\underline{x}) \cong \underline{h}\left(\underline{x}^{0}\right)+H\left(\underline{x}^{0}\right) \cdot \Delta \underline{x}^{0}
$$

sendo:

$$
\begin{aligned}
& \Delta \underline{x}^{0}=\underline{x}^{-} \underline{x}^{0} \\
& H\left(\underline{x}^{0}\right)=\frac{\partial \underline{h}(\underline{x})}{\partial \underline{x}} \mid \underline{x}=\underline{x}^{0}
\end{aligned}
$$

De (1) obtém-se:

$$
\underline{Z}=\underline{h}\left(\underline{x}^{0}\right)+H\left(\underline{x}^{0}\right) \cdot \Delta \underline{x}^{0}+\underline{w}
$$

Definindo:

$$
\Delta \underline{Z}\left(\underline{x}^{0}\right)=\underline{Z}-\underline{h}\left(\underline{x}^{0}\right)
$$

onde $\underline{\underline{Z}}$ é o erro de estimação, obtendo-se:

$$
\Delta \underline{Z}\left(\underline{x}^{0}\right)=H\left(\underline{x}^{0}\right) \cdot \Delta \underline{x}^{0}+\underline{w}
$$

Assim, a função objetivo passa a ser;

$$
J(\underline{x})=\left[\Delta \underline{Z}\left(\underline{x}^{0}\right)-H\left(\underline{x}^{0}\right) \cdot \Delta \underline{x}^{0}\right]^{t} \cdot W^{-1} \cdot\left[\Delta \underline{Z}\left(\underline{x}^{0}\right)-H\left(\underline{x}^{0}\right) \cdot \Delta \underline{x}^{0}\right]
$$

E o mínimo é encontrado fazendo: 


$$
H\left(\underline{x}^{0}\right)^{t} \cdot W^{-1} \cdot\left[\Delta \underline{Z}\left(\underline{x}^{0}\right)-H\left(\underline{x}^{0}\right) \cdot \Delta \underline{x}^{0}\right]=0
$$

Portanto:

$$
\Delta \underline{x}^{0}=\left[H\left(\underline{x}^{0}\right)^{t} \cdot W^{-1} \cdot H\left(\underline{x}^{0}\right)\right]^{-1} H\left(\underline{x}^{0}\right)^{t} \cdot W^{-1} \cdot \Delta \underline{Z}\left(\underline{x}^{0}\right)
$$

onde a matriz ganho é dada por:

$$
\begin{gathered}
G^{0}=\left[H\left(\underline{x}^{0}\right)^{t} \cdot W^{-1} \cdot H\left(\underline{x}^{0}\right)\right\rfloor \\
\mathrm{e} \quad \underline{x}^{1}=\underline{x}^{0}+\Delta \underline{x}^{0}
\end{gathered}
$$

Assim, a estimativa de $\underline{x}_{v}$ corresponde ao valor de $\underline{x}$ de uma determinada iteração, em que se verifique um índice de convergência pré fixado.

Quando os erros das medidas são Gaussianos [Schweppe e Handschin (1974)], o estimador WLS funciona muito bem, mas falha na ocorrência de erros grosseiros. Em razão disso, foram desenvolvidos métodos para detecção e identificação de erros grosseiros.

\subsection{Processamento de Medidas com Erros Grosseiros}

Através dos algoritmos baseados na análise dos resíduos, a detecção de erros grosseiros em medidas é realizada através do índice $J(\underline{\hat{x}})$, por intermédio de um teste de hipótese.

Considerando a hipótese de que não haja erro grosseiro, o valor do índice $J(\underline{\hat{x}})$, calculado para $\underline{\hat{x}}$ obtido após a convergência do processo de estimação de estado, é comparado com o parâmetro $\lambda$. $O$ valor de $\lambda$ é previamente determinado, supondo uma distribuição $\chi^{2}$, com $(\mathrm{m}-\mathrm{N})$ graus de liberdade para o índice $J(\underline{\hat{x}})$ e fixando uma certa probabilidade $\rho$ de se tomar a decisão errada, rejeitando-se a hipótese quando ela é verdadeira. A suposição de que o índice $J(\underline{\hat{x}})$ apresente uma distribuição $\chi^{2}$, com $(m-N)$ graus de liberdade, foi mostrada por Handschin et al. (1975). Se $J(\underline{\hat{x}})>\lambda$, rejeita-se a hipótese de que não haja erro grosseiro e se $J(\underline{\hat{x}})<\lambda$ aceita-se a mesma.

Se a hipótese de que não haja erro grosseiro for aceita, consideram-se confiáveis os resultados obtidos pelo estimador de estado. Mas, se essa 
hipótese for rejeitada, deve-se identificar e eliminar as medidas que estejam com erros grosseiros.

O processo de identificação de medidas com erros grosseiros realiza-se através da análise dos resíduos de estimação normalizados. O vetor resíduo de estimação pode ser definido como:

$$
\underline{r}=\underline{Z}-h(\underline{\hat{x}})
$$

que pode ser representado também da seguinte forma [Handschin et al. (1975)]:

$$
\underline{r}=\Gamma \underline{w}
$$

onde:

$\underline{w} \Rightarrow$ é o vetor aleatório dos erros das medidas;

$\Gamma \Rightarrow$ é a matriz sensibilidade do resíduo, "deterministíca", dada por:

$$
\Gamma=I-H(\underline{\hat{x}}) \cdot\left[H(\underline{\hat{x}})^{t} \cdot W^{-1} \cdot H(\underline{\hat{x}})\right]^{-1} \cdot H(\underline{\hat{x}})^{t} \cdot W^{-1}
$$

sendo / uma matriz identidade.

A partir da equação (2.19), pode-se obter o valor médio de vetor resíduo de estimação [Garcia et al (1979)]:

$$
\underline{\bar{r}}=\Gamma \underline{\bar{w}}
$$

e a matriz covariância do vetor $\underline{r}$ é a matriz $R$, dada por:

$$
R=W-H(\underline{\hat{x}})\left[H(\underline{\hat{x}})^{t} \cdot W^{-1} \cdot H(\underline{\hat{x}})\right]^{-1} \cdot H(\underline{\hat{x}})^{t}
$$

Considerando $\rho_{i i}$ o elemento $(\mathrm{i}, \mathrm{i})$ da matriz $R$, os resíduos normalizados $r_{i}^{N}$, ficam definidos como:

$$
r_{i}^{N}=\frac{r_{i}}{\sqrt{\rho_{i i}}}, \quad \text { com } \quad \mathrm{i}=1,2, \ldots \mathrm{m} .
$$

onde $r_{i}^{N}$ tem aproximadamente uma distribuição normal de média $\bar{r} i$, dada por:

$$
\bar{r}_{i}^{N} \equiv \frac{\overline{r_{i}}}{\sqrt{\rho_{i i}}}
$$

e desvio padrão unitário. 
Quando for detectada a presença de medidas com erros grosseiros, é acrescentada à equação (2.1) um vetor determinístico b, para representar os erros grosseiros. Assim a equação (2.1) toma a seguinte forma:

$$
\underline{Z}=h\left(\underline{x_{v}}\right)+\underline{w}+\underline{b}
$$

Considerando que apenas a medida $j$ possua erro grosseiro, o vetor $\underline{b}$ será dado por:

$$
\underline{b}=\left[\begin{array}{c}
0 \\
\cdot \\
\cdot \\
j \\
\cdot \\
0
\end{array}\right], \quad \text { sendo } b_{j} \text { o erro grosseiro da medida } j .
$$

Assim, pela equação (2.21), a média do resíduo de estimação é:

$$
\underline{\underline{r}}=\Gamma \underline{b}=\left[\begin{array}{c}
\gamma_{1 j} \\
\cdot \\
\cdot \\
\gamma_{i j} \\
\cdot \\
\cdot \\
\gamma_{m j}
\end{array}\right] . b j \Rightarrow \bar{r}_{i}=b_{j} \cdot \gamma_{i j} \quad, \quad \mathrm{i}=1,2,3, \ldots, \mathrm{m} .
$$

onde $\gamma_{i j}$ é o elemento (i,j) da matriz $\Gamma$, que é obtida pela equação (2.20). Através da equação (2.24) chegamos à expressão:

$$
\bar{r}_{i}^{N}=\frac{b_{j} \cdot \gamma_{i j}}{\sqrt{\rho_{i i}}}, \quad \mathrm{i}=1,2, \ldots, \mathrm{m}
$$

Entretanto, para cada medida, somente um $\rho_{i i}$ é encontrado. Desta forma, as médias dos resíduos normalizados de cada medida são diferentes, mas com variâncias iguais e unitárias. Portanto, as distribuições de probabilidade dos resíduos normalizados, de cada medida, diferem apenas no que se refere às médias. Consequentemente, para a identificação de medidas com erros grosseiros, basta examinar as médias dos resíduos normalizados de cada medida. A medida que tiver o $r_{i}^{N}$ mais distante das demais, ou seja, a 
medida que tiver o maior resíduo normalizado corresponderá à medida com erro grosseiro [Schweppe (1970), Handschin et al. (1975)].

Quando uma medida com erro grosseiro é identificada, a mesma é eliminada do conjunto de medidas ${ }^{2}$, sendo necessário proceder-se novamente à estimação de estado, através do novo conjunto de medidas. O método de identificação de medidas, descrito acima, permite identificar uma medida de cada vez; assim, para situações em que ocorram múltiplos erros, esse processo torna-se muito pesado, pois, para cada medida com erro grosseiro que se elimine, realizar-se-á uma nova estimação de estado, até que todas as medidas com erros grosseiros sejam eliminadas.

Existem métodos que propiciam a eliminação de mais de uma medida de cada vez, reduzindo assim o tempo de processamento, para detectar e identificar medidas com erros grosseiros [Mili et al. (1984)].

Como mencionado anteriormente, os métodos para detecção e identificação de erros grosseiros baseado na análise dos resíduos apresentam um bom desempenho, para diversas situações, mas possuem algumas limitações, como, por exemplo, o fato de não detectarem erros grosseiros em medidas críticas e não identificarem erros grosseiros em conjuntos críticos de medidas.

Apresentam-se, a seguir, as definições de medidas críticas e conjuntos críticos de medidas, bem como uma análise dos métodos já desenvolvidos para identificação de medidas críticas e de conjuntos críticos de medidas.

\subsection{Medidas Críticas}

Recordando a definição apresentada no capítulo 1 deste trabalho, medida crítica é a medida que, se retirada do conjunto de medidas de um sistema observável, torna o mesmo não observável. Isto acontece porque a medida crítica é a única medida dando a informação de uma determinada variável de estado.

Analisando a estrutura da matriz Jacobiana, cujas linhas correspondem às equações de medidas e as colunas às variáveis de estado a serem

\footnotetext{
${ }^{2}$ Em Garcia et al. (1979), ao invés de eliminar a medida com erro, elimina-se o efeito dessa medida.
} 
estimadas, verifica-se que as medidas críticas estão associadas às linhas linearmente independentes dessa matriz. Como conseqüência, a retirada de uma dessas linhas causaria a diminuição do posto dessa matriz.

Outra importante característica das medidas críticas, decorrente do fato de essas medidas estarem associadas às linhas linearmente independentes da matriz Jacobiana, é que são nulos os elementos da diagonal principal da matriz sensibilidade de resíduo, dada pela equação (2.20), associados às medidas críticas [Clements et al. (1981)].

Devido ao fato de as medidas críticas representarem um risco para a observabilidade de um sistema de potência, independentemente da sua quantidade, assim também por não se permitir a detecção de erros em tais medidas, é de vital importância que o operador de um sistema saiba, durante a operação, da existência das mesmas e possa identificá-las, a fim de permitirse-lhe a operação de uma forma mais confiável.

Igualmente, a identificação de medidas críticas é também importante para a supervisão de um conjunto de medidas já existente, porquanto, identificando-as, torna-se possível ao projetista determinar onde e que tipo de medidor deve ser instalado no sistema, para garantir-se a não presença, no mesmo, de medidas críticas.

\subsection{Conjuntos Críticos de Medidas}

Conjunto crítico de medidas, também conhecido na literatura como "minimally dependent sets of measurements", ou "bad data groups", pode ser definido, segundo Ayres \& Haley (1986), de duas formas:

Definição numérica: os conjuntos críticos de medidas são aqueles correspondentes às submatrizes da matriz covariância dos resíduos, com posto igual a 1 ;

Definição topológica: conjunto crítico de medidas é o conjunto de medidas formado por medidas não críticas, em que a eliminação de uma medida qualquer, a ele pertencente, torna as demais medidas críticas.

A identificação dos conjuntos críticos de medidas é importante para um desempenho confiável do estimador de estado [Simões-Costa et al (1990)]. Isto 
porque, além de esses conjuntos representarem um risco para a observabilidade de um sistema de potência ${ }^{3}$, os resíduos normalizados das medidas de um conjunto crítico são iguais [Mili et al. (1984)]. Assim, embora seja possível detectar a existência de erro grosseiro, em uma das medidas pertencentes a um conjunto crítico, é impossível identificar qual, dentre essas medidas, é aquela com erro grosseiro.

\subsection{Metodologias Desenvolvidas para Identificação de Medidas Críticas e de Conjuntos Críticos de Medidas}

Reportaremos, a seguir, aos fundamentos principais de alguns trabalhos, dentre os citados no início deste capítulo e que foram desenvolvidos na tentativa da identificação das medidas críticas e dos conjuntos críticos de medidas. Relativamente a isto, salientaremos as limitações dos métodos correspondentes, o que vem justificar sobremaneira a nossa escolha em tomar os algoritmos propostos por London Jr. et al (2004) como base para o desenvolvimento do software proposto.

Os mencionados trabalhos podem enquadrar-se em dois grupos: os baseados na teoria de grafos, conhecidos como algoritmos topológicos, e os que requerem cálculos numéricos, chamados de algoritmos numéricos.

\section{Algoritmos Topológicos}

Os algoritmos topológicos utilizam o conceito de observabilidade topológica. Apresentam natureza combinatorial, não exigem cálculo numérico, necessitando apenas da topologia da rede, e do tipo e localização das medidas.

Vale destacar aqui que um sistema de potência é dito "topológicamente" observável, com relação a um conjunto de medidas, unicamente se existir, associada a tal sistema, uma árvore representativa de posto completo. (Árvore representativa é uma árvore abrangendo todas as barras da rede; uma árvore é

\footnotetext{
${ }^{3}$ A eliminação de quaisquer duas medidas, pertencentes a um conjunto crítico de medidas, associado a um sistema de potência observável, torna tal sistema não observável.
} 
de posto completo, se for possível atribuir-se-lhe a cada ramo, pelo menos uma medida distinta).

A desvantagem desses trabalhos é a exigência da criação de rotinas específicas e complexas.

Dentre os trabalhos pertencentes a esse primeiro grupo, podemos destacar os desenvolvidos por: Clements et al. (1981), Simões-Costa et al. (1990) e Bretas et al (2005).

O algoritmo desenvolvido por Clements et al. (1981) foi o primeiro a permitir-nos a identificação de medidas críticas e determinação da área de espalhamento de resíduo. Os teoremas apresentados nesse trabalho, com relação à medida crítica e à área de espalhamento de resíduo, serviram de base a outros trabalhos. O algoritmo baseia-se na árvore representativa de posto completo, definida anteriormente, identificando como medida crítica aquela que, caso perdida, impede a construção da árvore representativa de posto completo. A determinação da área de espalhamento de resíduo realizase através de uma busca por ramos incidentes, apenas para medidas redundantes.

O algoritmo idealizado por Simões-Costa et al. (1990) permite identificar as medidas críticas, através da teoria de "Matroid Intersection", que é uma forma diferente de representar grafos. A análise baseada em Matroid, assim como as baseadas na teoria de grafos tradicionais, requerem a construção de uma árvore representativa de posto completo (isto é, tenho que ter medidas que conectam todas as barras do sistema). Para determinar os conjuntos críticos de medidas, tal algoritmo remove, do conjunto de medidas, uma medida redundante de cada vez, evidenciando aquelas que se tornaram críticas. Estas medidas, juntamente com a medida redundante retirada, identificam os conjuntos críticos de medidas, para tanto sendo necessário que o algoritmo de identificação de medidas críticas seja processado em torno de $\left(m_{s c}-N\right)$ vezes, sendo $m_{s c} 0$ número de medidas, não se considerando as medidas identificadas como críticas, e $\mathrm{N}$ o número de variáveis de estado a serem estimadas.

$\mathrm{Na}$ tentativa de obter-se um método topológico simples e rápido, foi proposto em Bretas et al (2005) um novo método para a identificação das medidas críticas. Neste método explora-se a natureza das medidas (fluxo e 
injeção), de forma a reduzir as possibilidades de busca, evitando, assim, "explosão combinatória" a que alguns dos métodos topológicos estão sujeitos. Entretanto, o método desenvolvido em Bretas et al (2005) não possibilita a identificação dos conjuntos críticos de medidas.

\section{Algoritmos Numéricos}

Os algoritmos numéricos são mais simples e a sua implantação mais fácil, em relação aos topológicos, entretanto, estão sujeitos a erros numéricos, pois dificuldades podem advir para diferenciar um número pequeno de um valor exatamente igual a zero.

Dos trabalhos pertencentes a esse segundo grupo podemos destacar: 0 de Ayres e Haley (1986), os de Korres e Contaxis (1991a), Korres e Contaxis (1991b) e Coutto Filho et al (2001).

O trabalho de Ayres e Haley (1986) apresenta dois algoritmos para a identificação dos conjuntos críticos de medidas: O primeiro baseado na definição topológica de conjunto crítico de medidas, o outro na definição numérica (definições apresentadas na seção 2.5). Entretanto, os dois algoritmos dependem da análise dos resíduos normalizados, e, por esta razão, ambos estão sujeitos a erros numéricos.

Korres e Contaxis (1991a), com base no modelo de rede reduzido, que idealizaram para análise de observabilidade [Contaxis e Korres (1988)], desenvolveram um algoritmo para o processamento de erros grosseiros, valendo-se do conceito de área de espalhamento do resíduo. Assim o fizeram tendo em vista que, através da determinação das áreas de espalhamento do resíduo, seria possível diminuir o esforço que se gasta nos processos de detecção e identificação de medidas com erros grosseiros. Isto porque, uma vez determinadas as áreas de espalhamento do resíduo, tornar-se-ia possível dividir a rede em função dessas áreas e realizar a detecção e identificação de erros grosseiros, em cada área, separadamente. Para a determinação das áreas de espalhamento do resíduo, é necessário realizar uma busca por ramos incidentes, apenas para medidas redundantes, requerendo, portanto, sejam conhecidas as medidas críticas. O algoritmo proposto por Korres e Contaxis (1991a) permite assim realizar a identificação dessas medidas, analisando os 
elementos da diagonal principal da matriz sensibilidade de resíduo, dada pela equação (2.20).

Em outro trabalho, Korres e Contaxis (1991b), utilizando o modelo de rede reduzido e a teoria de grafos, lançaram um algoritmo que permite a identificação de medidas e de conjuntos críticos de medidas, possibilitando ainda a atualização destes conjuntos, quando alguma medida for eliminada.

Esse algoritmo reduz o número de cálculos necessários, pois baseia-se nas propriedades das chamadas ilhas de fluxo, necessitando ainda da análise dos resíduos das medidas.

Tomando por base os resíduos normalizados das medidas e o coeficiente de correlação desses resíduos, Coutto Filho et al (2001) apresentaram um algoritmo para identificação de medidas críticas e de conjuntos críticos. Nessa abordagem, os resíduos de estimação são processados através de operações matriciais; sem a necessidade de se conhecer os valores das medidas. Realiza-se apenas uma estimação de estado simbólica, assumindo o valor 1 para todas as medidas disponíveis.

Como mencionado anteriormente, utilizando a mudança de base proposta por London Jr. et al (2001), em London Jr. et al (2004) foram propostos dois algoritmos numéricos para o tratamento das características qualitativas de conjuntos de medidas para efeito de estimação de estado em SEP, sendo que:

O primeiro permite a identificação de medidas críticas e de conjuntos críticos de medidas, de uma forma direta e simples, sem exigir a obtenção da matriz de sensibilidade dos resíduos, nem mesmo uma estimação de estado inicial. As vantagens desse algoritmo em relação aos já desenvolvidos para identificação de medidas críticas e de conjuntos críticos de medidas são as seguintes: (i) Possibilita a identificação de conjuntos críticos de medidas de uma forma bastante direta, sem exigir busca baseadas na teoria de grafos; (ii) Não requer que o procedimento de identificação de medidas críticas seja processado em torno de $\left(m_{s c}-N\right)$ vezes, assim como alguns métodos exigem; (iii) Em relação aos métodos numéricos já desenvolvidos, a quantidade de cálculo necessária é bem menor, pois não exige a obtenção da matriz de sensibilidade, nem mesmo de uma estimação de estado inicial. Requer apenas, como será 
apresentado no próximo capítulo, a obtenção da matriz Jacobiana, a fatoração dessa matriz e da análise dos elementos não nulos que aparecem na matriz Jacobiana fatorada, que recebe o nome de matriz $H_{\Delta}$ [London Jr. et al (2001)];

O segundo algoritmo possibilita, de uma forma bastante rápida em termos de velocidade de execução, atualização das características qualitativas do conjunto de medidas (análise e restauração da observabilidade e identificação de medidas críticas e de conjuntos críticos de medidas) após a perda de medidas. Em razão disto acreditamos que o mesmo seja o mais indicado para operação em tempo real. Para possibilitar uma rápida atualização das características qualitativas, quando há perda de medidas, o algoritmo faz uma "pré-análise" dos dados antes de ser colocado em operação, isto é, antes de analisar uma amostragem de medidas que se torna disponível no centro de operação. 


\section{Capítulo 1}

\section{Introdução}

A operação em tempo real dos sistemas elétricos de potência (SEP) tem como principal objetivo o suprimento de energia elétrica, em obediência à trilogia de continuidade, qualidade e economia de serviço. Para alcançar tal objetivo, é necessário que os níveis de tensão, freqüência, fluxos nas interligações, carregamento de linhas e equipamentos, sejam mantidos dentro de faixas, ou limites de segurança. Desta forma, a operação dos sistemas elétricos de potência exige que uma grande quantidade de informações esteja disponível para os operadores dos sistemas. Essas informações devem permitir a determinação do estado operativo corrente do SEP, isto é, se o mesmo está ou não operando adequadamente e, caso não o esteja, devem indicar o que deve ser feito, para corrigir essa operação inadequada.

Para determinar o estado operativo corrente do SEP, cumpre analisar um conjunto de restrições, que são funções das variáveis de estado do sistema, ou seja, são funções das tensões complexas nas barras do mesmo, que, por sua vez, são obtidas através de um conjunto de medidas realizadas no SEP. Em função da grande dimensão dos SEP, tais medidas são realizadas através dos sistemas de telemedição, isto é, medições feitas à distância, que nem sempre propiciam a obtenção de todas as informações necessárias, estando ainda sujeitas a uma série de erros [Monticelli (1999)]. Assim, para a obtenção de um banco de dados confiável, é necessário que as medidas sejam filtradas. A ferramenta utilizada nos centros de controle e operação, para realizar essa filtragem, é o estimador de estado. Portanto, a estimação de 
estado consiste na obtenção, em tempo real, das variáveis de estado de um sistema elétrico, através de um conjunto redundante de medidas com ruído, constituído usualmente de medidas de fluxo de potência ativa e reativa nas linhas, de injeção de potência ativa e reativa e de algumas magnitudes de tensão nos barramentos (medidas analógicas).

O sucesso da implantação de um estimador de estado vai depender da qualidade dos medidores disponíveis, bem como do número, tipo e localização dos mesmos. A primeira questão é verificar se é possível, através desse conjunto de medidas disponível, determinar as magnitudes de tensão e os ângulos em todas as barras do sistema de potência. Em caso afirmativo, o sistema dir-se-á observável. Caso contrário, a falta de medidas pode ser suprida por pseudo-medidas ${ }^{1}$, tornando o sistema observável como um todo. Entretanto, a observabilidade do sistema não é uma condição suficiente para obter-se uma estimação de estado confiável. É uma condição necessária, mas não suficiente. Isto ocorre porque as medidas analógicas, fornecidas ao estimador de estado, estão sujeitas a erros grosseiros ${ }^{2}$, que levam o processo de estimação a variáveis de estado não verdadeiras, ou, até mesmo, à não convergência.

Devido à fragilidade do conjunto de medidas, a capacidade de detectar e identificar medidas com erros grosseiros é uma das funções importantes do estimador de estado.

Pelo fato de não ser possível detectar a ocorrência de erros grosseiros em medidas críticas ${ }^{3}$ [Clements et al. (1981)], nem mesmo identificar tais erros em medidas pertencentes a conjuntos críticos de medidas ${ }^{4}$ [Mili et al. (1984)], para obter-se sucesso na estimação de estado, é necessário que o nível de redundância das medidas seja tal que garanta a ausência das medidas críticas e dos conjuntos críticos de medidas.

\footnotetext{
${ }^{1}$ Pseudo-medidas são dados de previsão de carga, previsão de geração, dados históricos, etc, que fazem parte do banco de dados dos centros de operação.

${ }_{2}^{2}$ Medidas portadoras de erros grosseiros são aquelas com grau de imprecisão muito maior do que o suposto no modelo de medição.

${ }_{3}^{3}$ Medida crítica é a medida que, quando perdida, faz um sistema de potência observável tornar-se não observável.

${ }^{4}$ Conjunto crítico de medidas é, segundo sua definição topológica, o conjunto de medidas formado por medidas não críticas, em que a eliminação de uma dessas medidas torna as demais medidas do conjunto críticas [Ayres e Haley (1986)].
} 
Em razão do que se disse, o primeiro passo para o sucesso de um estimador de estado é a obtenção de um plano de medição confiável, isto é, um plano de medição que atenda aos seguintes requisitos técnicos:

1. Observabilidade e confiabilidade: o número, tipo e localização dos medidores e das Unidades Terminais Remotas (UTRs) ${ }^{5}$ instaladas devem garantir a observabilidade do sistema, mesmo com a perda simultânea de 1 ou 2 medidas quaisquer, ou, até mesmo, com a perda de uma UTR qualquer;

2. Detecção e identificação de erro grosseiro: o nível de redundância das medidas disponíveis deve garantir a não presença das medidas críticas e dos conjuntos críticos de medidas.

Entretanto, possuir um plano de medição confiável não garante 0 sucesso do estimador de estado. Isto porque, durante a operação de um sistema de potência, podem ocorrer problemas no sistema de aquisição de dados, acarretando a perda de um número de medidas e/ou UTRs. Desta forma, o resultado da estimação de estado pode não ser bom, mesmo que o plano original seja confiável.

Em situações como essa, para tornar ainda possível uma estimação de estado confiável, é necessária, com a máxima brevidade possível, que se obtenham as seguintes informações:

1. Se o sistema em análise continua observável;

2. Caso continue observável, é necessário verificar a existência de medidas críticas e de conjuntos críticos de medidas;

3. Caso o sistema tenha perdido a observabilidade, determinar as pseudomedidas necessárias à sua restauração.

Ao longo dos últimos anos, diversos métodos têm sido propostos para análise e restauração da observabilidade [Krumpholz et al. (1980); Monticelli e Wu (1985a); Monticelli e Wu (1985b); Bretas (1996)], bem como para identificação de medidas críticas e de conjuntos críticos de medidas.

Os métodos para identificação de medidas críticas e de conjuntos críticos de medidas podem ser divididos, de uma forma geral, em dois grupos: os

\footnotetext{
${ }^{5}$ Equipamentos eletrônicos responsáveis pela leitura das medidas dos sistemas, nas usinas e subestações, e pelo seu envio aos centros de operação do sistema. Deve-se observar que, uma UTR, em geral, é responsável pela transmissão de dados de mais de um medidor.
} 
topológicos [Clements et al. (1981); Crainic et al. (1990); Simões-Costa et al. (1990); Bretas et al (2005)], baseados na teoria de grafos; e os numéricos [Korres e Contaxis (1991a); Korres e Contaxis (1991b); Ayres e Haley (1986); Coutto Filho et al (2001)] baseados em análise estatística. Os métodos do primeiro grupo possuem a vantagem de possibilitar a identificação de medidas críticas e de conjuntos críticos de medidas, sem exigir uma estimação de estado inicial; por outro lado, exigem a criação de rotinas complexas e lentas, quanto à velocidade de execução, sendo de natureza combinatorial e não possibilitando a identificação de conjuntos críticos, de uma forma direta. Conseqüentemente, acreditamos que esses métodos não sejam apropriados para aplicação em tempo real.

Os métodos numéricos, por outro lado, são conceitualmente mais simples, podendo, entretanto, apresentar problemas numéricos, pois, a maioria desses métodos requer o cálculo e a análise da matriz de sensibilidade dos resíduos.

Em London Jr. et al (2004), foram apresentados dois algoritmos, ambos não requerendo uma estimação de estado inicial. O primeiro permite a identificação de medidas críticas e de conjuntos críticos de medidas, de uma forma direta e simples, sem exigir a obtenção da matriz de sensibilidade dos resíduos. O segundo, a nosso ver, é uma ferramenta fundamental para a operação em tempo real dos SEP, pois, após a perda de medidas, tal algoritmo permite, de uma forma rápida, em termos de velocidade de execução, atualizar as características qualitativas do conjunto de medidas (análise e restauração da observabilidade e identificação de medidas críticas e de conjuntos críticos de medidas). Os dois algoritmos baseiam-se na análise do relacionamento entre as medidas e as variáveis de estado equivalentes, que são obtidas via fatoração triangular da matriz Jacobiana.

É importante observar que, além dos erros grosseiros, em medidas analógicas, o processo de estimação de estado está sujeito ainda aos chamados erros topológicos e erros de parâmetros ${ }^{6}$. Erros topológicos são aqueles resultantes de informações erradas, quanto aos estados de chaves e/ou disjuntores; e erros de parâmetros são aqueles causados por informações erradas de algum parâmetro do sistema, tais como resistência, reatância série

\footnotetext{
${ }^{6}$ Impedância de linhas de transmissão e posição de taps de transformadores.
} 
e shunt em linhas, bem como reatores shunt em barras, posições dos taps dos transformadores, etc.

\subsection{Objetivos}

A grande contribuição do trabalho de London Jr. et al (2004) foi o desenvolvimento de um algoritmo que, em situação de perda de medidas, possibilita, de uma forma rápida e simples, a atualização das características qualitativas do conjunto de medidas, isto é, análise e restauração da observabilidade, bem como identificação de medidas críticas e de conjuntos críticos de medidas.

Estudos iniciais demonstraram ser possível aumentar a eficiência computacional através da utilização de técnicas de esparsidade e de técnicas para desenvolvimento de programas computacionais.

Face ao exposto, propõe-se este trabalho, cujo objetivo é, tomando por base os algoritmos desenvolvidos por London Jr. et al (2004), o desenvolvimento de um programa computacional que possibilite, não apenas a análise das características qualitativas de um conjunto de medidas, mas também a atualização dessas características, após a perda de medidas.

Para atingir-se o objetivo em vista, as atividades a serem desenvolvidas são as seguintes:

1. Estudos de técnicas de esparsidade e de técnicas para desenvolvimento de programas computacionais, tendo em vista a definição das mais apropriadas para o desenvolvimento do programa proposto;

2. Estudo dos algoritmos propostos por London Jr. et al (2004);

3. Projetar, implementar e documentar todos os módulos do programa proposto, segundo um padrão único, de forma a possibilitar que outros pesquisadores possam desenvolver e integrar módulos adicionais ao programa. 


\subsection{Discriminação dos próximos capítulos}

No capítulo 2 será apresentado um pequeno histórico, salientando algumas pesquisas desenvolvidas na área, além de algumas definições importantes para o entendimento do trabalho. Os algoritmos que serão utilizados como base para o desenvolvimento do programa proposto, desenvolvidos por London Jr. et al (2004), juntamente com exemplos das suas aplicações, são descritos no capítulo 3. No capítulo 4 são mostradas as técnicas de esparsidade. No capítulo 5, são apresentadas as técnicas de desenvolvimento de programas computacionais, empregadas neste trabalho. No capítulo 6, descreve-se o programa computacional proposto, juntamente com exemplos da sua aplicação. Os testes e a análise dos resultados são mostrados no capítulo 7. Finalmente, as conclusões são apresentadas no capítulo 8. 


\section{Capítulo 8}

\section{Conclusões}

Em London Jr. et al (2004), como mencionado anteriormente no capítulo 1, foi desenvolvido um algoritmo de fundamental importância para a operação em tempo real dos SEP, pois, após a perda de medidas, esse algoritmo permite, de uma forma bastante rápida em termos de velocidade de execução, proceder à atualização das características qualitativas do conjunto de medidas (análise e restauração da observabilidade e identificação de medidas críticas e de conjuntos críticos de medidas).

Daí a razão por que propusemos este trabalho, por verificarmos a possibilidade de aumentar a eficiência daquele algoritmo, em termos de velocidade de execução, através da utilização de técnicas de esparsidade e de técnicas para desenvolvimento de programas computacionais.

Para ilustrar o desenvolvimento deste trabalho, recordaremos, a seguir, as atividades que haviam sido pré-definidas, para o atendimento do objetivo em mira, apresentadas no capítulo 1:

1. Estudos de técnicas de esparsidade e de técnicas para desenvolvimento de programas computacionais, tendo em vista a definição das mais apropriadas para o desenvolvimento do programa proposto;

2. Estudo dos algoritmos propostos por London Jr. et al (2004);

3. Projetar, implementar e documentar todos os módulos do programa proposto, segundo um padrão único, de forma a possibilitar que outros 
pesquisadores possam desenvolver e integrar módulos adicionais ao programa.

As técnicas de esparsidade, bem como as técnicas para desenvolvimento de programas computacionais foram estudadas e apresentadas nos capítulos 4 e 5 , respectivamente.

Conforme se divulgou no capítulo 3, realizou-se um estudo detalhado dos algoritmos desenvolvidos por London Jr. et al (2004).

O programa proposto foi desenvolvido e bem documentado, para tanto importando salientar que se utilizaram técnicas de esparsidade e de desenvolvimento de programas computacionais, conforme apresentado no capítulo 6.

No programa desenvolvido, o armazenamento da matriz Jacobiana foi implementado como objeto, utilizando as técnicas de esparsidade estudadas, permitindo utilizar tal armazenamento da matriz como uma caixa preta, ou seja, não sendo importante então compreender como ocorre o funcionamento interno do objeto, mas apenas conhecer as operações de consulta e atribuição de valor na matriz. Isto porque o funcionamento interno do objeto não altera as estruturas das outras funções.

Esse novo paradigma deve tornar mais simples a integração, por outros usuários, de novos módulos ao programa, pois não é necessário preocupar-se com a estrutura utilizada para o armazenamento das matrizes, isto é, os mesmos trabalham como se as matrizes estivessem armazenadas da forma tradicional.

Os testes realizados, apresentados no capítulo 7, comprovam a eficiência do programa proposto. Em termos de velocidade de execução, diante da estrutura de dados utilizada para o armazenamento da matriz, bem como da realização apenas de cálculos "simbólicos", verifica-se que o algoritmo aqui desenvolvido para atualização das características qualitativas de conjuntos de medidas, requer menos operações que aquele desenvolvido por London Jr. et al (2004).

Conforme apresentado no capítulo 6, o programa desenvolvido possui uma interface gráfica que possibilita, através de janelas, uma iteração bem amigável com o usuário, permitindo a visualização de todas as etapas do 
processo de análise e restauração das características qualitativas de conjuntos de medidas.

\subsection{Principais Contribuições do trabalho}

Relacionamos, a seguir, as principais contribuições deste trabalho, que nos fazem acreditar possa o mesmo contribuir, com eficácia, para a área a que se refere:

$>$ Desenvolvimento e implementação, em computador, de um programa que possibilita, de forma bastante rápida, não apenas a análise das características qualitativas de conjuntos de medidas, para efeito de estimação de estado em SEP, mas também a atualização dessas características, na ocorrência de perda de medidas;

> Em razão de os módulos do programa proposto terem sido projetados, implementados e documentados, segundo um padrão único, torna-se simples a integração de módulos adicionais a esse programa. Conseqüentemente, acreditamos que a partir do programa proposto teremos, em breve, um programa computacional, que possibilitará a análise de todas as etapas do processo de estimação de estado, de uma forma integrada, permitindo analisar todos os tipos de erros, a que está sujeito o estimador, de forma individual ou simultânea ${ }^{1}$.

Observação 8.1: Importa destacar que este trabalho de mestrado deu origem a um artigo que acaba de ser aceito para publicação no IX EDAO (Encontro para Debates de Assuntos de Operação) organizado pelo ONS e CIGRÉ e nesta edição pela CELG (Companhia Energética de Goiás), que será realizado em março de 2007, na cidade de Rio Quente, Goiás, Brasil.

\footnotetext{
${ }^{1}$ Nessa direção importa destacar que, num outro projeto, em desenvolvimento no Laboratório de Análise Computacional em SEP, já está sendo integrado ao programa proposto um módulo, destinado a Estimação de Estado e processamento de Erros Grosseiros.
} 


\subsection{Perspectivas Futuras}

Mencionamos, a seguir, diversos estudos que pretendemos realizar, em trabalhos futuros, visando à utilização do programa aqui proposto para o tratamento de outras questões relacionadas ao processo de estimação de estado em SEP.

(i) Como mencionado na seção anterior, acreditamos que em breve, a partir do programa desenvolvido neste trabalho, será possível a obtenção de um programa computacional que possibilitará a análise de todas as etapas do processo de estimação de estado, de uma forma integrada, permitindo analisar todos os tipos de erros a que está sujeito o estimador, de forma individual ou simultânea;

(ii) Estudos serão realizados visando, a partir do programa aqui desenvolvido, à obtenção de um método para projeto e fortalecimento de plano de medição, levando em consideração não apenas critérios técnicos (observabilidade e redundância de medidas e de UTRs), mas também o custo associado à instalação de medidores e UTRs. Nesse sentido, a idéia é utilizar uma técnica de Inteligência Artificial, chamada Computação Evolutiva (CE), para obter-se uma dependência entre o custo do plano de medição e o atendimento àqueles critérios técnicos. O atendimento a esses critérios técnicos será analisado através do programa aqui proposto, que possibilita uma análise rápida e direta; (iii) Investigar a possibilidade de o programa proposto permitir atualização das características qualitativas de conjunto de medidas na ocorrência de mudança de topologia e não apenas na ocorrência de perda de medidas. 


\section{Capítulo 7}

\section{Testes e Análise dos Resultados}

Os testes realizados, apresentados neste capítulo, visam a comprovar a eficiência do programa proposto, que permite análise e atualização das características qualitativas de conjuntos de medidas, na ocorrência de perda de medidas.

Para realizar os testes, foram utilizados 3 sistemas: o primeiro foi o IEEE 14 barras (figura 7.1); o segundo foi o IEEE 30 barras (figura 7.2); e o terceiro foi o 121 barras da ELETROSUL.

O programa foi implementado em um microcomputador equipado com um processador Pentium IV 2.4 GHz, com 1G.Bytes de memória RAM.

\subsection{Testes com o sistema de 14 barras do IEEE}

O programa é aplicado ao sistema de 14 barras do IEEE associado ao conjunto de medidas ilustrado na figura 7.1, considerando, ainda, a disponibilidade das seguintes pseudo-medidas: $\mathrm{P}(8-7)^{1}, \mathrm{P}(7-4), \mathrm{P}(9-14)$ e $\mathrm{P} 4 .^{2}$

\footnotetext{
${ }^{1} \mathrm{P}(\mathrm{i}-\mathrm{j})$ : Pseudo-medida de fluxo da barra "i" para a barra "j".

2 Pi: Pseudo-medida de injeção na barra "i".
} 


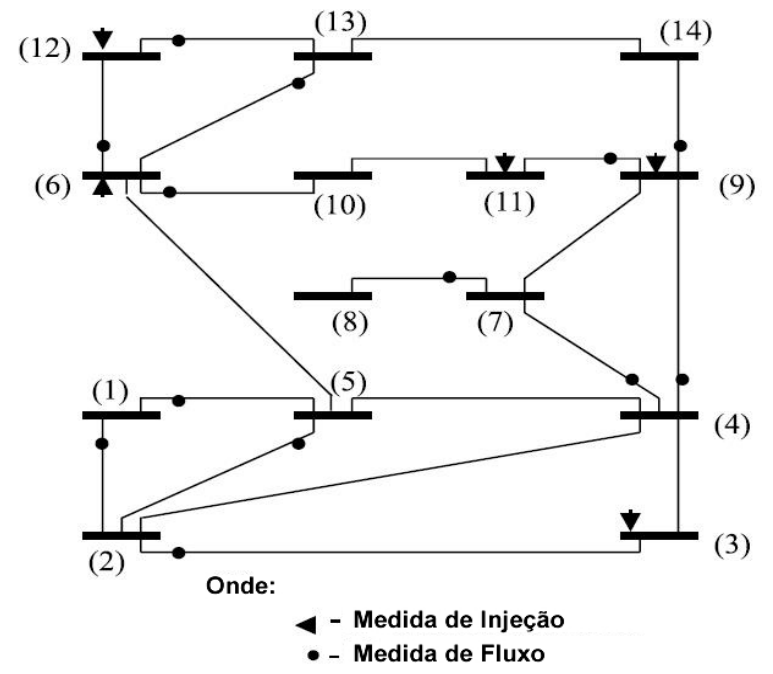

Figura 7.1 - Sistema de 14 barras do IEEE

O resultado obtido foi o seguinte:

Medida crítica: F(7-8).

$>$ Conjuntos críticos: [111, I6, F(6-10), I3, F(2-3)]; [19, F(9-14), F(4-7)].

O algoritmo permitirá a análise das seguintes contingências: Contingência 1: Perda da medida $F(7-8)$; Contingência 2: Perda das medidas 16 e 19; Contingência 3: Perda das medidas 19, F(9-14) e F(4-7). Contingência 1: Perda da medida F(7-8).

O resultado obtido foi o seguinte:

O Sistema perdeu a Observabilidade.

> Pseudo-medida selecionada: $\mathrm{P}(8-7)$.

Medida crítica: $\mathrm{P}(8-7)$

$>$ Conjuntos críticos: $[F(2-3), 111]$; $[F(4-7), 19]$; [I3, I11]; [F(6-10), I11]; $[F(9-14), 19] ;[16, I 11] ;[F(1-2), F(1-5)]$.

Contingência 2: Perda das medidas 16 e 19.

O resultado obtido foi o seguinte:

$>$ O Sistema continua Observável.

> Medidas críticas: F(2-3); F(4-7); I3; F(6-10); F(7-8); F(4-9); F(9-11); $\mathrm{F}(9-14) ; \mathrm{I} 11$.

Conjunto crítico: [F(5-2), $F(1-5), F(1-2)]$. 
Contingência 3: Perda das medidas 19, F(9-14) e F(4-7).

O resultado obtido foi o seguinte:

$>$ O Sistema perdeu a Observabilidade.

> Pseudo-medidas selecionadas: $\mathrm{P}(7-4) ; \mathrm{P}(9-14)$.

> Medidas críticas: P(7-4); F(7-8); P(9-14).

Conjunto crítico: [I11,I6,F(9-11),F(6-10),I3,F(4-9),F(2-3), F(1-5),F(1-2].

\subsection{Testes com o sistema de $\mathbf{3 0}$ barras do IEEE}

O programa proposto é aplicado ao sistema de 30 barras do IEEE, associado ao plano de medição ilustrado na figura 7.2, considerando, ainda, a disponibilidade das seguintes pseudo-medidas: $\mathrm{P} 25, \mathrm{P}(1-2)$ e $\mathrm{P}(1-3)$.

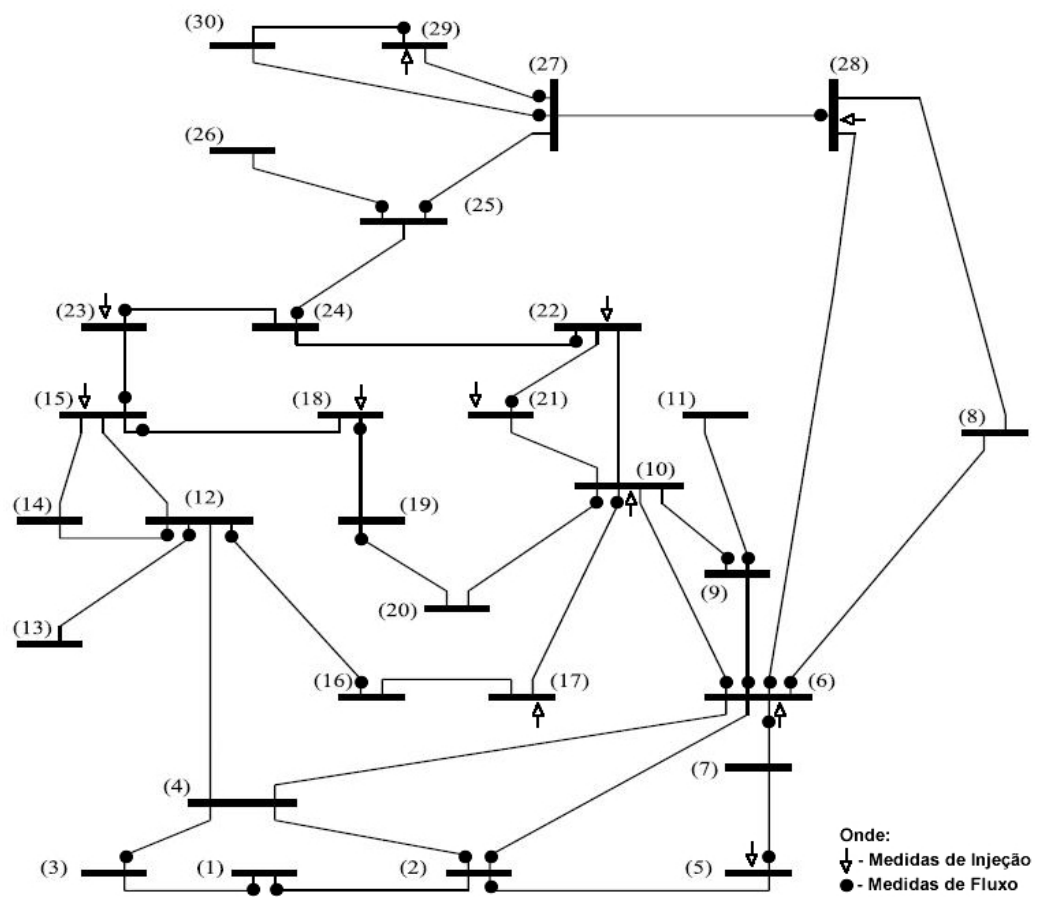

Figura 7.2 - Sistema de 30 barras do IEEE

O resultado obtido foi o seguinte:

$>$ Medidas críticas: F(9-11); F(12-13); F(25-26).

$>$ Conjuntos críticos: $[F(24-25), F(25-27)]$; [117, I15, F(12-14)]; [F(3-4), $F(1-3), F(1-2)]$.

O algoritmo permitirá a análise das seguintes contingências: Contingência 1: Perda da medida F(25-26); Contingência 2: Perda das medidas 
$F(1-2)$ e $F(3-4)$; Contingência 3: Perda das medidas $F(1-2), F(3-4), F(1-3)$, $F(25-26), F(24-25)$.

Contingência 1: Perda da medida F(25-26).

$O$ resultado obtido foi o seguinte:

$>$ O Sistema perdeu a Observabilidade.

$>$ Pseudo-medida selecionada: P25.

> Medidas críticas: F(9-11); F(12-13) e P25.

$>$ Conjuntos críticos: [F(24-25), F(25-27)]; [117, I15, F(12-14)]; [F(3-4), $F(1-3), F(1-2)]$.

Contingência 2: Perdas das medidas F(1-2) e F(3-4).

O resultado obtido foi o seguinte:

$>$ O Sistema perdeu a Observabilidade.

> Pseudo-medida selecionada: $\mathrm{P}(1-2)$.

> Medidas críticas: $F(1-3) ; P(1-2) ; F(9-11) ; F(12-13) ; F(25-26)$.

$>$ Conjuntos críticos: [F(24-25), F(25-27)]; [16, F(2-4)]; [117, I15, F(1214)].

Contingência 3: Perdas das medidas $F(1-2), F(3-4), F(1-3), F(25-26)$, $F(24-25)$.

O resultado obtido foi o seguinte:

$>$ O Sistema perdeu a Observabilidade.

> Pseudo-medidas selecionadas: $\mathrm{P}(1-2) ; \mathrm{P}(1-3) ; \mathrm{P} 25$.

$>$ Medidas críticas: $\mathrm{P}(1-2) ; \mathrm{P}(1-3) ; \mathrm{P} 25 ; \mathrm{F}(9-11) ; \mathrm{F}(12-13) ; \mathrm{F}(25-27)$.

$>$ Conjuntos críticos: [16, F(2-4)]; [117, I15, F(12-14)]; [128, F(28-27)].

\subsection{Testes com o sistema de 121 barras da ELETROSUL}

O programa proposto foi aplicado ao sistema de 121 barras da ELETROSUL, associado a um conjunto de medidas constituído por 65 medidas de fluxo, 69 medidas de injeção e 387 pseudo-medidas (a topologia desse sistema pode ser encontrada em London Jr. et al (2004)). O algoritmo identificou 59 medidas críticas e 14 conjuntos críticos de medidas. Na perda simultânea de 15 medidas críticas, o sistema tornou-se não observável e 0 algoritmo necessitou de 0,062 segundos para atualizar as características 
qualitativas do conjunto de medidas, selecionando um total de 15 pseudomedidas, para restaurar a observabilidade, identificando 96 medidas críticas e 12 conjuntos críticos de medidas.

Analisando essa mesma contingência através do algoritmo proposto por London Jr. et al (2004), obteve-se o mesmo resultado. Entretanto, tal algoritmo exigiu 0,23 segundos, comprovando, assim, a superioridade do programa aqui proposto, em termos de velocidade de execução para atualização das características qualitativas de conjuntos de medidas.

\subsection{Análise dos resultados}

Como pode ser constatado através dos testes realizados, verifica-se a eficiência do programa proposto, tendo em vista a resposta coerente com London Jr. et al (2004). Importa destacar que os objetos desenvolvidos para a implementação do programa proposto serão de inteira importância para futuros trabalhos no LACO (Laboratório de Análise Computacional em Sistemas Elétricos de Potência) da Escola de Engenharia de São Carlos - Universidade de São Paulo, já que essas rotinas serão utilizadas para o desenvolvimento de programas para o tratamento de outras etapas envolvidas no Processo de Estimação de Estado em Sistemas Elétricos de Potência. 